University of San Diego

Digital USD

2009-08-01

\title{
Psychometric Testing of the Information-Motivation-Behavioral Skills Model of Behavior Change Questionnaire in Mexican- Americans with Diabetes Type 2
}

Beverley Brownell PhD

University of San Diego

Follow this and additional works at: https://digital.sandiego.edu/dissertations

Part of the Nursing Commons

\section{Digital USD Citation}

Brownell, Beverley PhD, "Psychometric Testing of the Information-Motivation-Behavioral Skills Model of Behavior Change Questionnaire in Mexican-Americans with Diabetes Type 2" (2009). Dissertations. 371. https://digital.sandiego.edu/dissertations/371

This Dissertation: Open Access is brought to you for free and open access by the Theses and Dissertations at Digital USD. It has been accepted for inclusion in Dissertations by an authorized administrator of Digital USD. For more information, please contact digital@sandiego.edu. 


\author{
UNIVERSITY OF SAN DIEGO \\ Hahn School of Nursing and Health Sciences \\ DOCTOR OF PHILOSOPHY IN NURSING
}

\begin{abstract}
PSYCHOMETRIC TESTING OF THE INFORMATION-MOTIVATIONBEHAVIORAL SKILLS MODEL OF BEHAVIOR CHANGE QUESTIONNAIRE IN MEXICAN-AMERICANS WITH DIABETES TYPE 2

By

Beverley Brownell
\end{abstract}

A dissertation presented to the

FACULTY OF THE HAHN SCHOOL OF NURSING AND HEALTH SCIENCE

UNIVERSITY OF SAN DIEGO

In partial fulfillment of the

Requirements for the degree

DOCTOR OF PHILOSOPHY IN NURSING

August 2009

Dissertation Committee

Anita Hunter, $\mathrm{PhD}, \mathrm{RN}, \mathrm{CPNP}, \mathrm{FAAN}$

Lois Howland, DrPH, RN

Mary-Rose Mueller, $\mathrm{PhD}, \mathrm{RN}$ 


\begin{abstract}
Background: The most successful diabetes self-management (DSM) programs focus on changing previously established behavior patterns. To develop focused and culturally appropriate self-management programs, health care providers need valid and reliable assessment tools. Purpose: To test the reliability and content and construct validity of an instrument developed to assess diabetes knowledge, motivation, and adherence to medical regimes. The Information-Motivation-Behavioral (IMB) Skills Diabetes scale was tested with 83 Mexican-American adults with type 2 diabetes from a community in Orange County, CA. Methodology: A cross-sectional correlational study design was conducted with 64 female and 19 male Mexican-American adults diagnosed diabetes type 2 patients. The participants completed a 101-item questionnaire comprised of a demographic section and 11 subscales for assessing diet and exercise knowledge, attitudes, motivational factors, and diabetes behavioral skills. The questionnaire concluded with seven short-answer questions to assess content validity of the instrument. Data Analysis: Descriptive statistics, correlations, and multiple regression analyses were used. Results: Participants had a low literacy level which affected their ability to read food labels, count carbohydrates, and understand information taught in diabetic education classes. They tended to have strong family support systems but poor internal motivation. Based on Cronbach's alpha reliability coefficient values, only seven of the 11 subscales were considered reliable. Gender differences were not significant except in one case: women scored higher in exercise behavior. Participants who read food labels and followed their dietary plan were more likely to have lower $\mathrm{HbAlc}$ values. Over $67 \%$ of all participants had suboptimal $\mathrm{HbAlc}$ levels and women had the highest percentage of
\end{abstract}


abnormal HbAlc scores, even though they had indicated they were more likely to read food labels and follow their dietary plans. Conclusions: The IMB scale demonstrated adequate item reliability, but poor ability to assess diabetes type 2 adherence with this population. These results have relevance to caring for Mexican-American diabetic patients and emphasizes the importance of culturally relevant nutritional intake and exercise expectations. Providers need to foster the development of their patients' internal personal motivators. 
Copyright $\mathbb{C} 2009$ by Beverley Brownell All rights reserved.

Requests for permission to make copies of any part of this work should be made to Beverley Brownell, bevpasbro@yahoo.com. 


\section{Dedication}

This dissertation is dedicated to the following people who have traveled with me and supported me throughout this long journey:

To my husband, Charles Brownell, who painstakingly read through multiple versions and provided valuable suggestions and stylistic adjustments that improved and clarified my presentation. "Hasn't it been worth it?"

To my children Dylan and Adam, who have been so accepting of my part-time presence in their lives for such a long time. Thank you for being there and motivating me to continue. I did this for you. I love you both. "Are you feeling motivated?"

To my parents Dora and Joe, my sisters Miki, and Janet and my brother Anthony for their unconditional support from afar in the UK. "It looks as though I'll be coming home more often now!"

To my all my friends who were there when I wasn't. "I'm back now! 


\section{Acknowledgments}

Even though producing this dissertation has been an isolating experience it would not have been possible without a great deal of help along the way. I owe so much to so many people.

I, therefore, would like to thank, first and foremost, my advisor and chair of my committee, Dr Anita Hunter for her expertise, guidance, motivation, and spirited encouragement in this venture.

I would also like to express my thanks to my committee members Dr. Lois Howland, Dr. Mary-Rose Mueller, and Dr. Andrea Hazen for their vital contributions and commitment to this dissertation. Not only were these four wonderful women readily available to me for advice, but their rapid feedback of my drafts and prompt responses to my queries were more than I could ever have wished for.

My thanks are also extended to the staff and patients at the Lestonnac Free Clinic in Orange County, Southern California, who made my data collection process such a pleasure. I also owe a particular debt of gratitude to Director Ed Gerber, for his incredible sense of humor and his faith and confidence in my abilities.

Finally I wish to thank two very special people who were also instrumental to my success, Dr. Chandra Osborn for the use of her research tool and Carmenmara Hernandez-Bravo a personal friend and Spanish professor to whom I give credit for refining my Spanish language skills. 


\section{Table of Contents}

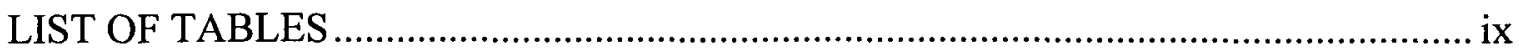

LIST OF ILLUSTRATIONS ..........................................................................

LIST OF APPENDICES .............................................................................

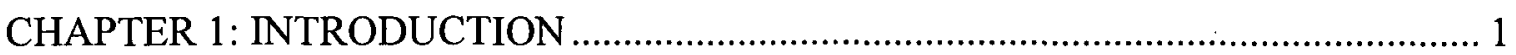

Statement of the Problem................................................................................ 1

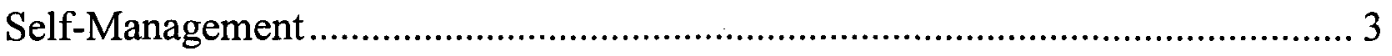

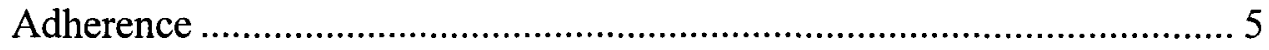

Culture and Acculturation............................................................... 7

Culturally Sensitive Intervention ................................................. 9

The IMB Model .................................................................................... 12

Research Goals................................................................................ 14

Significance to Nursing and Clinical Practice ......................................... 15

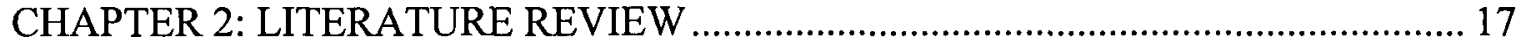

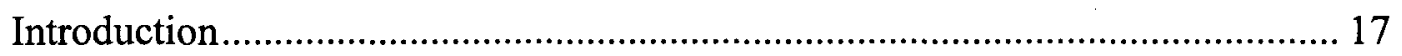

The Toll of Diabetes ........................................................................ 17

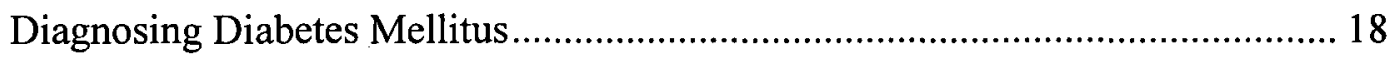

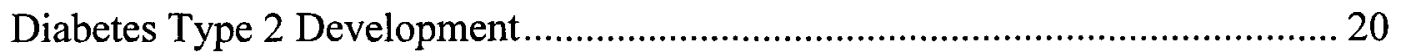

Treatment Options for Diabetes Mellitus .................................................. 23

Diabetes Self-management Intervention Programs ................................... 24

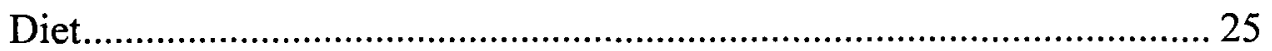

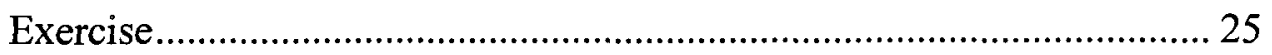

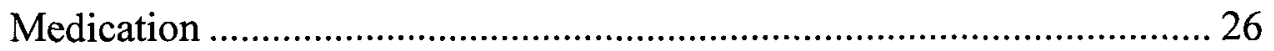




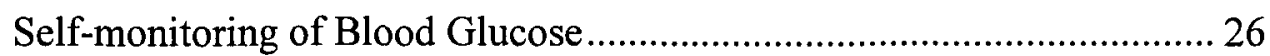

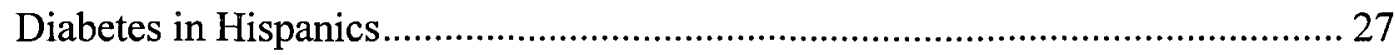

Diabetes Self-management Adherence in Hispanics ................................ 30

Acculturation and Adherence ................................................................ 31

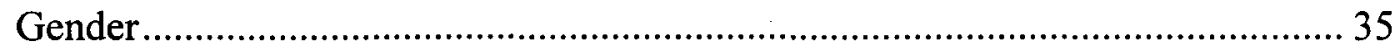

Diabetes Self-Management Education.............................................................. 37

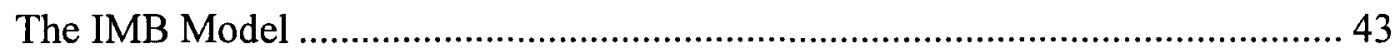

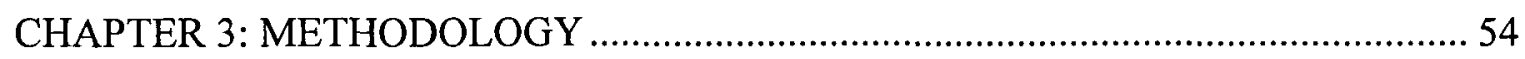

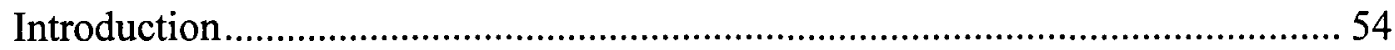

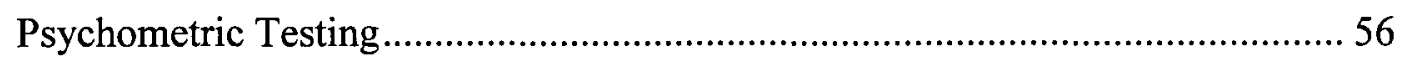

Participant Selection and Characteristics........................................................... 57

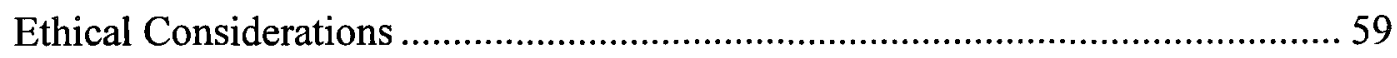

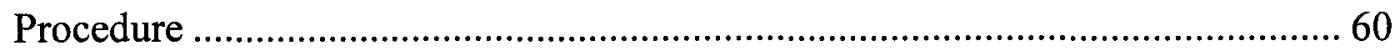

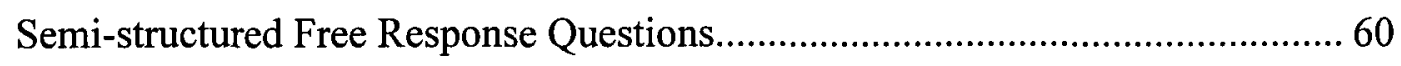

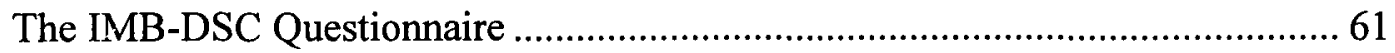

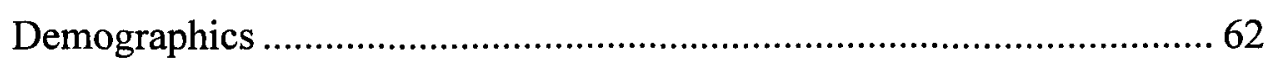

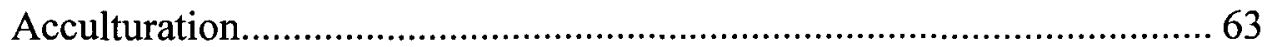

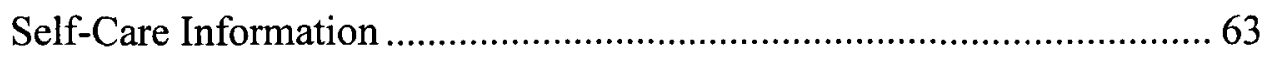

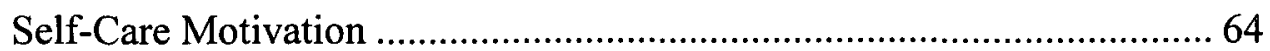

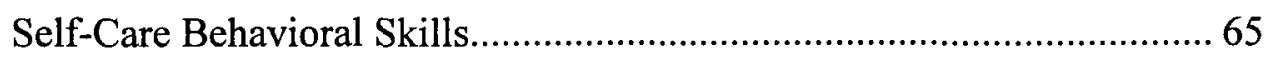

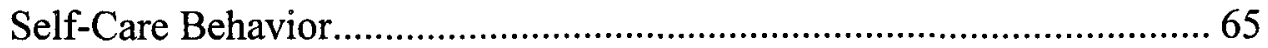

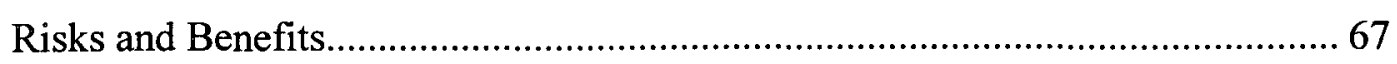

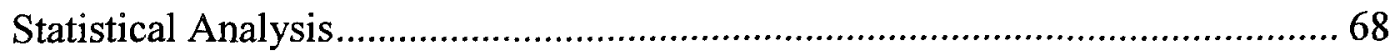


CHAPTER 4: RESULTS

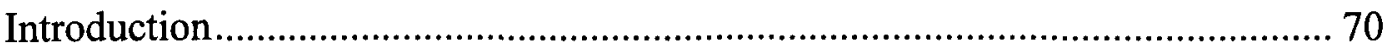

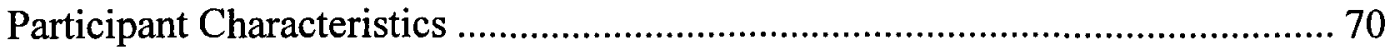

Results from the IMB Subscales.................................................................. 72

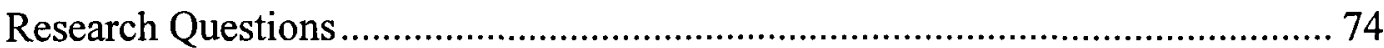

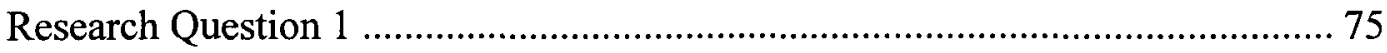

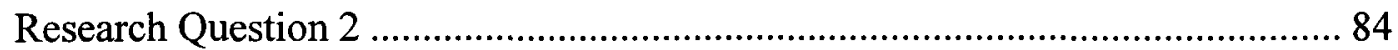

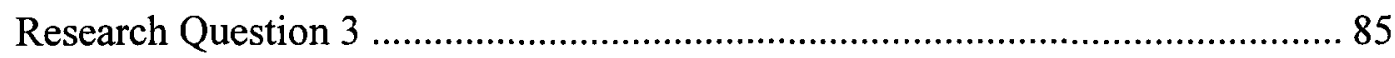

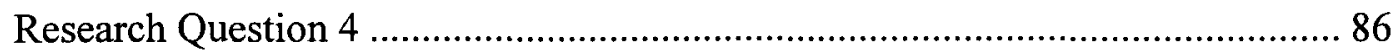

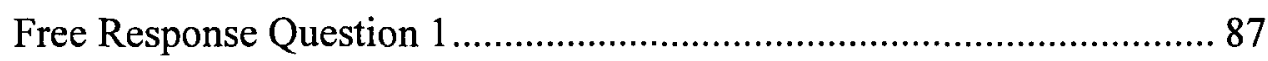

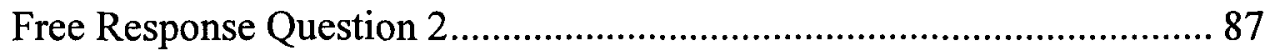

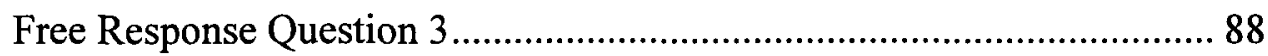

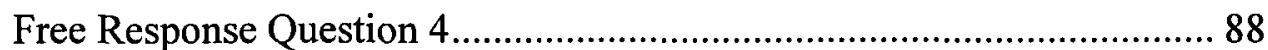

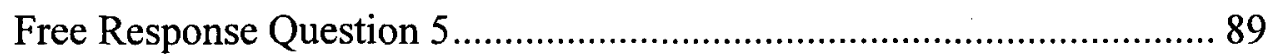

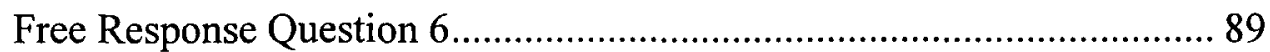

Free Response Question 7................................................................ 90

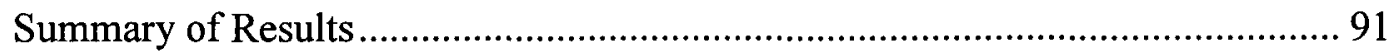

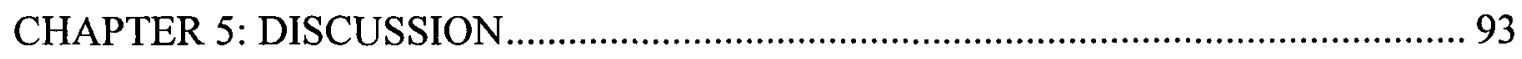

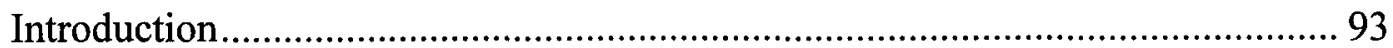

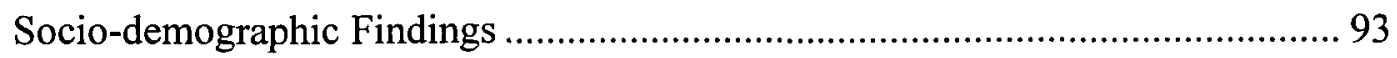

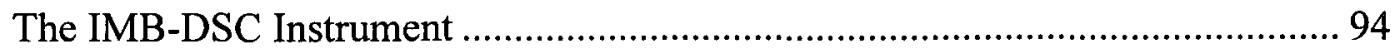

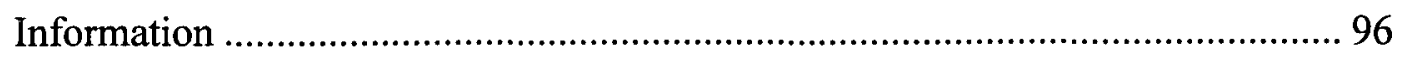

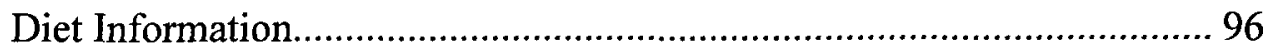




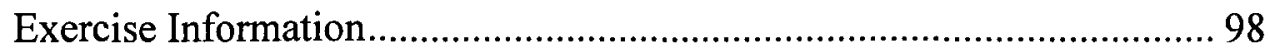

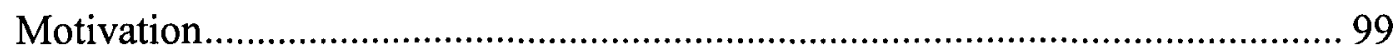

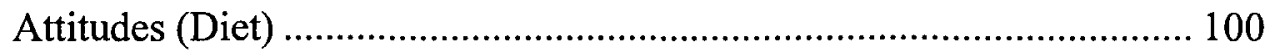

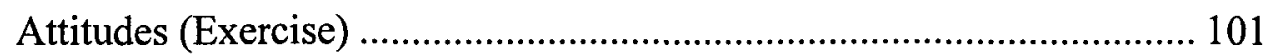

Diet (Social Support) and Exercise (Social Support) ............................. 103

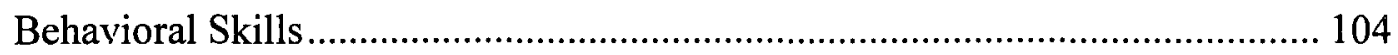

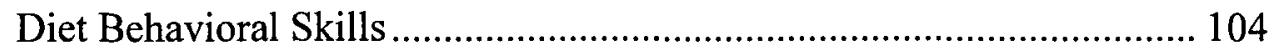

Exercise Knowledge and Exercise Behavioral Skills ............................. 105

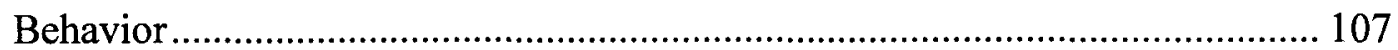

Reading Food Labels Behavior....................................................... 107

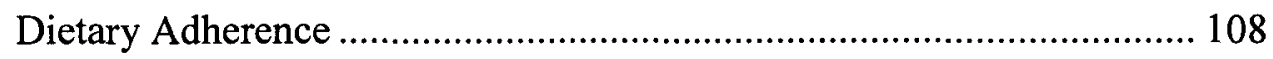

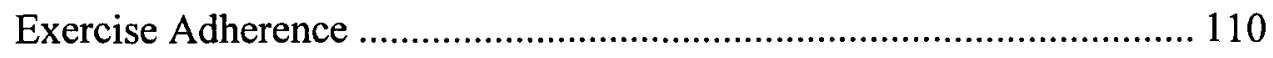

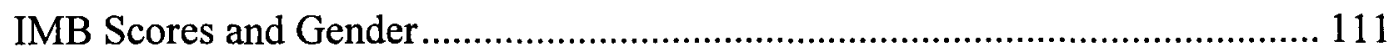

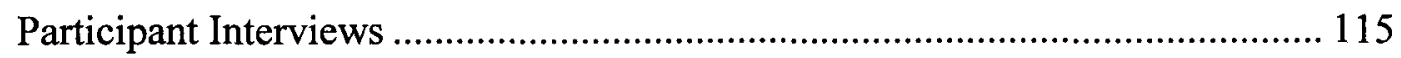

Validity and Reliability of the IMB-DSC Scale ………................................... 118

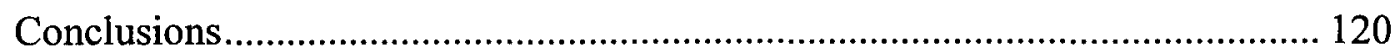

Clinical Implications ...................................................................... 121

Limitation of the Study .................................................................... 123

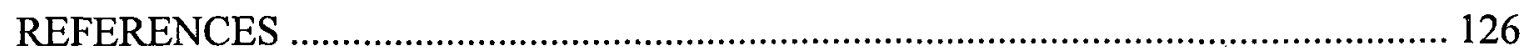

APPENDIX A: QUESTIONNAIRE (ENGLISH) ................................................. 148

APPENDIX B: QUESTIONNAIRE (SPANISH) …................................................ 155

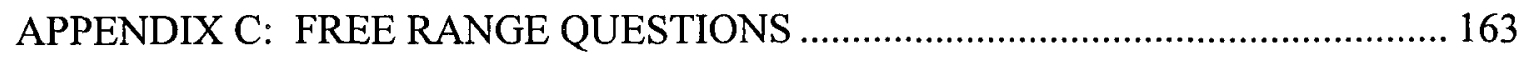

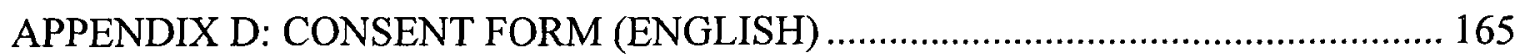


APPENDIX E: CONSENT FORM (SPANISH) ……............................................. 167

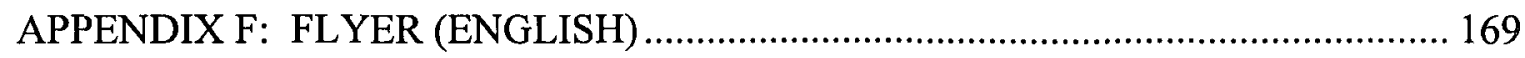

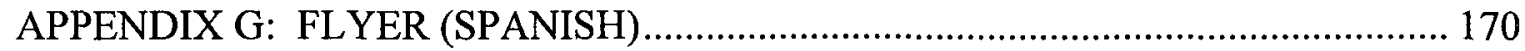

APPENDIX H: RECRUITMENT PRESENTATIONS .............................................. 171

APPENDIX I: APPROVAL FROM CLINIC DIRECTOR ......................................... 172

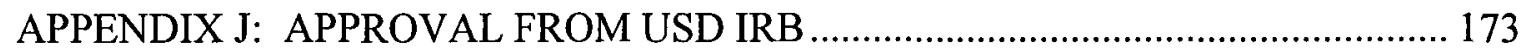




\section{LIST OF TABLES}

Table 1. Demographic profile of study participants $(\mathrm{N}=83)$

Table 2. Summary of the 11 subscales of the IMB-DSC Measure

Table 3. Mean scores of independent and dependent variables $(\mathrm{N}=83)$

Table 4. T-test results for the known groups' comparison.

Table 5: T-test group statistics for the relationship between gender and IMB scores.

Table 6. Summary of Pearson intercorrelations for 12 subscales. 


\section{LIST OF ILLUSTRATIONS}

Figure 1. Information-Motivation-Behavioral-Skills Model (Adapted from Fisher \& Fisher, 1992).

Figure 2. The self-management program (SMP) behavior sequence (adapted from Fisher \& Fisher, 1992).

Figure 3. IMB model analysis on adherence to diabetes self-management program. (Source: Modified from Fisher et al., 2001) 


\section{LIST OF APPENDICES}

APPENDIX A: QUESTIONNAIRE (ENGLISH)

APPENDIX B: QUESTIONNAIRE (SPANISH)

APPENDIX C: FREE RANGE QUESTIONS

APPENDIX D: CONSENT FORM (ENGLISH)

APPENDIX E: CONSENT FORM (SPANISH)

APPENDIX F: FLYER (ENGLISH)

APPENDIX G: FLYER (SPANISH)

APPENDIX H: RECRUITMENT PRESENTATIONS

APPENDIX I: APPROVAL FROM CLINIC DIRECTOR

APPENDIX J: APPROVAL FROM USD IRB 


\title{
CHAPTER 1: INTRODUCTION
}

\author{
Statement of the Problem
}

Diabetes has become a public health problem of pandemic proportions with an estimated 1.5 million new cases diagnosed each year (Centers for Disease Control and Prevention, 2008; National Diabetes Information Clearinghouse (NDIC), 2007).

Currently 24 million people have been diagnosed with diabetes or approximately $8 \%$ making diabetes the seventh leading cause of death in the United States. In addition 6.2 million are estimated to have the disease but as yet are undiagnosed and 57 million are estimated to have pre-diabetes, which puts them at increased risk for developing the disorder (Centers for Disease Control and Prevention, 2008). It is the leading cause of non-traumatic amputations in the U.S. (82,000 each year or 225 each day), blindness among working-adults (22,000 each year or 60 each day), and end-stage renal disease (44,000 each year or 122 each day) (Centers for Disease Control and Prevention, 2007b).

In the U.S. according to recent CDC data, 2.5 million or $9.5 \%$ of all Hispanics 20 years and older have type 2 diabetes and are 1.7 times more likely to have the disease when compared to non-Hispanic white individuals of a similar age group (Centers for Disease Control and Prevention, 2007b). Hispanics also have an earlier onset of diabetes, typically between 30 to 50 years of age. It is the $4^{\text {th }}$ leading cause of death in Hispanic women and the Hispanic elderly where chronic hyperglycemia results in a particularly 
high incidence of diabetes-related complications and mortality (Brown, Blozis, Kouzekanani, Garcia, Winchell \& Hanis, 2007; Brown, Garcia, Kouzekanani, \& Hanis, 2002; Brown, Harrist, Villagomez, Segura, Barton \& Hanis, 2000).

It is the consistently poor glucose control leading to cardiovascular, renal, retinal and micro-vascular complications that make diabetes such a costly disease. An estimated $\$ 132$ billion is spent on diabetes-related outcomes each year, a cost that could largely be prevented with adequate diabetes screening and tight glucose control managed by diabetes self management (DSM) intervention programs (American Diabetes Association, 2007c, 2008c; Diabetes Control and Complication Trial Research Group, 1993; NDIC, 2007; Paterson, Rutledge, Cleary, Lachin, \& Crow, 2007). Although the figures previously quoted refer to all forms of diabetes (i.e., type 1, type 2 and gestational), $90-95 \%$ of cases involve type 2 diabetes (American Diabetes Association, 2007).

The escalating national burden of diabetes and the enormous growth in diabetes prevalence have understandably prompted a very extensive body of research into diabetes care (American Diabetes Association, 2008; Centers for Disease Control and Prevention, 2007b; Diabetes Control and Complications Trial Research Group, 1993, 1996; UK Prospective Diabetes Study Group, 1998a; UKPDS, 1998b; UKPDS, 1998c). The vast majority of studies have focused their efforts on diabetes self management among nonHispanic, white, middle class populations. With the Hispanic population projected to triple, from 46.7 million to 132.8 million during the $2008-2050$ period (U.S. Census Bureau, 2009) there is an urgent need for additional research to explore the factors that influence the observed increased incidence of uncontrolled diabetes within the Hispanic population. 
Mexican-Americans in particular (the largest Hispanic subgroup in the United States) have found the goal of achieving tight glycemic control particularly challenging and a number of barriers have been identified. These include the use of curanderos (folk healers), reliance on family for health advice, poor access to health care, transportation difficulties, poor quality of health care and language differences with health care workers (Brown, et al., 2002). Others factors include a suboptimal provider-patient relationship and the limited success of traditional provider-directed intervention programs (Carbone, Rosal, Torres, Goins \& Bermudez, 2006; Hargraves, Hargraves, Cunningham, \& Hughes, 2001; Mainous, Diaz, Koopman, \& Everett, 2007; Welch, Oster, Gazmararian, Rask, Schild, Cutler, et al., 2006).

Identifying significant factors that could result in tighter glycemic control are thus critical objectives for improved health status outcomes. Psychometrically sound questionnaires that are reliable, valid and culturally appropriate are consequently essential tools for evaluating interventions designed to improve the health status outcomes of Hispanic adults with diabetes type 2 (Brown et al., 2002).

It is, therefore, the purpose of this pilot study to psychometrically test the Information Motivation Behavioral Skills measure of Diabetes Self-Care in order to determine its utility in identifying factors that hinder effective diabetes self management in Mexican Americans with diabetes type 2.

\section{Self-Management}

Two landmark studies, the Diabetes Control and Complication Trial Research Group (1993) and the United Kingdom Prospective Diabetes Study Group (UKPDS, 1998a, b) have clearly demonstrated that motivated individuals with diabetes, who clearly understand the management of their condition and maintain glucose levels within near 
normal ranges, experience significantly fewer diabetes-related complications. Lifestyle self-management is the cornerstone to achieving the desired blood glucose levels required in patients with type 2 diabetes (Nagelkerk, Reick, \& Meengs, 2006).

Self-management education programs focus on four major elements of diabetes care: 1) dietary modifications, designed to reduce weight, reduce blood pressure and improve glycemic control; 2) an exercise regimen, which involves the addition of aerobic physical activity at least five times per week; 3) self monitoring of blood glucose; and 4) use of oral anti-diabetic medication or insulin as needed (American Diabetes Association, 2008; American Association of Clinical Endocrinologists, 2007). Briefly, the selfmanagement of diabetes involves dietary modifications that include a diet low in saturated fats, moderate carbohydrates and proteins and high in fiber (American Diabetes Association, 2008). A dietary intake of approximately $250-500$ fewer calories, an exercise regimen of $\geq 30$ minutes of moderate-intensity activity ideally every day, plus resistance training 3 times a week will promote a reduction in weight that tends to lower glucose level, blood pressure and other cardiac risk factors associated with type 2 diabetes. Self-monitoring of blood glucose (SMBG) at least three times a day is recommended for those patients that are using multiple insulin injections, with less frequent monitoring for those that use less insulin or use oral hypoglycemic medication (American Diabetes Association, 2008; AACE, 2007). Though these regimes are ideal, very few people are able to participate in them or, if they begin, very few are able to maintain them due to the difficulties that they experience in integrating such a complicated regime into their daily routine. The multiple barriers encountered thus result in less adherence to well intentioned health care plans ( Nagelkerk, Reick, \& Meengs, 2006). 


\section{Adherence}

Williams \& Friedland (1997) defined "adherence" as the extent to which a client's behavior follows or coincides with medical or health advice. McNabb (1997) considered "adherence" to be the degree to which an individual's behavior meets that of a standard or recommended practice (rather than to the recommendation of a provider). Adherence behavior may include following up referrals, keeping medical, dental and eye appointments, and observing appropriate dietary and exercise regimes. Success is mediated through ethnic and cultural boundaries known to have a strong influence on the provider-patient relationship and ultimately upon adherence rates (Johnson, Saha, Arbelaez,Beach, \& Cooper, 2004; Oster, Welch, Schild, Gazmararian, Rask, \& Spettell, 2006; Van Ryn, 2002; Welch et al., 2006).

Several studies have demonstrated that if the Latino patient receives a culturally appropriate plan of treatment, and is well educated regarding the lifestyle behaviors necessary, adherence rates are dramatically increased. The ideal plan incorporates Spanish speaking providers who are aware of their patients' cultural beliefs and are allowed sufficient time to deal with multiple medical problems (Brown et al., 2002; Johnson et al., 2004). Adherence is not just a patient issue. It is also a health care provider issue and there is a growing demand for a health care system that is able to provide not only culturally sensitive education but also culturally appropriate health care options (Barron, Hunter, Mayo, \& Willoughby, 2004).

The Cross-National Diabetes Attitudes, Wishes, and Needs (DAWN), 2005 study revealed that adherence rates vary with the type of self-management criteria being measured. Patient-reported medication adherence rates for type 2 diabetes were $78 \%$, keeping appointments $72 \%$, dietary control $37 \%$, and $38 \%$ adhering to exercise (Peyrot, 
Rubin, Lauritzen, Snoek, Matthews, \& Skovlund, 2005). The degree of adherence to one aspect of the regime thus may be unrelated to the degree of adherence to another aspect of the regime. Adherence to one task may to be a poor predictor of adherence to other tasks, suggesting that factors associated with non-adherence are legitimate areas for future research (Koenigsberg, Bartlett, \& Cramer, 2004).

Given these findings, providers should be cognizant of what is most important for the patient to adhere to in the health care plan prescribed. Low adherence rates have longterm effects that dramatically increase health care costs. Repeated episodes of hyperglycemia can result in multiple complications such as retinopathy leading to blindness; and persistent microalbuminuria and nephropathy leading to chronic kidney disease (American Diabetes Association, 2008; NDIC, 2007).

The control that an individual has over following a treatment plan is an important factor in determining that person's probability of adhering to that plan. In other words if an individual encounters situations that make it difficult for him or her to adhere to the prescribed regime adherence rates will more likely be low.

Many factors or barriers have been associated with lower rates of adherence to self-management of diabetes. For example, the self management regime may be too complex, generating confusion regarding medication and dietary regimes. There may be time limitations, competing family concerns, difficulty with transportation, and lack of communication between patient and provider (Benavides-Vaello, Garcia, Brown, \& Winchell, 2004; Brown, Becker, Garcia Barton, \& Hanis; 2002; Brown, Garcia, et al., 2002; Funnell, Brown, Childs, Haas, Hosey, Jensen, et al., 2008); Seid, Castaneda, Mize, Zivkovic, \& Varni, 2003). In addition, factors such as ethnicity and acculturation also affect self-management. Cultural factors can significantly influence patients' perceptions 
and assumptions about diabetes, patients' choice of health provider, patient-provider relationships, treatment options, and patient adherence (Barron et al., 2004; Walsh, Katz, $\&$ Sechrest, 2002).

\section{Culture and Acculturation}

Acculturation, the cultural change of minority individuals to the majority culture, has also been shown to be a factor having multiple effects upon diabetes management and glycemic control (Mainous, Diaz, \& Geesey, 2008). Cultural barriers and attitudes can directly influence how an individual perceives the illness, its treatment, and from whom to seek care. Patients may rely more on family and curanderos (folk healers) for advice than on knowledgeable health care services. Patients often have family members and friends with diabetes, and this can lead to a fatalistic attitude, where the patient believes it is their destiny to have it as well (Brown et al., 2002; Carbone et al., 2006; Lujan, Ostwald, \& Ortiz, 2007). Similarly, many Hispanics are culturally more focused on the "here and now", leaving the future "in the hands of God". Controlling blood glucose levels, taking medication and scheduling eye and foot examinations may not be considered high priority (Caballero \& Tenzer, 2007; Lara, Gamboa, Kahramanian, Morales, \& Bautista, 2005; Walsh et al., 2002; Weiler, 2007). The nature of the communication between a patient and the health care provider is also influenced by cultural factors and can, in turn, affect patient adherence. Providers need to be able to identify key factors that influence diabetes self management adherence so that they can become more culturally competent and implement interventions that overcome these cultural issues that affect the health outcomes of the ever-expanding Latino (Hispanic) population (Davidson, Ansari, \& Karlan, 2007; Harris, 2001; Lanting, Joung, Mackenbach, Lamberts, \& Bootsma, 2005). Appropriate assessment tools are crucial in 
examining factors that result in risky behavior patterns. It is, therefore, the purpose of this pilot study to test a newly developed Information Motivation Behavioral Skills measure of Diabetes Self-Care to determine its utility in identifying factors that hinder effective diabetes self management in Mexican Americans with diabetes type 2.

Several researchers have discovered gender-related differences in selfmanagement success: men have been found to have a higher compliance rate than women (Van der Ven, Weinger, Pouwer, Ader, ven der Pleog, \& Snoek, 2003). The difference is generally attributed to specific barriers that women experience as a result of family commitments. Exactly how these commitments may interfere with adherence and successful self-management is not known, and may be another fruitful line of inquiry especially in a population where the incidence is rising and the poor health outcomes are placing an undue burden on society. Cultural beliefs, attitudes and habits determine how Hispanics perceive diabetes. Understanding these cultural value systems is, therefore, a vital factor in identifying barriers and in providing diabetes education and appropriate health care that fosters adherence to self-management plans.

Brown and colleagues, since 1999 have developed and implemented the use of culturally appropriate Spanish-language education material into their interventions programs with a great deal of success, and yet there are relatively few instruments that provide a measure of predictors that hinder effective diabetes self management outcomes in culturally sensitive programs. Cultural attributes and values such as a fatalistic belief in the etiology of diabetes, strong interdependence with family members, respect and conformity towards health care providers in authority, gender role differences, the fondness for traditional foods all contribute to suboptimal health outcomes (Brown et al., 2006, Hatcher \& Whittemore, 2007). There is clearly a need for measures that have 
been created to be used in minority Hispanic populations which are comprehensive, culturally sensitive, reliable and valid (Fain, 2007).

It is apparent that effective diabetic self-management programs must promote patient knowledge and reduce weight and blood glucose levels. However, the most successful of programs focus on changing previously established behavior patterns through modification of attitudes and motivation. There is a need for a more complete understanding of how to enhance adherence to complicated self-management programs by identifying and incorporating cultural and ethnic influences that could be used to design a culturally acceptable program of treatment for ethnic minorities (Brown et al., 2000, Brown et al., 2002, Brown et al., 2005, Osborn, 2006). Culturally appropriate assessment and evaluation tools are an essential initial step in identifying factors that hinder adherence to DSM regimes. It is these tools that can assist providers in understanding the barriers to successful diabetes self management that ethnic minorities experience and promote the inclusion of these identified deficits into diabetes intervention programs.

\section{Culturally Sensitive Intervention}

The past ten years has seen recognition that adherence rates are improved by interventions that are culturally sensitive and more meaningful to patients. These culturally sensitive programs have been labeled "target" interventions if they adopt a single intervention approach to care defined by the subgroup. They are labeled "tailored" interventions if they are designed to appeal to a specific person characterized by individual assessments (Kreuter, Stretcher, \& Glassman, 1999; Kreuter, Lukwago, Bucholtz, Clark, \& Sanders-Thompson, 2003). Together with the inclusion of social support and reinforcing educational material, these types of programs are producing 
promising but limited results (Kreuter \& Skinner, 2000). Both approaches, it would appear, need to be further refined in order to adapt to the ethnic groups that have the highest rates of diabetes and diabetic complications.

Several well documented studies have focused on providing culturally sensitive diabetes intervention programs to Mexican-Americans (Bacardi-Gascon, Rosales-Garau, \& Jimenez-Cruz, 2004; Brown et al., 2005, Brown et al., 2002; Brown \& Hanis, 1995) but there is a lack of an in-depth perspective regarding how barriers to these newer programs prevent optimal self-care behaviors and success in glycemic control. The perceived complexity of the topic has justly prompted authors to suggest frameworks for identifying and organizing factors that have been found to affect self-care behaviors for use in diabetes self-management programs (Osborn, 2006; Sarkisian, Brown, Norris, Wintz, \& Mangione, 2003).

Extensive reviews of diabetes self-management programs conducted over the past 10 years (Brown, 1999; Norris, Lau, Smith, Schmid, \& Engelau, 2002; Osborn, 2006; Sarkisian et al., 2003) have revealed that adherence to these programs do indeed improve patients' knowledge, and help to reduce weight and blood glucose levels. However, the most successful programs target behavior change as a more lasting solution to diabetes control. What factors contribute to this change in behavior remain unclear and in the case of ethnic groups, have received little attention. Theoretical models have proven to be effective at initiating and maintaining behavior change as they serve to identify those critical factors that influence behavior patterns (Hall, Joseph, \& Schwartz-Barcott, 2003; Rutter \& Quine, 2002;). Although these models have been widely used to inform interventions that promote health behavior change in other areas, they have not been extensively used in the field of diabetes self-management education specifically among 
ethnic groups (Sarkisian et al., 2003), making it very difficult to identify the critical elements that would potentially affect health behavior change in these populations. Filling in these gaps in the literature and in our knowledge with the help of theory-based models and the use of theory-based assessment tools is, therefore, essential to designing more effective culturally appropriate diabetes self-management programs targeted at ethnic groups. Theory-based evaluation tools can then be used to determine the success of DSM programs which to date have been poorly supported.

Up to now, culturally sensitive diabetes self- management programs have been designed for African-Americans (Funnell et al., 2008), Asians (Wang \& Chan, 2005), and Mexican-American Hispanics (Brown et al., 2002) but all have lacked a well defined theoretical framework by which to identify critical factors necessary for behavioral change and improved adherence rates. Knowing that interventions are more effective when they contain content material that is both culturally relevant and appropriate to the target population (Fisher \& Fisher, 1992), this pilot study proposes to use the "Information, Motivation-Behavioral Skills (IMB)" model of behavior change to identify the needs, deficits and barriers that serve to affect adherence to the diabetes selfmanagement behaviors of diet and exercise. These factors can then inform the design of a more focused intervention education program specifically to address the needs of the Mexican-American population or alternatively address specific needs of patients exhibiting at- risk behaviors.

Osborn (2006), in her work using the IMB model to promote self-management behaviors in Puerto Ricans with diabetes type 2 developed an IMB Self-Report Questionnaire to better understand the specific diabetes-related needs of that population. The present study will psychometrically test and validate her findings as well as explore 
gender and acculturation differences that may exist between Mexican-American men and women with type 2 diabetes and their adherence to diabetes self-management education programs

\section{The IMB Model}

The IMB model of health behavior change has been chosen as the framework for this study as its principal components, Information, Motivation and Behavioral skills, have been identified in the research literature as being determinants of performing DSM behaviors. For a complete description of the model the reader is referred to Chapter 2 . In brief, the model, holds that unhealthy behavior patterns and poor health outcomes result from a combination of lack of non-specific unfocussed information, insufficient motivation and poor behavioral skills (Fisher, Fisher, Amico, \& Harman, 2006; Misovich, Martinez, Fisher, Bryan \& Catapano, 2003; Starace, Massa, Amico, \& Fisher, 2006). The model emphasizes increasing health behavior change through overcoming identified barriers and deficits and motivating individuals to refine behavior skills (Fisher \& Fisher, 1992).

According to the model three prerequisites promote healthy behavior change: (1) relevant, applicable subject-specific information, (2) personal and social motivation, which includes support for and attitude towards performing the health behavior and (3) the behavioral skills which is the skill-set required to perform the behavior as well as the self-efficacy or belief that one can perform the DSM behavior easily (Bandura, 1986). (See Chapter 2, Fig. 2.)

Information and motivation work largely through and are limited by the behavioral skills to carry out the desired DSM behavior, however, information and motivation may exert their effects directly when the DSM behavior is uncomplicated. 
For example, performing a healthy DSM behavior such as walking for 30 minutes daily requires information regarding the exercise, personal motivation, social support to undertake it and the ability to be able to exercise for that duration. Making appointments to have 3 monthly HbAlc levels drawn on the other hand constitutes a direct effect of relevant and specific information to achieve its treatment goals.

The IMB model has successfully been validated in health promotion areas such as reducing HIV risk behaviors (Fisher, Fisher, Miskovich, Kimble \& Malloy, 1996), adhering to medication regimes (Fisher, Fisher, Amico, \& Harman, 2006), maintaining breast health (Misovich, Martinez, Fisher, Bryan, \& Catapano, 2003) and promoting selfmanagement behaviors in Puerto Ricans with diabetes (Osborn, 2006).

The IMB-DSC questionnaire is a scale that has been developed to measure (capture) behavior-specific information, motivation and behavioral skills directly related to diabetes diet and exercise behaviors. The instrument, crafted from selected elements of the "Diabetes Knowledge Questionnaire" (DKQ-24, Spanish version, Garcia Villagomez, Brown, Kouzakani, \& Hanis, 2001), adds a number of items that specifically target diet and exercise knowledge which were found to be deficient in the original questionnaire. The resultant tool thus consists of 28 new items addressing specific diet and exercise knowledge and incorporates areas that address motivational factors and behavioral skills, a format which follows the constructs of the IMB model of behavior change. The newly devised instrument has currently only been used to promote selfmanagement behaviors in a Puerto Rican population with diabetes type 2 (Osborn, 2006). A study of this nature has not yet been carried out in Mexican-Americans which are a culturally distinct subpopulation to Puerto Ricans and in whom the prevalence and risk factors differ (Brown et al., 2002). 
Evidence does exist that suggest that appropriate information, adequate motivation and the relevant behavioral skills has an effect upon the health outcomes of Mexican-American adults but little research has to date been done on this topic using such a specifically designed measurement tool (Brown et al., 2002). As it is very important to better understand the barriers that hinder successful diabetes self management and the deficits that patients may experience in maintaining their self care plans, it is imperative that reliable assessment tools be tested that identify the factors that affect successful management.

\section{Research Goals}

This purpose of this cross-sectional pilot study it to test the reliability and content and construct validity of the Information, Motivation, and Behavioral Skills Diabetes scale (IMB-DSC) as an assessment tool in Mexican American adults, with diabetes type 2 , with a view to identifying gaps in diabetes knowledge, motivational influences and diabetes behavioral skills practices that impact both women and men in their success in diabetes self management.

The study will involve a quantitative investigation with regard to diabetes selfmanagement knowledge, attitudes and skills related to DSM adherence. A convenience sample of participants from a local community clinic serving predominantly MexicanAmericans will be presented with an Information-Motivation-Behavioral Skill Measure of Diabetes Self-Care (IMB_DSC) self-report questionnaire. Participants upon completion of the questionnaire will then be asked to answer seven semi-structured questions related to the barriers to self-management. It is hoped that information emerging from these questions can then be used both to further develop the questionnaire 
and validate its use as an assessment tool to identify individual patients with at-risk diabetes related health behaviors.

The research questions to be answered are...

1). Is the Information-Motivation-Behavioral Skill Measure of Diabetes Self-Care (IMB_DSC) self -report questionnaire a valid and reliable tool for use in MexicanAmerican adults with type 2 diabetes?

2). What is the relationship between gender and IMB scores?

Hypothesis ${ }_{1}$ : There is no relationship between gender and IMB scores

3). What is the relationship between IMB scores and diabetic health outcomes (HbAlc)?

Hypothesis $_{1}$ : There is no relationship between IMB scores and HbAlc values.

4). Does the IMB-DSC instrument accurately assess Mexican-American's knowledge (information) motivation, and behavioral skill level regarding their diabetes and its management?

Significance to Nursing and Clinical Practice

The pilot study will empirically serve to test the content and construct validity and reliability of the IMB skills measure of diabetes self care report questionnaire in identifying gaps in diabetes related knowledge (information), motivational influences and behavioral skills related to diabetes self-management in Mexican-Americans with diabetes type 2 . The results could be used to evaluate intervention programs and identify areas of weakness that need to be focused on in order to promote an increase in healthy behavior practices and thus improve health outcomes in this population.

With regards to clinical practice, the new knowledge obtained will be used to enhance our current understanding of the barriers that Mexican-Americans face when diagnosed with diabetes and embark on a complicated program of self management 
behavior practices. Nurses can incorporate culturally appropriate regimes into their clinical practice to improve health care provider-patient relationships and improve the adherence of these patients to their diabetic management regimes.

The results can effect nursing education through the development of culturally specific education programs that provide nurses with an enlightened awareness of the factors that impede adherence to diabetes self-management programs in a MexicanAmerican population. Such knowledge will provide nurses with the ability to identify those patients that are high risk for diabetes related complications. Nurses, in collaboration with an interdisciplinary team of health care providers, can then create culturally appropriate, tailored diabetes self-management programs which cater to individual patient needs, thus improving diabetes education for patients on a case by case basis.

In summary, it has been established that diabetes type 2 is a significant problem in the Hispanic population; there are culturally appropriate interventions but adherence is still a problem in this population; and there are no valid and reliable instruments to assess why. The intent of this research study is to assess the reliability and content/construct validity of a possible tool health care providers could use to assess the barriers Hispanic patients may have in being adherent with therapy. 


\section{CHAPTER 2: LITERATURE REVIEW}

\section{Introduction}

The present chapter will review the basic types of diabetes with an emphasis on type 2 diabetes, will also introduce the current Standards for type 2 diabetes medical management and also review the trends in diabetes self-management education. The specific cultural belief and meaning that diabetes portrays plus the challenges of diabetes self-management in Hispanics will then be discussed and the effects of acculturation and gender upon DSM health outcomes will be explored. Finally the theoretical framework, the Information-Motivation-Behavioral Skills model of behavior change, will be examined and discussed and its relevance to diabetes self-management evaluated.

\section{The Toll of Diabetes}

The incidence of Diabetes Mellitus has increased dramatically over the past 10 years and it continues to rise alarmingly. The estimated number of people in the U.S. with diagnosed diabetes is now approaching 17.5 million with approximately 12.2 million or $23.1 \%$ of all people 20 years and older being affected. Within this age group $11.2 \%$ are men and $10.2 \%$ are women. With the prevalence of diabetes increasing with age, the burden of diabetes on the country and on the health care system is destined to increase as the average age of the nation's population rises (NDIC, 2007).

According to the American Diabetes Association (2008c), diabetes accounted for $\$ 174$ billion in medical costs and lost productivity. Absenteeism due to diabetes cost nearly $\$ 2.6$ billion. Reduced productivity while at work cost $\$ 20$ billion, and the loss due to disability days is about $\$ 7.9$ billion (American Diabetes Association, 2007; Centers for 
Disease Control and Prevention, 2007b). Diabetes takes a toll not only on the affected individual but on the nation as a whole.

The deleterious effect of diabetes is a result of the persistent chronic state of hyperglycemia. Individuals with diabetes consequently have a shorter life span than those without the disease (American Diabetes Association, 2007; Boyle, Honeycutt, Narayan, Hoerger, Geiss, Chen, 2001; Brown, Gerzoff, Karter, Gregg, Safford, Waitzfelder, et al., 2003. In 2005, $44 \%$ of newly diagnosed cases of kidney failure were attributed to diabetes alone and currently the disease accounts for $65 \%$ of deaths associated with cardiovascular disease and strokes (American Diabetes Association, 2007; Charles, 2002).

There are racial disparities in the prevalence of diabetes and diabetes-related complications (Economic consequences of diabetes mellitus in the US in 2007), as Mexican-Americans suffer disproportionately from poor health outcomes as a result of diabetes-related complications such as cardiac disease, nephropathy, and kidney failure (Gordon, 2004; Groman \& Ginsberg, 2004). In addition, Mexican-Americans have a tendency to be diagnosed with diabetes at earlier ages, have higher fasting glucose levels, decreased insulin sensitivity, increased insulin response and an increased severity of diabetic complications (Alberti, Zimniet, Shaw, Bloomgarden, Kaufman, \& Silink, 2004; Brown et al., 2002; Brown et al., 2003)

\section{Diagnosing Diabetes Mellitus}

Individuals are typically diagnosed with diabetes when they satisfy one or more of the following three criteria: 1) a fasting plasma glucose FPG; of greater than $126 \mathrm{mg} / \mathrm{dl}$; (no calorie intake within 8 hours); 2) a 2 hour postprandial level greater than $200 \mathrm{mg} / \mathrm{dl}$; 
and 3) diabetic symptoms which include increased thirst (polydipsia), increase urination (polyuria), hunger, weight loss, increased incidence of infections, blurred vision, and nausea. Some individuals with diabetes have no symptoms whatsoever (American Diabetes Association, 2009).

Diabetes is classified into three categories, each characterized by hyperglycemia resulting from deficiencies in insulin secretion, insulin action or both: 1) Type 1 diabetes (formerly known as insulin-dependent diabetes or juvenile onset diabetes mellitus (IDDM); 2) type 2 (previously known as non-insulin dependent diabetes mellitus (NIDDM); and 3) gestational diabetes (GDM) which is diabetes that occurs during pregnancy (American Diabetes Association, 2009)

In type 1 diabetes mellitus there is generally a malfunctioning of the body's immune system that results in reduced or non-existent secretion of placental insulin. With a tendency to occur suddenly among a younger population the abrupt reduction in insulin results in the symptoms of polyphagia, polyuria, rapid weight loss and general malaise (Charles, 2002). Patients in this category are thus rarely obese when they present with this type of diabetes.

Those with type 2 diabetes retain some pancreatic activity and insulin production. However, they often exhibit signs of insulin resistance or insensitivity (American Diabetes Association, 2007). Diabetes type 2 in this population has a more gradual onset and may occur at any age. The majority of patients are diagnosed after the age of 40 and have a tendency to be overweight or obese (BMI $>30 \mathrm{~kg} / \mathrm{m}^{2}$ ) which further contributes to their insulin resistance or insensitivity (Guthrie \& Guthrie, 2004). 
In the case of Gestational Diabetes Mellitus (GDM) the diagnosis is made during pregnancy when any degree of glucose intolerance is identified. The importance of GDM is firstly that it may cause complications such as an increased risk of cesarean section, chronic hypertension as well as increased perinatal morbidity and mortality (American Diabetes Association, 2009). Secondly, many expectant mothers diagnosed with GDM will progress to develop either type 1 or type 2 diabetes many years later (American Diabetes Association, 2009; Centers for Disease Control and Prevention, 2007b)

Diabetes Type 2 Development

Currently type 2 diabetes accounts for $90-95 \%$ of all cases of the disorder. It is commonly associated with obesity, lack of physical exercise, family history of diabetes and race/ethnicity. It is a syndrome with various signs and symptoms, with its onset influenced by illness, genetic and environmental factors (Charles, 2002; Edelman \& Kim, 2002) that trigger the body to either fail to produce or improperly use insulin.

The chronic hyperglycemia of diabetes type 2 is a result of a combination of the body's resistance to pancreatic insulin, insufficient pancreatic insulin production over time and poorly regulated and/or increased hepatic glucose production (Guthrie \& Guthrie, 2004). During the early stages, glucose levels are mildly higher than normal but as the disease progresses glucose and insulin levels rise to a point where the level of insulin may reach 5 times that of normal. The body, unable to cope with the high glucose levels, demonstrates the observed signs of insulin resistance with more insulin being produced to compensate for the high levels of glucose. Eventually with prolonged insulin resistance, glucose levels escalate due to liver production of even more glucose, until 
insulin secretion fails and type 2 diabetes develops (Charles, 2002; Guthrie \& Guthrie, 2004).

The end results of the prolonged hyperglycemia are the observed diabetes -related complications such as stroke, kidney failure, and cardiovascular disease (American Diabetes Association, 2009). Heart disease remains the leading consequence of diabetes-related deaths with individuals facing 2-4 times the incidence of developing stokes or other cardiac disorders (American Diabetes Association, 2007). Diabetes is also the leading cause of blindness among adults 20-70 years of age due to the reduction in blood flow to the eyes resulting in ischemia, edema, micro-aneurysms, and thickening of the retina (Abu-lebdeh, 2007). Diabetes accounts for approximately $44 \%$ of all newly diagnosed cases of end-stage renal disease (ESRD) and approximately 60-70\% of diabetics suffer with mild to more severe forms of nervous system damage (American Diabetes Association, 2007).

The prevalence of all the above complications is increased in American minorities, specifically Mexican-Americans due to the Native American genetic admixture that may predispose them to reduced rates of energy expenditure, increase risk of obesity and in the distribution pattern of body fat (Brown et al., 2002). There is also some speculation that a Spanish admixture may also play a significant role in determining these risk-factors (Lorenzo, Serrano-Rios, Martinez-Larrad, Gabriel, Williams, GonzalezVillalpando et al., 2001).

More recent studies, however, are approaching the obesity/diabetes phenomenon from a systems viewpoint and consider that the resultant obesity/diabetes epidemic in our minority populations (for our purpose the Mexican-American community) could well be 
due to a complex series of factors ranging from genetic, cellular, biologic, and psychological effects to social, historical, economic and political influences (Candib, 2007). These closely interacting factors which also include events such as intrauterine malnutrition and low birth weight in the prenatal and early postnatal period lead to the development of obesity and metabolic syndrome in later life. This thrifty phenotype concept ultimately causes irreversible metabolic differentiation with an increased risk of certain chronic diseases in adulthood, such as diabetes (Candib, 2007).

Environmental factors that compound the obesity/diabetes problem are the dietary modifications and reduction in exercise level common to populations that migrate from rural areas to cities in search of a better life. The high calorie, high fat dietary modifications common to resource poor communities referred to as the nutritional transition and the tendency to walk less and ride more increase the risk of obesity and diabetes particularly among immigrants (Bates, Acevedo-Garcia, Alegria \& Krieger, 2008). A more thorough description of the interesting factors that interconnect obesity with diabetes is not within the scope of this dissertation; however, a better awareness of the issues underlying this connection needs to be addressed by researchers and clinicians working with ethnic minority populations.

In summary, the combined defects of insulin resistance, insufficient insulin production and hepatic overproduction of glucose make treatment of diabetes type 2 a very complicated process (American Diabetes Association, 2008). Fasting hyperglycemia is thus attributed to increased hepatic glucose output whereas elevated postprandial hyperglycemia results from the combined effects of abnormal insulin secretion, defective hepatic glucose secretion and impaired glucose uptake (Brunton, Carmichael, Funnell, 
Lorber, Rakel, \& Rubin, 2005; Giorgino, Laviola, \& Leonardini, 2005). Focusing treatment efforts on reducing both fasting and post-prandial hyperglycemia should ultimately result in a reduced risk of diabetes-related complications. It is with this focus in mind that this study attempts to assess the reliability of an instrument that may explore the factors that impede adherence to this goal.

\section{Treatment Options for Diabetes Mellitus}

Treatment for diabetes mellitus concentrates on maintaining blood glucose levels within the normal range. The American Diabetes Association recommends a glycosylated hemoglobin (HbAlc) level of $<7 \%$ and a fasting plasma glucose (FPG) of $<120 \mathrm{mg} / \mathrm{dl}$ (American Diabetes Association, 2007b, 2008a). Glycosylated hemoglobin is a form of hemoglobin in which glucose is attached or glycosylated to a form of hemoglobin known as $\mathrm{HbAlc}$. It is this molecule of hemoglobin with its attached glucose that laboratories are able to measure and report as a specific value, the HbAlc. This glycosylated form of hemoglobin circulates with red blood cells for the duration of their lifespan (approximately 120 days). Thus, if HbAlc concentration is elevated, it indicates that average blood glucose concentration over a three-month period has also been elevated. Measuring $\mathrm{HbAlc}$ concentration is a fairly reliable method for assessing a patient's blood glucose control over the preceding 3 months (American Diabetes Association, 2008). Physicians and other healthcare providers can then make their treatment recommendations based upon these laboratory values (American Diabetes Association, 2008).

The overall goal of type 2 diabetes treatment is to maximize the effect of endogenous insulin through decreasing insulin resistance. Treatment options are aimed at 
restoring and maintaining blood glucose at or as near as possible to normal levels through medication, dietary modifications and exercise (American Diabetes Association, 2008).

The American Diabetes Association recommendation of glycosylated hemoglobin (HbAlc) levels of $<7 \%$ and a fasting plasma glucose (FPG) of $<120 \mathrm{mg} / \mathrm{dl}$ have been associated with a reduction of microvascular and neuropathic complications as well as possibly macrovascular disease (American Diabetes Association, 2007b) but in order to achieve maximum gain from these treatment options patients are required to adhere to diabetes self management regimes with a rigidity that calls for substantial personal determination and effort.

Through the seminal work of the Diabetes Control and Complication Trial (1993, 1996) Research Group and the United Kingdom Prospective Diabetes Study (UKPDS, 1998a,b) Group it has clearly been illustrated that tight glycemic control can play a key role in the prevention and reduction of diabetes-related micro-vascular complications. However, successful glycemic control of type 2 diabetes requires certain prerequisites and a clear understanding by patients of the chronic nature of the condition, and its associated lifelong treatment implications and progression. These pre-requisites are more commonly referred to as Diabetes self-management (DSM) Intervention Programs Diabetes Self-management Intervention Programs Diabetes self-management intervention programs which are also referred to as lifestyle self-management (or lifestyle modification) regimes are the cornerstone to achieving the blood glucose levels so necessary for optimum management (Nagelkerk, Reick, \& Meengs, 2006). Self-management of diabetes involves four major elements: 1) dietary modification, weight reduction, blood pressure reduction and improve glycemic 
control; 2) exercise; 3) self monitoring of blood glucose; and 4) use of oral anti-diabetic medication (American Diabetes Association, 2007). There is extensive literature regarding the use of anti-diabetic medication and its role in the management of type 2 diabetes (American Diabetes Association, 2009). This study will focus on dietary and exercise strategies along with motivational influences and behavioral skills used in treatment management in the Mexican American study population.

Diet

Dietary changes include a diet low in saturated fats, moderate carbohydrates and proteins and high fiber (American Diabetes Association, 2007). A dietary intake of approximately $1,200 \mathrm{kcal} / \mathrm{day}$ is recommended for patients weighing $120-174 \mathrm{lbs}$ (54$78 \mathrm{~kg}) ; 1,500 \mathrm{kcal} /$ day for those weighing $175-219 \mathrm{lbs}(79-99 \mathrm{~kg}) ; 1,800 \mathrm{kcal} /$ day for those weighing 220-249 lbs (100-113 kg); and 2,000 kcal/day for those weighing $250 \mathrm{lbs}$ (114 kg) (American Diabetes Association, 2007). These caloric intake values, when combined with exercise, are designed to promote a reduction in weight which has a lowering effect on the patient's glucose level, blood pressure and other cardiac risk factors associated with type 2 diabetes (Wing, 2001).

Exercise

In terms of physical activity, at least 150 minutes of moderate-intensity aerobic exercise per week distributed over 3 days is currently recommended or at least 30 minutes of exercise five times per week with no more than 2 consecutive days without exercise activity (American Diabetes Association, 2008). Additionally, for those patients with no health or physical contraindications, the American Diabetes Association also endorses an additional routine of resistance exercise targeting the major muscle groups at 
least 3 times per week. When vigorous exercise is contraindicated, however, as in cases of poor physical health or long-term diabetes related complications, non-weight bearing activities such as swimming, bicycling, or arm exercises are recommended (American Diabetes Association, 2007; Dunstan, Daly, Owen, de Court, \& Shaw, 2002).

\section{Medication}

Traditionally diabetes type 2 management calls for a period of time with oral agents and then the final transition to insulin as pancreatic beta-cell function decreases and endogenous insulin production fails (American Diabetes Association, 2008). Of the nine classes of hypoglycemic medications currently available for the treatment of diabetes type 2, all target either fasting blood glucose and/or postprandial blood glucose levels (American Diabetes Association, 2008). The average A1C reduction achieved by oral pharmacologic agents ranges from 0.5 to $1.5 \%$. Of the three classes of injectable agents available (Insulin, Amylin and the incretin mimetic Exenatide), insulin is by far the most popular and cost-effective (American Diabetes Association, 2008; Nathan, Buse, Davidson, Heine, Holman, Sherwin, et al., 2006).

\section{Self-monitoring of Blood Glucose}

Frequent self-monitoring of blood glucose (SMBG) is another essential component of diabetes self-management. For those patients that use insulin as adjunct therapy in their regime, it involves monitoring blood glucose levels at least three times a day, 1-2 hours after meals. Those patients on oral hypoglycemic medication require daily blood glucose monitoring (American Diabetes Association, 2007a). The Association recommends routine $\mathrm{HbAlc}$ testing twice a year for those patients that are adequately controlled (i.e., have Alc levels $<7 \%$ ) and more frequently, every 3 months, for those 
patients who are not as well controlled. For those patients with Alc levels $>8 \%$ the recommendations are that their treatment should be re-evaluated regularly until values are restored to recommended limits.

Despite all efforts, glycemic control appears to be worsening. Data from the most recent National Health and Nutrition Examination Survey (NHANES) which compares the 1999-2000 figures with the 1988-1994 figures reveals that among adults with diabetes type 2, the A1c level has risen from $7.7 \%$ to $7.9 \%$. This increase translates to a $21 \%$ reduction in the likelihood of achieving glycemic control (Koro, Bowlin, Bourgeois, \& Fedder, 2004). The American Diabetes Association treatment target continues to be $<7 \%$ and Ford (2004) and colleagues have demonstrated that $>50 \%$ of Americans are attaining these $\mathrm{A} 1_{\mathrm{c}}$ levels. Unfortunately there remain nearly $40 \%$ of Americans who fall short of these glycemic goals. The highest failure rate appears to be experienced in ethnic minorities, including Mexican-Americans, the population that comprises the focus of this study (McBean, Li, Gilbertson, Collins, 2004; NDIC National Diabetes Statistics, 2007).

Diabetes in Hispanics

The poorer glycemic control that Hispanics experience when compared with Caucasians, has prompted researchers to hypothesize that these health disparities are a result of poorer access to health care and the receipt of lower-quality care (Brown et al., 2003, Hargraves et al., 2001). However, when health care services have been found to be equally available Hispanics still emerge with inferior blood glucose levels. Other factors, therefore, are contributing to the adverse health outcomes identified in this population (Welch et al., 2006). 
Researchers have suggested that if health care providers were better aware of the cultural value system held by Hispanics they would be better able to serve this population. By identifying specific cultural risk factors, therefore, interventions can thus be developed that will address these health care deficiencies and meet the needs of this community (Brown et al., 2006, Mainous et al., 2008; Quatromoni et al., 1994) .

Few studies have investigated Mexican American beliefs about diabetes and its management. Those that have explored the topic, however, have identified some important prevailing attitudes regarding causes of diabetes its symptoms and course, treatment options, the role of diet and exercise, and family involvement (Brown et al., 2003; Brown et al., 2006; Coronado, Thompson, Tejeda, \& Godina, 2004; Hatcher \& Whittemore, 2007).

Genetics or hereditary influences have been reported by Mexican Americans as principal causes of diabetes, but many still consider diabetes to be more of a trait that they carry in their blood which they subsequently pass on to their offspring (Acury , Skelly, Gesler, \& Dougherty, 2004). Susto meaning a sudden fright or a traumatic emotional state such as anger (coraje), sadness (tristeza), joy (gusto) and fatalism ,(fatalismo $)$, the belief that diabetes is a punishment from God or is God's will are also considered to be sufficient grounds for the onset of diabetes (Caban \& Walker, 2006; Coronado et al., 2004). Conversely, Hispanic culture, however, does place a significant role on the religious belief that God and prayer have positive effects by guiding self management diabetes plans (Caban \& Walker, 2006).

For many Mexican-Americans, diet and lifestyle can also trigger diabetes. Eating a diet high in fat and sugar, consuming excessive amounts of alcohol, smoking, substance 
use and generally not taking care of oneself such as not getting sufficient sleep for prolonged periods of time are all additional causes of diabetes (Hunt et al., 1998). Common symptoms identified as being related to the onset of diabetes and recognized as prompting immediate medical attention are blurry vision, tired eyes, fatigue, weakness, headaches, excessive thirst, increased urination, dry mouth and weight loss. Other symptoms not so immediate but nonetheless important are signs of depression, immediate anger, intense sadness and depression (Acury et al., 2004; Coronado et al., 2004; Jezewski \& Poss, 2002; Rivera, 2003).

The use of folkhealers (curanderos) and home remedies are important additions to prescribed treatment plans among Mexican-Americans. Herbal treatments such as prickly pear cactus (nopal) and aloe vera (Savila) are among the most common of the natural and less expensive of the herbs used. Knowledge regarding their use in combination with traditional hypoglycemic medication, however, is scant and Hispanics often turn to family, friends and neighbors for advice as to the quantities to use (Poss et al., 2003).

Family involvement for support, decision-making and guidance in the treatment of diabetes is a fundamental feature in helping Mexican-Americans to maintain good care of themselves. Important decisions regarding use of medication, type and amount of exercise, type of foods to eat are all choices made in collaboration with the family and thus a great deal of emphasis is placed upon familial values and beliefs (Hatcher \& Whittemore, 2007). 


\section{Diabetes Self-management Adherence in Hispanics}

Although there is a paucity of research information that has specifically identified the specific barriers and deficits that Mexican-Americans face in adhering to their Diabetes Self management, it has been found that they do lack an understanding of their dietary and exercise plan and believe that the instructions provided to them are often too vague and lack clear guidelines (Brown et al., 2006; Nagelkerk, Reick, \& Meengs, 2006). Even though Mexican-Americans consider diet to be an important factor in the treatment of diabetes type 2 they are often unsure what constitutes an appropriately healthy diet and consider those described by health care providers to be too rigid in content, insufficient in quantity and not culturally appropriate (von Goeler et al., 2003). In terms of exercise, many women consider that household chores are an adequate form of exercise but are uncertain how often and for what length of time they are to be performed. Interestingly many Mexican-Americans do not often realize the value of exercise as a weight loss tool in controlling their diabetes (Kieffler et al., 2002).

Other obstacles that patients have identified include the lack of Spanish speaking health care personnel and their own personal low literacy levels which together impede the understanding of any knowledge about diabetes, medication, diet, exercise, glucose monitoring and self- management plans that are to be initiated (Chilton, $\mathrm{Hu}, \&$ Wallace, 2006). Difficulties in remembering when to take medication, time taken to prepare special foods for the family and the lack of time available to routinely exercise because of family commitments have all been identified and common problems (Oomen, Owen, \& Suggs, 1999). . 
Lack of a provider-patient relationship so important from a cultural perspective, is exacerbated by the language barrier which prevents Mexican-American patients from disclosing pertinent information which providers could most certainly use in coordinating care. Patient care providers who share a common language have been reported by Adams ( 2003) to be an advantage but more so than that, providers that demonstrate caring and a respect for the patient are more meaningful provider characteristics. With experiences generated by such poor interactions it can easily be seen why MexicanAmerican patients report being frustrated, discouraged and lacking the motivation to continue with their prescribed diabetes self management plans.

Negative attitudes about their ability to control their diabetes, and frustration and helplessness due to lack of glycemic control, regardless of adherence, has fostered a continued belief in fatalistic attitudes that regard progression of the diabetes as an eventuality. Mexican-Americans with this view are less likely to comply with their treatment recommendations due to a despondent view of the disease (Anshel, 2000; Arcury et al., 2004; Nagelkerk, Reick, \& Meengs, 2006).

Acculturation and Adherence

For Hispanics in particular the majority of the cultural factors, beliefs and influences previously mentioned have been identified as key components that significantly affect adherence rates (Brown et al., 2002; Cabellero, 2005; OOmen et al., 1999). Acculturation may be a significant contributor to adherence.

Acculturation is defined as the process by which "immigrants adopt the attitudes, values, customs, beliefs, and behaviors of a new culture" (Abraido-Lanza, White, \& Vasques, 2004). It is a process in which immigrants modify or completely take on the 
cultural habits of the majority or dominant culture (Antshel, 2002). Berry (1990) identified four possible effects of acculturation: assimilation, integration, separation and marginalization. Assimilation involves giving up one's cultural identity and heritage and taking on the cultural characteristics of the host culture, blending into the host community (Barron et al., 2004). This type of individual would communicate more comfortably in English rather than in Spanish. In the process of integration, one's cultural identity is retained but new relationships are initiated with the host culture. This individual would speak the language of both cultures equally and develop friendships and relationships with those from the host culture. In the separation phase a close relationship or bond is maintained with their cultural heritage and the choice is made not to adopt the cultural habits or influences of the host culture. This individual will be Spanish-speaking only and has, for various reasons, chosen not to learn and speak English. Finally in marginalization the individual gives up their original cultural identity in order to pursue identification with the host culture but experiences rejection by the group to which they are acculturating (Cuellar, Arnold, \& Maldonado, 1995; Bereolos, 2007). It is the stress involved in the process of acculturation which places the individual in a state of cultural marginality that results in a health related effect (Barron et al., 2004).

Acculturation of Mexican Americans to the U.S. culture has tended to have mixed responses. Mainous et al., (2008) found that acculturation negatively influenced the healthy dietary practices of the Mexican-Americans who had adopted the US cultural practices related to eating and food choices. The result was an increasing incidence of obesity and type 2 diabetes in which these researchers concluded that acculturation, which is generally thought to have a beneficial effect on health outcomes due to the 
improvement observed in access to health care and socio-economic status, was in fact a negative effect as the less acculturated Latinos with diabetes followed the healthier diets. This finding suggested that adopting an American diet may not be a desirable health behavior change in Latinos especially when studies have clearly demonstrated that Latinos have difficulty in maintaining healthy dietary habits while adapting to the mainstream culture (Devlin, Roberts, Okaya, \& Xiong, 2006; Mainous et al., 2008). Brown and associates (2000) on the other hand in their studies related to health beliefs and acculturation in diabetic individuals of Mexican origin found a positive relationship between acculturation and diabetes knowledge. The higher the acculturation, the greater the knowledge of diabetes and its management.

As yet very little research has focused on the impact of acculturation on the dietary preferences among Latinos with diabetes and so there remain substantial gaps in our understanding of the significant role that acculturation might play in promoting adherence to healthy dietary behaviors. It is clear, however, that acculturation plays a prominent factor in a patient's perceptions and assumptions about their illness, and its treatment options. Choice of health care provider and the patient-health care provider relationship which follow this interaction has also been found to have a profound impact upon patient adherence to treatment regimes (Walsh et al., 2002; Barron et al., 2004). Adherence, which refers to the extent to which an individual follows the advice offered by the health care provider, is known to be heavily influenced by acculturation (McNabb, 1997). Lack of adherence to diabetes self-management regimes may be due to a multitude of factors including the individual's struggle to protect traditional habits. 
Under these circumstances, understanding the cultural attitudes and beliefs of an ethnic population becomes extremely important to health care providers.

When Mexican-Americans attitudes and beliefs regarding their health have specifically been studied, specific viewpoints have significantly influenced the patient's perception and adherence to their prescribed plan of care (Barron et al., 2004). Fatalism (fatalism) as mentioned previously is the belief that a chronic disease such as diabetes is determined by God and is to be accepted and endured as punishment (castigo divino) as a result of some form sinful behavior. Hispanics, therefore, who uphold these attitudes are unlikely to comply with treatment that they consider will have little to no effect. Health to many Hispanics particularly those of Mexican descent who are not well acculturated, also tends to represent a continuum of mind, body and spirit (espiritu) in which psychosocial stressors such an emotionally charged events i.e. a death or severe accident may appear as a somatic complaint such as fright (susto), or a nervous crisis (ataque de nervios) (Hatcher \& Whittemore, 2007; Samaan, 2000).

Personal relationships (personalismo) involve the relationship with the health care provider and deals with the concept of the physical space between patient and provider. Hispanic patients are more accustomed to expect friendly, personal gestures such as a hand on the shoulder from their health care providers, rather than the 3 feet or more distance that is common and customary in Anglo-Americans. This situation can thus lead to feelings of hostility and distrust between patient and provider which can result in less adherence with treatment plans (Antshel, 2002).

Kindness (simpatia) and respects (respeto) are two other concepts associated with the patient-provider relationship that can affect treatment adherence. Simpatia, relates to 
the value that Hispanics place on positive interpersonal interactions and the art of being agreeable. Anstel (2002) cites the example of a patient nodding or shaking their head during a discussion giving the impression of complete understanding when this may not be the case. It is also important to remember that many Hispanic are reluctant to disclose disagreeable or uncomfortable side effects, complications and difficulties that they may be experiencing which may be causing them to stop adhering to previously arranged self management directions particularly if they already have a distrust for their health care provider. Those who are not so well acculturated may well choose to uphold the beliefs of a more traditional health care system which practices traditional medicine delivered by Mexican-American spiritual healers or (curanderas). These medicinal treatments often include the use of herbal powders and tea accompanied by a prayer ritual. Health care providers, therefore, need to be aware of not only these cultural practices but also the acculturation level of their patients which may well affect diabetes treatment adherence. Open discussions about such beliefs needs to be initiated so that collaborative decisions making can incorporate these ideas into a more culturally appropriate self management program in which patients are invested and wish to adhere to (Barron et a, 2004). In this study, therefore, the acculturation level of Mexican-American adults with diabetes type 2 will be investigated with a view to identifying its relationship with diabetes health outcomes.

\section{Gender}

Gender is also thought to be a factor in determining effective DSM adherence particularly in a population that values traditional male and female roles (Brown et al., 2000). Hispanic families are often patriarchal with males fulfilling a dominant, 
authoritarian role referred to as machismo. Within this socially constructed role are the expectations that the females are responsible for the day-to-day management of the household, childcare duties and the provision of care to ailing family members, particularly those with chronic diseases (Anstel, 2002). Several researchers have identified greater DSM adherence rate among men as a result of female gender role burden and its associated pressure of commitment to the family (Van der Ven, Weinger, Pouwer, Ader, ven der Pleog, \& Snoek, 2003; Ponzo, Gucciardi, Weiland, Masi, Lee \& Grace, 2006); whilst Brown and associates (2007) reported gender differences in social support among Mexican-Americans with diabetes, with women perceiving less support than men. A distinct gap in the knowledge of how women in general manage their diabetes clearly exists. For example, it has been found by health care providers working with Hispanic women that their reluctance to adhere to their prescribed treatment regime is considered self-indulgent. This finding in regard to a term referred to as hembrismo or marionismo, is defined as "the undercover power and dignity that comes from selfsacrifice for the family" (McGoldrick, Pearch, \& Giordano, 1982).

Diet is also an important factor in DSM programs particularly for Hispanic women. With many programs emphasizing the need to follow a strict dietary regime a person's environment and socio-economic status play key roles in the issue of compliance. If recommended foods are not readily accessible or too expensive Hispanic women may view the demand to change dietary habits as one which places undue burden on the family; therefore, resulting in lack of adherence to that particular part of the selfmanagement plan. 
The observed importance of social support and family involvement in Hispanic women for supportive relationships, transportation needs, and emotional support has prompted particular attention to gender differences in diabetes self-management. In this study, therefore, the differing barriers that Mexican-American men and women with type 2 diabetes face that affect their adherence to DSM programs will also be explored (Oomen, Owen, \& Suggs, 1999).

\section{Diabetes Self-Management Education}

Historically the management of diabetes was managed by the healthcare professional whose role was to educate the patient about the disease process and about medication use, to demonstrate all the necessary skills required and finally to monitor the condition. Patients were taught in small groups where educators used a pedagogical approach to instruction. There would typically be 4-6 lectures, followed by quizzes. Skills would be demonstrated and followed up by a return demonstration session (Brown et al., 1992). Patients were not generally encouraged to actively participate. They absorbed the material as best they could in the hope that the knowledge provided about the disease would motivate them to modify their behavior.

Results were understandably variable i.e, $39 \%$ performed self-monitoring of blood, $18.4 \%$ had their HbAlc checked within the past year, and 54\% had a foot exam in the last year (Krichbaum, Aarestad, \& Buethe, 2003). With such low rates of adherence it became evident that there was a significant gap between what was being taught and the take- home message to the patient. Behavior patterns were not changing sufficiently to reach projected goals. Factors that were impeding these progressions needed to be sought. 
Simply educating a person about their condition rarely results in them freely adopting the behavior patterns necessary to manage the disease (Brown et al., 1992). Current studies are revealing that the face of self-management education is changing to incorporate 1) longitudinal research designs as opposed to cross-sectional approaches, 2) testing the comprehension levels of the content of the education programs, 3) attempting to identify factors that could contribute to better glycemic control, 4) moving from a cognitive to a behavioral approach, and 5 ) evaluating programs to determine gaps and deficits that can then be added to produce better health outcomes (Krichbaum et al., 2003). It follows that since $95 \%$ of diabetes care is self care, targeting self-care behaviors would seem to be the most appropriate strategy for success.

Since people with diabetes type 2 typically have to provide approximately $95 \%$ of their own care on a day by day basis, the task of health care providers is to use diabetes education as a tool to help patients develop the skills that will eventually bring their blood glucose under tight control. Diabetes self-management education content, therefore, is beginning to address more fully the physiology of diabetes, an extensive knowledge of the diet, an exercise plan, monitoring of blood glucose levels and a means to address psychosocial needs (American Diabetes Association, 2009). In addition researchers have now identified other important factors that need to be included as part of the educational regime. They include psychosocial adjustment of people to the diagnosis of diabetes, family support, emotional adjustment, influence of other people, selfefficacy, patient empowerment, problem solving, decision making, formation of a functional patient-provider partnership and taking action (Brown et al., 2007; Lorig \& Holman, 2003; D’Zurilla, 1986). 
In studies that have specifically addressed factors that affect diabetes selfmanagement adherence in Hispanics additional factors have been identified that impact diabetes self management success. Factors such as low levels of education, low literacy, poor perception of the disease, lack of language appropriate information and poor patientprovider interrelationship have all been identified (Adams, 2003; Brunt et al., 1998; Quatromoni et al., 1994). Other reasons that have been associated with the observed decline in glycemic control include lengthy, complicated self management classes, unsuited to the learning needs of the population, inconvenient class schedules, confusing medication regimes, competing family concerns, transportation difficulties, and lack of communication between patient and provider (Brown et al., 2002; Brown et al., 2003; Brown et al., 2005, Melnik, Hosler, Sekhobo, Duffy, Tierney, \& Engelgau, 2004; Nagelkerk et al., 2006, von Goeler, Rosal ,Ockene, Scavron, \& De Torrijos, 2003).

Research indicating that the management of glycemic control is worsening, those individuals with diabetes type 2 need to be encouraged to adopt the skills that will enable them to manage their diabetes. The most effective method for educating and teaching self-management techniques, however, remains unclear. We do know, however, that there are important differences between social structure and health care delivery (Deakin, McShane, Cade, \& Williams, 2005).

Many studies have investigated education intervention approaches. Those educational programs that have historically had the most success to date in increasing diabetes knowledge alone are those that involve group sessions, and multimedia classes (Norris, Engelgau, \& Narayan, 2001). Those that have had greater success in increasing diabetes nutritional knowledge have ultimately found that information retention has a 
tendency to wane after about 3 months (Brown et al., 2002; Brown et al., 2003). Retention of information transferred during collaboration between health care provider and patient was improved with strategic reviews of previously learned topics at key intervals (Brown et al., 2005).

Over the past 10 years more culturally sensitive, diabetes intervention programs have emerged. They tend to be more understandable and appropriate for those from ethnic minority groups. Such programs are available for African-Americans, Asians, and Hispanics (Funnell et al., 2008; Brown, Garcia, et al., 2002; Wang \& Chan, 2005) and generally fall into one of two categories, those that are "targeted" or those that are “tailored" (Sarkisian et al., 2003).

Kreuter \& Skinner (2000) use the term "targeting" to refer to "a single intervention approach which is applied to a population sub-group." Programs of this nature adapt their education approaches to account for the characteristics shared by the members of the subgroup. Tailoring refers to an approach that uses the unique characteristics of the person, thereby creating a more individualized intervention program. Both strategies have met with a certain degree of success in diabetes management and resulted in increased patient adherence, improved diet, HbAlc and fasting blood glucose levels and frequency of visits. However, of the two, tailoring has proven to be the most effective method, suggesting that interventions should not only be targeted towards a specific population, but should also be tailored to the individual in order to promote behavior change and adherence (Kreuter \& Skinner, 2000).

There are several studies which have specifically targeted Hispanics, in particular Mexican-Americans (Bacardi-Gascon, Rosales-Garay, \& Jimenez-Cruz 2004, Brown, 
Garcia, et al., 2002; Brown \& Hanis, 1995) but there is a need for these programs to modify their interventions towards the specific individual needs of their target population (Kreuter \& Skinner, 2000). The focus of these studies has been population targeting, not individual tailoring. Since no two patients are alike the time is right to develop DSM from a more personal, case-by-case perspective.

Research has shown that interventions of both types do have a positive influence on increasing metabolic control, improving patient outcomes and reducing diabetesrelated complications. However there still remains a paucity of evaluation tools to gather data that could inform the development of studies that guide interventions programs aimed at Mexican Americans with diabetes type II (Brown et al., 2007; Von Goeler et al., 2003).

Day-to-day adherence to a self-care plan is critical to achieving the desired blood glucose levels; however, Hispanic patients need to be appropriately educated culturally regarding the acquisition and implementation of the skills necessary to successfully achieve these goals. Although a few diabetes self-management education programs do exist that have been specifically developed for Latino populations, they are limited and often lack culturally appropriate resources. Furthermore very few of them have been evaluated and their success determined (Mauldron, Melkus, \& Cagganello, 2006). There is clearly a need for comprehensive, culturally sensitive, reliable and valid measures that evaluate diabetes self management knowledge (Brown, 2007).

This pilot study hopes to add to the current literature on diabetes type 2 in a Mexican-American population by testing the validity and reliability of the Information, Motivation, and Behavioral Skills Diabetes Self-Care ( IMB-DSC) self report 
questionnaire in Mexican Americans. The questionnaire will help to explore the gaps and deficits that contribute to poor self management adherence and better inform tailored diabetes intervention programs.

Due to the inadequate attention often paid to psychosocial factors in recent years, researchers have begun to study ways in which people can change their behavior patterns in what is considered a collaborative approach. As emphasized by Norris et al., (2001), group settings are highly recommended, especially with regards to setting group weight loss goals in order to aid in monitoring glycemic control (Krichbaum et al., 2003). More recent intervention education has significantly benefited adherence rates due to its emphasis on simple and uncomplicated procedures, individualization of the study material, repetition or reinforcement, social support from health care providers and family members, and adaptation of the program goals to the individual and tailoring to the individual's personal habits and daily routine (Brown et al., 2005; Von Goeler et al., 2003).

The control that an individual has over following a treatment plan is an important factor in determining that person's probability of adhering to that plan. In other words if an individual encounters situations that make it difficult for him or her to adhere to the prescribed regime then adherence rates will undoubtedly be low. The perceived complexity of the topic has justly prompted authors to suggest frameworks for identifying and organizing factors that have been found to affect self-care behaviors for use in clinical intervention programs with type 2 diabetes such as characteristics of the patient, the patient's family, the practitioner and the health system and the community/work setting (Fisher \& Fisher, 2000; Rutter \& Quine, 2002). The current trend in literature on 
adherence is a move towards the more cognitive-motivational process whereby one's personal attitudes, intentions, self-care behaviors and outcomes of patient-provider interactions are utilized (Koch, 2002). The Information-Motivation-Behavioral Skill model of Behavior Change it one of these models. Chosen for this study because it embodies the essence of the key factors that have been identified in research studies as barriers to health behavior change, the model has been used to guide the creation of an assessment/evaluation tool for use on Mexican American adults with diabetes type 2 . The IMB-DBS measure was subsequently used to determine patient specific information, motivation and behavioral skill with a view to identify gaps in patient knowledge that could ultimately lead to lack of adherence and thus risky health behaviors (Albarracin, Johnson, Fishbein, \& Muellerleile, 2001; Fisher, Fisher, \& Harman, 2003).

\section{The IMB Model}

The Information-Motivation-Behavioral skills (IMB) model has been chosen specifically for study as it incorporates the key factors that have been identified in Hispanics as barriers to healthy behavior change. Lack of appropriate, meaningful information, insufficient motivation to comply with the instructions that have been provided and a deficiency in practical skills all result in non -adherence to self management programs (Albarracin, Johnson, Fishbein, \& Muellerleile, 2001; Fisher, Fisher, \& Harman, 2003).

The IMB model (Fig. 1) holds that unhealthy behavior patterns result from the lack of relevant information about the condition, insufficient motivation and poor behavioral skills (Fisher, Fisher, Amico, \& Harman, 2006; Misovich, Martinez, Fisher, Bryan, \& Catapano, 2003; Starace et al., 2006). The model thus focuses on increasing 
health behavior change through providing the information that will eventually motivate individuals to refine skills in order to effect such change. Overcoming identified barriers and deficits is consequently vital to initiating and maintaining successful diabetes selfmanagement adherence behaviors (Fisher \& Fisher, 1992).

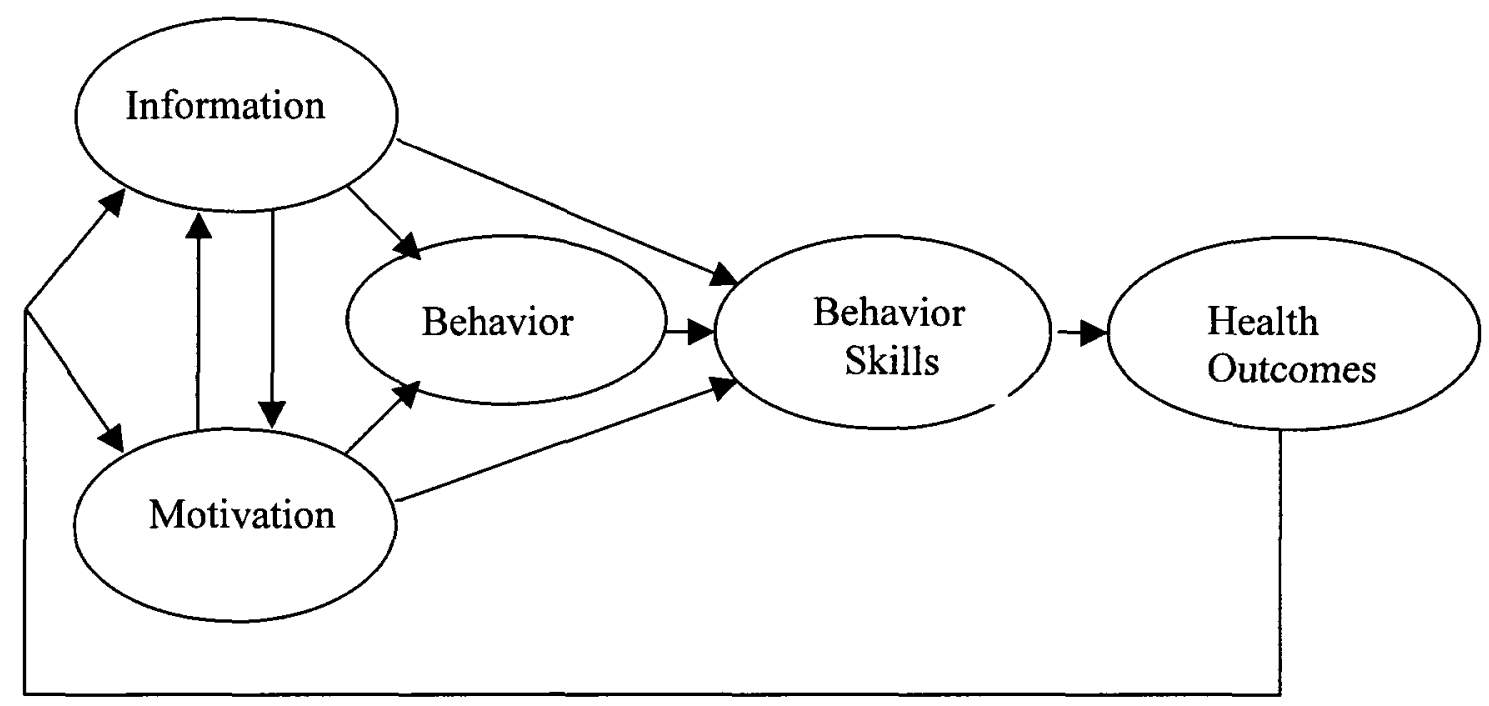

Figure 1. Information-Motivation-Behavioral-Skills Model (Adapted from Fisher \& Fisher, 1992a).

The Information Motivation Behavioral Skills Model of Behavior Change (Fisher \& Fisher, 1992) used in this study states that information, motivation and behavioral skills, concepts that have been validated to be crucial elements in AIDS risk reduction literature and clinically in AIDS-risk reduction behavior, are among the most important aspects that determine adherence to health promoting behaviors in general. The model is based on the principle that information and motivation support the development of the required behavioral skills, which in turn result in behavior changes that encourage 
positive health outcomes. In other words when applied to type 2 diabetes, if a patient has the appropriate diabetes related information has a adequate support system (i.e. family members, friends), a good provider-patient relationship, and is capable of carrying out the activities necessary to adhere to a self-management program such as counting carbohydrates, reading food labels, administering insulin, then adherence behavior is improved, resulting in better health outcomes. Failing to adhere to diabetes self management (DSM) behaviors is, therefore, a direct result of lack of appropriate knowledge, motivation and behavioral skills. Resolving these deficits should, therefore, result in improved adherence.

In addition to the principal tenets of the model, Fisher \& Fisher (1992) have also identified that information and motivation are independently capable of having direct effects upon behavior patterns particularly when the behavior is simple and easy to perform. In other words, well informed patients sufficiently motivated to act upon improving their health care behaviors and who possess the relevant behavioral skills to accomplish the task at hand will be most likely to adopt healthy behavior patterns.

Within the model the constructs of information and motivation have been found to be independent of each other as knowledgeable or well informed individuals may have either high or low levels of motivation to practice positive health behaviors and, conversely, well motivated individuals may or may not be well-informed to practice them (Fisher, Fisher, Williams, \& Malloy, 1994). Information and motivation may also have direct effects on health behavior practices particularly when that behavior does not require a complicated behavior skill such as scheduling regular appointments for laboratory tests (Fisher \& Fisher, 2000). 
There remain two very important features of the model that have been found to be crucial in inducing behavior change and promoting adherence. One (see Figure 2) is seven-step sequential behavioral pattern that will initiate behavior change when an

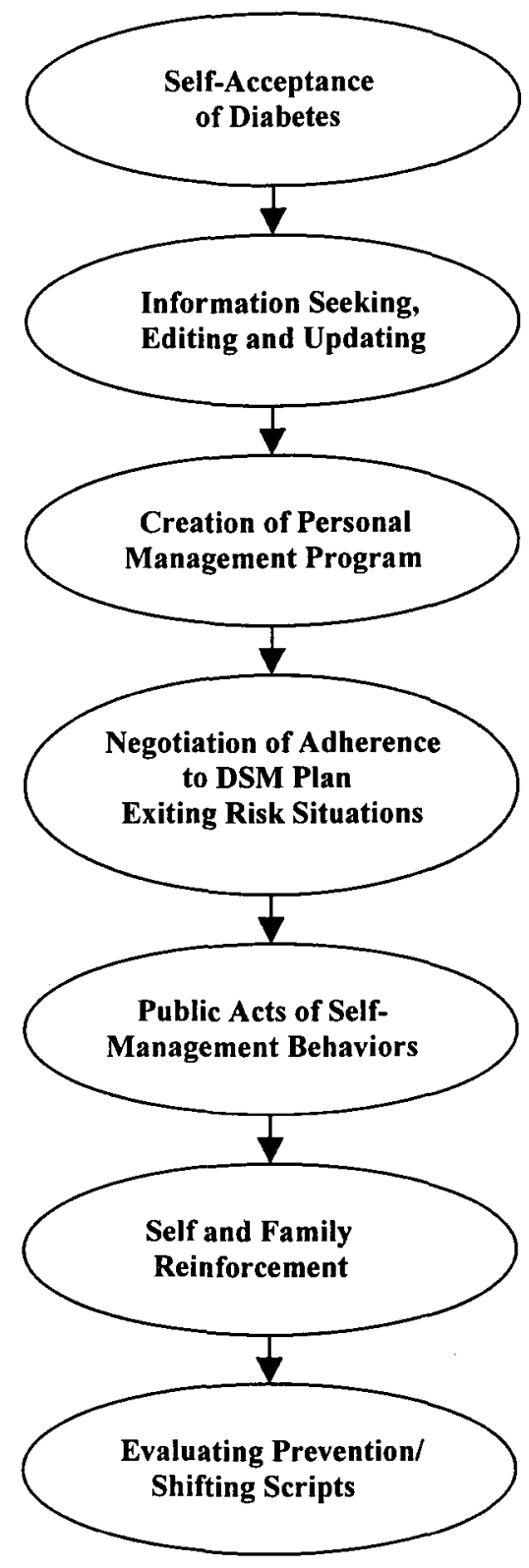

Client accepts fact that he or she has diabetes and is receptive to learning required DSME skills

Client is given appropriate DSME info, seeks additional information as needed and updates existing knowledge

Client is assisted to put together a self-management plan, Knowledge and prevention of complications

Client learns negotiating skills to promote self-adherence to SMP to be enacted when unmotivated to adhere to agenda

Client openly participates

in self-management behaviors

Client accepts fact that he or she has diabetes and is receptive to learning required skills

Client accepts fact that he or she has diabetes and is receptive to learning required skills

Figure 2. The Self-Management program (SMP) behavior sequence (adapted from Fisher $\&$ Fisher (1992a). 
individual has the appropriate information and motivation required (Fisher \& Fisher, 1992) the other is a strong sense of self-efficacy, or a belief in one's own capability to successfully carry out these healthy behaviors (Ajzen, 1990; Ajzen, \& Madden, 1986; Bandura, 1989). Simply stated, if one possesses a high level of behavioral skills this may well translate into a high-level of self-efficacy (personal capability to perform these tasks), which may as a result encourage the practice of healthy behavior practices (Bandura, 1989). In successful diabetes management the seven-step sequence to be carried out is as follows and is depicted in Fig 2.

Self acceptance of diabetes and the awareness that preventive behaviors are necessary.

1. The ability to acquire accurate information, to differentiate between diabetes myths and facts, and to update new information as it develops.

2. The capacity to develop with assistance a personal self-management plan of action to reduce risky behaviors patterns and complications

3. The skill to negotiate and use the agenda when placed in a risky situation.

4. The ability to publicly demonstrate self-management behaviors.

5. The capability to reinforce positive self-management behaviors with self and partner.

6. The ability to monitor and evaluate the quality of the preventive behavior. (W. Fisher, Fisher, 1992(a)

These foundational concepts for the IMB model are borrowed from the Theory of Reasoned Action (Ajzen \& Fishbein, 1980; Fishbein \& Ajzen, 1975; Fishbein \& Middlestadt, 1989). The theory states that individual participation in positive health 
behaviors depends upon their intention to do the required acts that in turn depend upon satisfying two motivational factors: one's personal attitude toward performing the desired act; and/or one's subjective norm or the perception of what significant others think should be done regarding the behavior in question.

Ajzen and Fishbein (1980) sub-define personal attitude and subjective norm still further and hold that an individual's personal attitude is a function of one's beliefs about the consequences of performing the behavioral act multiplied by the value that one places on its consequences. Similarly, subjective norms about performing a behavior depend upon the beliefs, opinions and support of what the authors refer to as 'specific referent others' or in other words, persons that exert an influences on one's decision-making, i.e., close friends, family, health care provider, husband, wife and so on. This construct is thus multiplied by an individual's motivation to comply with the wishes of these specific referents.

The behavioral skills portion of the model thus requires that these activities be actively taught, rehearsed in a script-like fashion such that the material is readily available for use (immediate recall), for example, in social settings. This can be done by video tapes or role playing in which models are observed enacting the desired behavioral skills (Bandura, 1994).

Fig. 3 is an adaptation of the IMB model to apply to type 2 diabetes. It upholds that the desired information needs to be specific and directly relevant in its content to have the desired impact on behavior change. An immediate recall or a "top-of-the-head" type response is required in retrieving relevant information, and this needs to be accompanied by appropriate motivation and behavioral skills to effect behavior change. 
Regarding dietary modifications, in order to promote effective behavior change

strategies, the diabetic must be able to recall immediately a list of foods that are high in

carbohydrate and for the most part need to be avoided. The motivation component of the

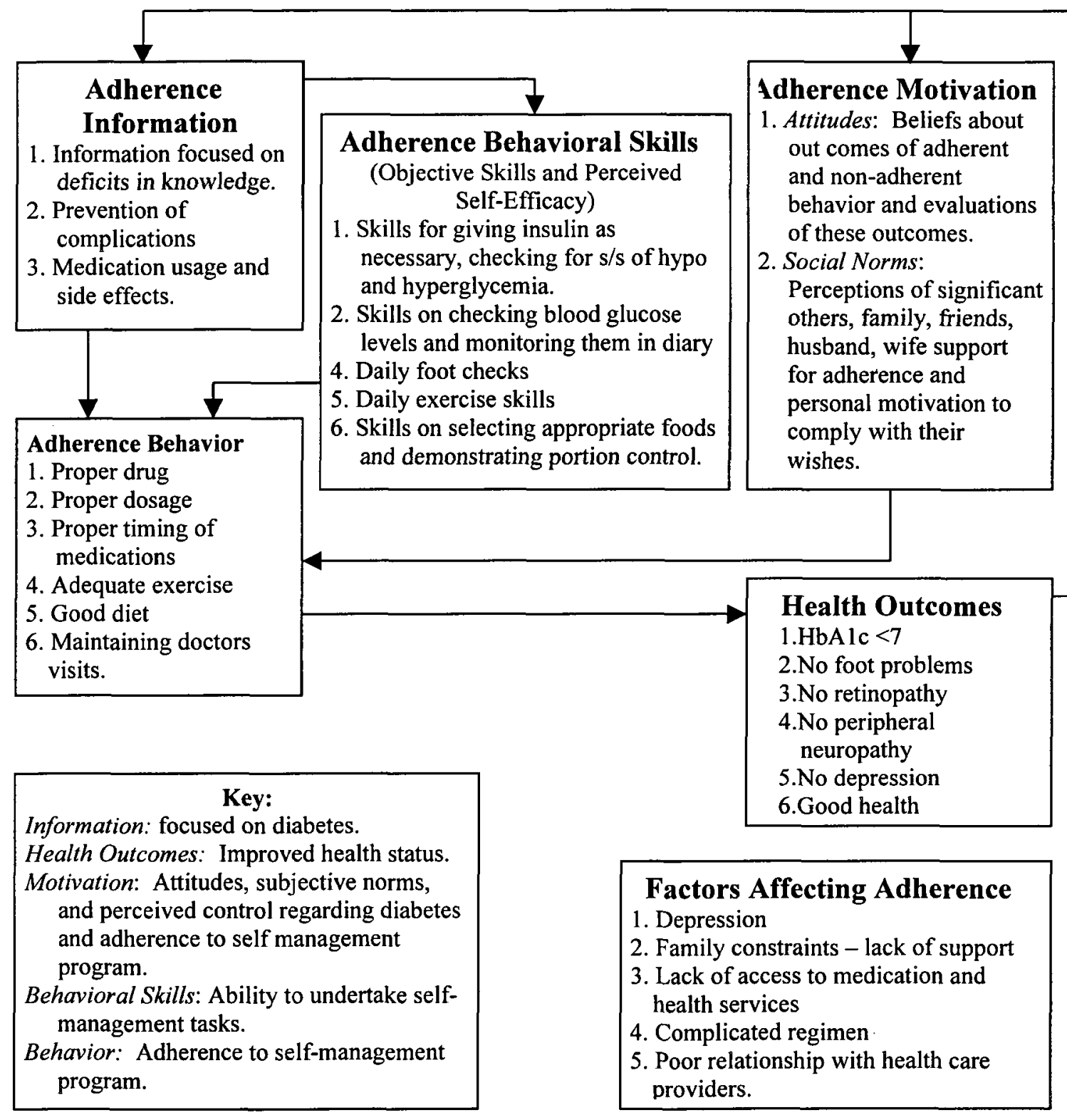

Figure 3. IMB model analysis on adherence to diabetes self-management program. (Source: Modified from Fisher et al., 2001) 
model requires a highly motivated individual to start and maintain health behavior change. The two components that determine one's motivation are personal motivation, which refers to the one's personal attitudes toward the value of the desired health behaviors, and a social motivation, which refers to the influence of one's social support upon performing the behaviors (Fisher \& Fisher, 1992).

The individual also needs to incorporate the behavioral skills which initiate behavior change when an individual has the required information and motivation and a strong sense of self-efficacy. According to the adapted model, for an individual to successfully perform the desired healthy behaviors required to self-manage their diabetes, health care providers have to provide relevant and specific information, promote positive personal attitudes and beliefs about performing the desired healthy behavior patterns, and ensure that the relevant skills to perform the behaviors can be learned without too much difficulty (Fig. 3).

The IMB model has been used in a variety of studies. One such study, though conducted with Puerto Rican diabetics, used questionnaires and focus groups to gather pertinent information about the factors that contribute to adherence (Adams, 2003; Lipton, Losey, Giachello, Mendez, \& Girotti, 1998; Quatromoni, Milbauer, Posner, Carballeira, Brunt, Chipkin, 1994). Adams (2003) found that many Puerto Rican women reported linguistic barriers between English-only speaking health care providers. They were left with a poor understanding of the disease and the disease process. Other studies have reported lack of language-appropriate material and a low level of education as barriers (Lipton, et al., 1998) which would explain why many Puerto Ricans reported not understanding the details of their self-management education programs. They exhibited a 
reluctance to disclose important information to the health care provider (whom they often considered their superiors), negative attitudes and fatalistic beliefs about the value of preventive measures, lack of motivation to follow complicated regimens, and had poor practical self-management skills (Quatromoni et al., 1994). It is no wonder that adherence to diabetes self-management programs is so low in this population.

Mexican-Americans appear to demonstrate many of the same self-management barriers reported by Puerto Ricans (Brown et al., 2002) yet no similar in-depth study has so far been applied to this population. It is the purpose of this study to psychometrically test the reliability and content/construct validity of the IMB model in Mexican-American adults to determine whether it can be successfully used to identify patients with at-risk diabetes related health behavior practices that would otherwise result in poor health outcomes.

The IMB model asserts that the specific constructs, and the relationships between them, serve as reliable predictive indicators of health behaviors. It is thus the goal of this study to use the IMB framework to determine information deficits and to identify the motivation and behavioral skills that must be modified if self-management programs are to result in improved outcomes. It is also hoped that the results obtained from the present study can be used to inform the design of a culturally appropriate tailored intervention program for use within a Mexican-American population.

Effective diabetes self-management (DSM) is a complex and demanding process with patients often being faced with a complicated set of guidelines that must be followed rigidly on a daily basis. Educating patients through DSM classes provides them with information about diet, medications, exercise regimes and blood glucose monitoring, 
factors that have been found to contribute to effective self management care. However, this information alone does not guarantee patient adherence, especially in Hispanics where additional problems such as low educational attainment, inadequate language, appropriate information, ineffective patient-provider interrelationships, lack of support, negative health beliefs, and inadequate skills levels to perform DSM behaviors have all been identified as additional prohibitive factors. Adhering to these complex treatment recommendations involves a great deal of patient time, effort, planning and motivation to adopt and maintain healthy behavior lifestyle changes.

Due to a genetic predisposition, low socioeconomic and a paucity of culturally appropriate health care and educational resources the U. S. is experiencing an epidemic among the Hispanic population (Lujan, 2008; Brown et al., 2000). The health care system is challenged to develop and implement culturally appropriate interventions that can reach the Hispanic population and improve the health of those with diabetes type 2 (Brown et al., 2002). However, before interventions can be successfully developed dependable questionnaires that are able to identify factors that constitute barriers to adherence to these intervention programs needs to be instigated. Psychometric questionnaires that are reliable, valid and culturally and linguistically appropriate are crucial to the success of diabetes self-management programs. Diabetes knowledge, motivation and practical behavioral skills are three of the variables that have been associated with positive health outcomes in Hispanics (Osborn, 2006). There is currently no single tool that measures these three important variables. The Information Motivation Behavioral Skills measure of Diabetes Self-Care is a comprehensive, newly devised instrument that may be a useful tool to be used in the assessment of these variables and in 
identifying at-risk patterns of behavior. Psychometric testing is, however, necessary to determine its utility in a Mexican-American population. 


\section{CHAPTER 3: METHODOLOGY}

Introduction

In this chapter the methodology chosen for this research will be presented. The chapter begins with a brief introduction to the research design, introduces and explains the reasons for using the chosen instrument, discusses the statistical methods used to analyze the data, and describes the handling of human subjects.

\section{Research Design}

A cross-sectional correlational design was used to assess the reliability and content and construct validity of the Information-Motivation-Behavioral Skills Measure of Diabetes Self-Care (IMB-DSC) measure (questionnaire) in identifying at-risk self management behavior patterns in Mexican American adults with type 2 diabetes

The IMB-DSC questionnaire, originally developed by Osborn (2006), was designed to provide a compact convenient tool to replace the array of individual scales that have previously been used in other studies to assess adherence behavior. The questionnaire emulates the constructs of the Information-Motivation-Behavioral Skills Model of Behavior Change by maintaining that behavior-specific information along with motivational and behavioral skills are principal determinants of health behavior adherence and health outcomes. For this reason the three primary variables considered in this study were information, motivation, and behavioral skills however, as gender and acculturation have both been found to play a role in adherence behavior, these two 
additional variable were added to the original study (Mainous et al., 2008; Brown et al., 2000).

The IMB model has been previously used to determine adherence behavior patterns in risky HIV behaviors in high school youth, gay men and heterosexual university students, HIV medication adherence regimes (Fisher, Fisher, Amico, \& Harman, 2006), promotion of breast self-examination (Misovich, Martinez, Fisher, Bryan, \& Catapano, 2003), use of protective motorcycle safety wear (Murray, 2001), and more recently in Puerto Rican immigrants with type 2 diabetes for which the IMB-DSC measure was initially created. For a more complete review of the model's applicability and validity across diverse populations the reader can refer to Fisher, Fisher, \& Harman (2003). The reliability information from the Puerto Rican study was $r=.85-.89$ (verbal communication: Chandra Osborn); however, no testing of the reliability and validity of this tool has yet been done with Mexican-American. Assessing the status of these two dimensions is important in order for practitioners to have dependable instruments when evaluating the complex issue of adherence with Mexican-American diabetic patients. An instrument able to identify adherence behavior patterns that hinder healthy behavior change would be a useful addition to any diabetes self- management education program and would assist patients in their efforts to follow their labor intensive self management regimes.

The IMB Model of Behavior Change used in this study states that information, motivation and behavioral skills, concepts that have been validated to be crucial elements in AIDS risk reduction literature and clinically in AIDS-risk reduction behavior, are among the most important aspects that determine adherence to health promoting 
behaviors in general (Fisher \& Fisher, 1992). When applied to type 2 diabetes, the model is based on the premise that if a patient has the appropriate diabetes related information, has a sufficient support system, and is capable of carrying out the activities necessary to adhere to a self-management program, adherence behavior rates are increased, resulting in improved health outcomes (Fisher \& Fisher, 1992). Failing to adhere to diabetes self management (DSM) behaviors is, therefore, a direct result of lack of appropriate knowledge, motivation and behavioral skills. Resolving these deficits should, therefore, result in improved adherence. In addition to the principal tenets of the model, Fisher and Fisher (1999) have also identified that information and motivation are independently capable of having direct effects upon behavior patterns, particularly when the behavior is simple and easy to perform

The IMB-DSC questionnaire used by Osborn (2006) in a Puerto Rican community has not been used in a Mexican American population. The goal of the present study, therefore, was to test the reliability and content/construct validity of the Osborn IMB instrument to determine its suitability as an assessment tool in identifying at risk-behavior patterns in Mexican American adults with type 2 diabetes, to determine whether gender and acculturation affect scores on the IMB measure, and finally to determine the relationship that the independent variables, information, motivation and behavioral skills, have on health behavior outcomes.

\section{Psychometric Testing}

Upon gaining the original developer's permission, English and Spanish versions of the IMB-DSC measure were obtained. Face and Content Validity of the measure was previously confirmed by the developers in consultation with a group of experts consisting 
of diabetes educators and patients with type 2 diabetes. A panel of 5 experts whose native language was Mexican-American Spanish were invited to review the content of the questionnaire and asked to provide suggestions on the items. An extensive literature review was also carried out to assess the validity of the content material (Osborn, 2006).

Construct validity was determined by a known group's technique. Participants were divided into two groups, group one considered (American Diabetes Association, 2009) suboptimal that had HbAlc values of $\geq 7$, the other, considered optimal with $\mathrm{HbAlc}$ values of $<7$. It was hypothesized that the suboptimal group would result in lower IMB subscale scores on the questionnaire than the optimal group (Polit \& Beck, 2008).

\section{Participant Selection and Characteristics}

A small, preliminary pilot study with 8 Mexican-American patients with diabetes type 2 was conducted at a clinic different from the eventual study site. The purpose was to assess readability and comprehension, as well as to determine the approximate time required to complete the questionnaire. The pilot study identified three specific issues, (1) several questions were identified as confusing; participants often found them vague and ambiguous and needed further clarification, (2) hesitancy in responding to the Likertscale type questions due to difficulty in differentiating between two very similar responses, (3) some questions were deemed to be too repetitive ...As a result, several questions on the original instrument were modified in order to accommodate the problems identified.

A pilot study, to assess the readability and comprehension of the tool, as well as the testing time required of the research participants, was conducted prior to the 
implementation of the exploratory study. The research study participants were selected over a period of 2-3 months at a local community clinic in Orange, Orange County that resides in an area with a large Hispanic population. Prospective participants were recruited by purposive sampling from the clinic which has a population of approximately 500 Mexican-Americans adults currently registered with diabetes type 2 .

There is a collaborative diabetes self-management program at the clinic managed by a healthcare team headed by several primary healthcare physicians, a nurse practitioner, a resident dietician, diabetes educator and ancillary nursing staff members. The diabetes education classes, which are so integral to effective diabetes self management, focus on the following subject areas: (1) diabetes disease process, (2) treatment options, (3) nutritional management, (4) exercise regimes, (5) medications, (6) monitoring blood glucose levels, and (7) preventing complications.

Following consultation and diagnosis with diabetes type 2, patients are referred to both a dietician and a diabetes educator for counseling and concurrent enrollment in the education program. Anti-diabetes medication and supplies for blood glucose testing are obtained through patient enrollment in California State funded medication programs or through Medical services. Glucometers are provided to patients once they have completed the 4 week education program. Other consumables such as diabetic test strips are also provided.

Recruitment procedures complied with Health Insurance Portability and Accountability Act (HIPPA) regulations. Clinic staff members assisted in the recruitment of participants and maintained confidentiality of patient's personal contact information. Participants were solicited through English and Spanish flyers posted at various sites in 
the clinic. Those patients desiring to be part of the study after a brief introduction were given a full explanation of the study aims by the principal researcher in either English or Spanish depending on the potential participant's language request. Consent forms were read to participants in their language of choice and signatures obtained. Recruitment procedures complied strictly with the HIPPA regulations of the clinic.

All individuals participating in the study were offered diabetic-appropriate snacks and drinks while they completed the research protocol (i.e., completed the questionnaire) and were compensated with a $\$ 10.00$ Target gift card. Participants had to meet the following criteria:

1) $20-75$ years of age

2) Diagnosed with diabetes type 2

3) HbA1c level performed within the past year with no hospitalizations within the past year

4) Taking hypoglycemic agents alone or with insulin for the past year (any combination).

Exclusion criteria were

1. Had difficulty understanding the material, even with assistance.

2. Had a self-reported or documented life-threatening illness (e.g., cancer)

3. Had significant cognitive impairment (e.g., dementia), mental retardation, or severe mental disorder (e.g., schizophrenia).

Ethical Considerations

Approval for the study was obtained from the Human Subject Review Committee of the agency operating the clinic as well as from the University of San Diego's IRB 
committee. Written consents were obtained from participants and confidentiality was guaranteed by assigning code numbers for identification purposes. The researcher reviewed the informed consent with each potential participant prior to the consent being signed. Questionnaires were available in both Spanish and English.

\section{Procedure}

Upon giving verbal permission the candidates were taken to a private room where they were presented with the questionnaire to be completed by paper and pencil. The principal bilingual researcher was in attendance to read the questionnaire aloud to participants if requested and/or to provide clarification of the questions as needed. Each participant packet was pre-numbered to insure patient confidentiality

Following completion of the questionnaire, participants were asked to answer the 7 additional semi-structured free response questions, listed below. The responses to these questions helped to qualitatively assess the validity of the instrument and to identify components of the questionnaire that might require modification in the future so as to better adapt it to the Mexican-American community.

\section{Semi-structured Free Response Questions}

1. Did the questions in this instrument adequately evaluate your knowledge about your diabetes? Yes No Please explain your answer.

2. Did the questions reflect your desire (motivation) to follow the health care program planned for you? Yes No Please explain your answer.

3. Did the questions reflect the behavior skills you feel are necessary for you to achieve the goals of diabetes management? Yes No Please explain your answer 
4. Do you think your time in the U.S. has affected your knowledge of diabetes?

Yes No Please explain your answer

5. Do you think your time in the U.S. has affected your desire to control your diabetes? Yes No Please explain your answer

6. Do you think your time in the U.S. has affected your skills to be able to manage your diabetes? Yes No Please explain your answer

7. Was the format of the questions easy to answer? Yes No Please explain your answer

After completion of the interview the principal researcher thanked each candidate for their participation in the study and each participant received a $\$ 10.00$ gift card from Target. A retrospective review of the medical chart was made by the principal researcher to assess the most recent $\mathrm{HbAlc}$ level taken within the past six months. This was the only information obtained from the medical record.

\section{The IMB-DSC Questionnaire}

The IMB-DSC questionnaire is a scale developed to measure behavior specific information, motivation and behavioral skills regarding diabetes -relevant diet and exercise behaviors. Although the "Diabetes Knowledge Questionnaire" (DKQ-24, Spanish version, Garcia, Villagomez, Brown, Kouzakanani, \& Hanis, 2001) is known for its reliability and validity on the more general aspects of diabetes knowledge, it did not contain enough diet- and exercise-specific items to satisfy the components of the IMB model. The model developers subsequently developed a completely new set of 28 items to better assess patient's specific knowledge about diet and exercise topics according to the constructs of the model (Osborn, 2006). 
Taking into account the average third grade educational level of the participants and any visual impairment that might hinder accurate responses, the newly developed items were created using simple language and translated from the original source language into a style of Spanish used by most Mexican Americans.. The questionnaire was also back-translated from Spanish into the original source language to determine its accuracy with the original by the original author and her team (Osborn, 2006). The itemresponse format of "yes, no, and I don't know" that is characteristic of the Spanish DKQ24 tool, was retained since it is known to reduce difficulties that Mexican-Americans may have in responding accurately to Likert scale questions (Flaskerud, 1988). Content validity of the scale was performed with an expert panel of researchers and nurses familiar with the diabetes-related problems of Mexican Americans (Osborn, 2006). The original reliability of the instrument was 0.85 (Osborn, 2006) you already have it as stated in chapter before.

There are two parts to the instrument. The first part consists of demographic and acculturation information. The second part assesses (a) the independent variables of diabetes specific knowledge, motivation and behavior skills and (b) the dependent health outcomes of reading food labels, dietary and exercise behavior, and $\mathrm{HbAlc}$ values. A thorough description of each part is presented below. The questionnaires themselves, in both English and Spanish, can be found in the Appendix.

\section{Demographics}

Eight items were used to measure the general demographic component. Participants report their gender (male/female), age, birth-date, interview-language 
preference, highest level of education completed, current employment status, health insurance category and finally current marital status.

\section{Acculturation}

Culture-related demographics are measured by five items. The first two items asked participants to indicate in which country they had lived most during their childhood (before the ages of 18) and as an adult; the third item asks participants to indicate the length of time that they have resided in the United 'States; the fourth item questions participants about their proficiency or ability to speak English; and the fifth item asks participants which language they mostly speak in the home.

\section{Self-Care Information}

The Self-Care Information section consists of 21 questions, eight of which are designed to assess participants' understanding of the important role that carbohydrates play in determining blood glucose level. Response options are "true," "false," and "I don't know". Correct items were summed to produce a diet knowledge score ranging from $0-24$. Thirteen additional foods were inserted into the questionnaire to determine patients' knowledge of carbohydrate containing foods, and the role that they play in maintaining a stable blood glucose level throughout the day (Osborn, 2006). Response options were "yes," "no" and "I don't know." Correct items were summed to produce a diet knowledge score ranging from $0-26$. Internal consistency and reliability was determined for this subscale (Brown et al., 2002). The internal consistency for its use with a Puerto Rican population yielded an alpha value of .85-.89 (Osborn, 2006).

Exercise information was measured with seven items that assess participant understanding of the benefits of exercise in controlling blood glucose levels. Correct 
items were summed to produce a resultant score for exercise knowledge ranging from 628. In the Puerto Rican study the measure showed fair to acceptable internal consistency $(\alpha=.64-.77)$

\section{Self-Care Motivation}

As motivation to practice desired health behaviors is considered to be based on favorable attitudes and subjective norms, dietary attitudes were measured with 10 items that asked the participant's opinions about dietary control of their carbohydrate content. Divided into two sections of five items each, section (a) asked participants such questions as "During the next 30 days, how GOOD or BAD would it be for your health to eat breakfast, lunch, and dinner everyday?" and "How PLEASANT or UNPLEASANT would it be for your health to eat breakfast, lunch, and dinner everyday? “ Items were summed to produce a diet attitudes score ranging from 10-50. In the Puerto Rican study the measure yielded good internal consistency $(\alpha=.80-.82)$.

Exercise attitudes were measured in the same manner but with 3 items asking participants "During the next 30 days, how GOOD or BAD would it be for your health to exercise everyday?" and "How UNPLEASANT would it be for you health to exercise everyday?" Items were summed to produce an exercise attitude score ranging from 6-30. In the Puerto Rican study the measure yielded good internal consistency $(\alpha=.70-.81)$.

Diet Subjective norms (social support) for diabetes-related diet subjective norms was measured with five statements such as "Most people who are important to me think I should eat breakfast, lunch, and dinner." Items were summed to produce a score ranging from 5-30. In the Puerto Rican study the measure yielded good internal consistency $(\alpha=.85-.91)$ 
Exercise subjective norms were measured with three items such as "Most people who are important to me think I should exercise." Items were summed to produce a score ranging from 3-18. In the Puerto Rican study the measure yielded good internal consistency $(\alpha=.81-.85)$

\section{Self-Care Behavioral Skills}

Dietary Behavioral Skills, which are closely related to a sense of self-efficacy in performing these objective tasks, were measured by asking participants eight items. Participants were asked four dietary related questions such as "How EASY or HARD would it be for you to eat breakfast everyday?" and four questions asking "How EFFECTIVELY or INEFFECTIVELY could you count how many carbohydrates you eat at breakfast?" Items were summed to produce a diet behavioral skills score ranging from 8-32 which yielded good internal consistency in the Puerto Rican study $(\alpha=.81-.86)$.

Exercise Behavioral Skills were measured with six items. Participants were asked three exercise related questions such as "How EASY of HARD would it be for you to create different exercise activities to do in your home? And "How EFFECTIVELY or INEFFECTIVELY could you add more activity to the things you already do (for example, use the stairs instead of the elevator)?"' Items were summed to produce an exercise behavioral skills score ranging from 6-24 which yielded good internal consistency in the Puerto Rican study $(\alpha=.70-.77)$. Self-Care Behavior

Reading Food Label Behavior, which has been shown to contribute to improved blood glucose control, was measured with four items which asked participants questions such as "In the last 30 days, how OFTEN did you look at the serving size information on 
a food label?" Response options on a Likert scale will range from $1=$ never, to $5=$ always. Items were summed to produce a food label behavior score ranging from $4-20$ which yielded good internal consistency in the Puerto Rican study ( $\alpha=.92-.94)$.

Dietary Adherence Behavior was measured by 8 items, 3 items that have been derived from the Summary of Diabetes Self-care Activities questionnaire (SDSCA) (Toolbert, Hampson, \& Glasgow, 2000) which has been used previously in brief intervention studies to measure one's level of adherence to a recommended diet, and has demonstrated high test-retest reliability, ranging from .55-.788, $\mathrm{p}<001$ (Toobert, Hampson, \& Glasgow, 2000). Participants were asked such questions as "In the last 30 days, during a typical week, how many days did you follow your eating plan?", "On how many of the last seven days did you follow a healthful eating plan, and "On how many of the last seven days did you space carbohydrates evenly throughout the day?". These questions areas were used due to the key role that carbohydrate counting plays in achieving effective blood glucose control (American Diabetes Association, 2008b). Five additional items were developed (Osborn, 2006) that ask participants such questions as "On how many of the last seven days did you eat the same amount of food at each meal? Response options ranged from 0-7 depending on the number of days of the week. The score was summed to produce a total score based on the average number of days that the participant had adhered to the dietary behavior plan for all eight items.

Exercise Adherence Behavior was measured by two items taken from the SDSCA that has also demonstrated test-retest reliability, ranging from .42-.55, $\mathrm{p}<001$ (Toobert, Hampson, \& Glasgow, 2000). Participants were questions such as "On how many of the last seven days did you participate in at least 30 minutes of physical activity?" and "On 
how many of the last seven days did you participate in a specific exercise session (such as swimming, walking, biking) other than what you do around the house or as part of your work?" Response options ranged from 0-7 depending on the number of days of the week. The physical activity score was based on the average (mean) number of days that the participant had adhered to the exercise behavior plan for both items. In the Puerto Rican study the measure showed high test-retest reliability at three months $(\mathrm{r}=.42, \mathrm{p}=.006)$.

Given the decent internal consistency of the IMB-DSC questionnaire in the Puerto Rican study it was anticipated that such findings would be evident in this study with Mexican-Americans. Chapter 4 discusses the reliability and validity of this questionnaire with a Mexican-population.

\section{Risks and Benefits}

The possible risks, discomforts, and side effects of the procedures are detailed below. The questionnaire was designed to measure the patient's knowledge of diabetes, beliefs, attitudes and behaviors regarding diabetes control. Patients may feel threatened, worrying that what they are being asked in an invasion of privacy or that services will be revoked if they don't answer positively. The consent form guaranteed that confidentiality was adhered to and that if any emotional distress was incurred by a participant, referrals to local mental health care services would be provided. The possible benefits of the study are advancing scientific knowledge related to understanding the dynamics of diabetes self-care management and the possibility of developing strategies to provide more culturally responsive diabetes type 2 services. 


\section{Statistical Analysis}

Descriptive and statistical analyses were performed using SPSS 17.0. Face and Content Validity of the measure have previously been confirmed by the developers in consultation with a group of experts consisting of diabetes educators and patients with diabetes type 2 . Construct validity for this study was determined by a known group's technique. In identifying questionnaires completed by two groups of patients, one that have $\mathrm{HbAlc}$ values above or equal to $7 \%$ (the suboptimal group) and the other that have HbA1c values of $7 \%$ or below (the optimal group), it was hypothesized that the suboptimal group would result in a lower IMB scores on the questionnaire than the optimal group. Content validity for this study was also confirmed through first-hand knowledge, and extensive literature review and consultation with identified experts. Internal consistency reliabilities, which are a measure of the accuracy of the instrument, were determined using Cronbach's Alpha coefficients for each of the subscales. " $t$ "-tests were used to determine the relationship between gender and the IMB scores; correlational analysis to determine the relationship between acculturation and IMB scores; linear regression to ascertain the relationship of gender and acculturation with IMB scores; and finally t-test, correlational analysis and linear regression were used to determine the relationship between gender, acculturation and Information-Motivation-Behavioral Skills scores with the dependent health behavior outcomes of a) reading food labels, b) dietary behavior, c) exercise behavior, and d) HbAlc values. The seven semi-structured questions were used to provide content validity and to enrich and improve results from the questionnaire and to modify its current state by adding or deleting necessary or superfluous items, respectively. 
In conclusion, the methodology was designed to maintain the rigor necessary to assess the validity and reliability of the IMB instrument. It was also designed to assess if modification of this instrument would be necessary to more accurately identify the diabetes type 2 patient's ability to be adherent with their diabetes regime and determine if revisions in current interventions need to occur. 


\section{CHAPTER 4: RESULTS}

Introduction

This chapter presents the findings of this descriptive cross-sectional study of the psychometric properties of the Information-Motivation-Behavioral Skills Diabetes Scale (IMB-DSC). The purpose of the study was to evaluate the reliability and validity of the scale as an assessment tool used to identify gaps in diabetes knowledge, motivational influences and diabetes behavioral skills practices that hinder Mexican-American women and men in their success in self management of diabetes type 2.

\section{Participant Characteristics}

A purposive sample of 83 Mexican-American men and women were recruited for the pilot study from a Free Clinic in Orange County during the months of January March 2009. The IMB-DSCs demographic data collection included seven questions related to age, preferred interview language, educational level, employment and marital status, and health insurance status. The remainder of the demographic section served as a modified acculturation scale which asked a number of questions related to selfidentification, for example: (1) level of English proficiency, (2) language primarily spoken at home, (3) number of years lived in the United States (4) country (U.S. or Mexico) lived in for most of one's life. The participants ranged in age from 27-75, the mean age being 53.13 years $(\mathrm{SD}=10.07)$. As can be seen from Table 1 , the majority of the participants were female (77\%), were married (53\%) and self-reported having a third grade or less educational level (73.5\%). Spanish was the only language spoken at home 
for $>71 \%$ of the sample, reflecting low language acculturation despite the number of years in the United States.

The questionnaire was tested with 83 Mexican-American men and women who had been previously diagnosed with diabetes type 2 . A response rate of $99 \%$ was achieved with only one male participant declining to take part in the study due to time constraints and outstanding family commitments. After providing informed consent, the candidates were taken to a private room where they were presented with the questionnaire to be completed by paper and pencil. The principal bilingual researcher was in attendance and was available to read the questionnaire aloud to participants and provide clarification of the questions as needed. Each participant packet was pre-numbered to insure patient confidentiality. Because of the low-literacy level of this particular study population, the principal researcher typically read the questionnaire to each participant. This approach also reduced the issue of missing data.

After completion of the questionnaire, participants were requested to answer and provide comments regarding seven additional semi-structured free response interview questions, which were used to assess the validity of the instrument and possibly identify important aspects that should be considered when modifying the questionnaire as to meet the needs of the Mexican-American community.

Table 1 shows data collected in the first part of the questionnaire, which focussed on collecting demographic and acculturation data on the participants. 
Table 1. Demographic profile of study participants $(\mathrm{N}=83)$.

\begin{tabular}{|c|c|c|}
\hline \multicolumn{3}{|l|}{$\begin{array}{l}\text { Demographic } \\
\text { Gender }\end{array}$} \\
\hline & & \\
\hline Female & 64 & 77.1 \\
\hline \multicolumn{3}{|l|}{ Marital status } \\
\hline Single/no partner & 23 & 27.2 \\
\hline Married & 44 & 53 \\
\hline Divorced & 7 & 8.4 \\
\hline Widowed & 9 & 10.8 \\
\hline \multicolumn{3}{|l|}{ Language of interview } \\
\hline English & 8 & 9.6 \\
\hline . Spanish & 75 & 90.4 \\
\hline \multicolumn{3}{|l|}{ Where lived most as a child } \\
\hline United States & 5 & 6.0 \\
\hline $\begin{array}{l}\text { Mexico } \\
\text { Other }\end{array}$ & $\begin{array}{r}76 \\
2\end{array}$ & $\begin{array}{l}91.6 \\
2.4\end{array}$ \\
\hline \multicolumn{3}{|l|}{ Where lived most as an adult } \\
\hline $\begin{array}{l}\text { United States } \\
\text { Unt }\end{array}$ & 15 & 18.1 \\
\hline Mexico & 66 & 79.5 \\
\hline Other & 2 & 2.4 \\
\hline \multicolumn{3}{|l|}{ Grade completed } \\
\hline No formal schooling & 7 & 8.4 \\
\hline $\begin{array}{l}\text { Eighth grade or less } \\
\text { Some high school }\end{array}$ & 54 & 73.5 \\
\hline Some high school & 15 & 18.1 \\
\hline High school grad or GED & 1 & 1.2 \\
\hline Some college & 5 & 6.0 \\
\hline $\begin{array}{l}\text { Finished } 4 \text { years college } \\
\text { Health Insurance }\end{array}$ & 1 & 1.2 \\
\hline \multicolumn{3}{|l|}{ Health Insurance } \\
\hline $\begin{array}{l}\text { Yes } \\
\text { No }\end{array}$ & 83 & 100 \\
\hline Mean age: 53.1 years (range $27-75$ & years) & \\
\hline
\end{tabular}

\section{Results from the IMB Subscales}

The second part of the questionnaire assessed (a) the independent variables of diabetes specific knowledge, motivation and behavior skills and (b) the dependent health outcomes of reading food labels, dietary and exercise behavior, and $\mathrm{HbAlc}$ values. The results are discussed below.

Of the 11 subscales included in the IMB-DSC questionnaire, only seven reflected acceptable Cronbach alpha levels. The lower scores could reflect the small sample size or poor instrument items or inability of the respondent to answer a question due to literacy or some other factor. Unfortunately, in assessing the content validity of the instrument, 
this researcher questioned the reliability coefficients of all the subscales because participants indicated either a lack of sufficient understanding about these scales and their Likert format or they found them so redundant that they began answering them more positively with each iteration.

Table 2 provides a summary of the 11 subscales and Table 3 portrays participant results and scoring of the 11 subscales.

Table 2. Summary of the 11 subscales of the IMB-DSC Measure

\begin{tabular}{|l|c|l|c|c|}
\hline & Scale & \multicolumn{1}{|c|}{ Scale Name } & Range & $\begin{array}{c}\text { Cronbach's } \\
\text { Alpha }(\alpha)\end{array}$ \\
\hline $\begin{array}{l}\text { Self-care } \\
\text { Information }\end{array}$ & 1. & Diet information & $0-21$ & $(\alpha)=.492$ \\
\cline { 2 - 5 } & 2. & Exercise information & $7-28$ & $(\alpha)=.407$ \\
\hline \multirow{3}{*}{$\begin{array}{l}\text { Self-care } \\
\text { Motivation }\end{array}$} & 3. & Diet attitudes & $10-50$ & $(\alpha)=.800^{*}$ \\
\cline { 2 - 5 } & 4. & Exercise attitudes & $6-30$ & $(\alpha)=.749^{*}$ \\
\cline { 2 - 5 } & 5. & Diet motivation & $5-30$ & $(\alpha)=.908^{*}$ \\
\hline \multirow{nyyyy}{*}{$\begin{array}{l}\text { Self-care } \\
\text { Behavioral } \\
\text { Skills }\end{array}$} & 6. & Exercise motivation & $3-18$ & $(\alpha)=.971^{*}$ \\
\hline \multirow{2}{*}{$\begin{array}{l}\text { Self-care } \\
\text { Behaviors }\end{array}$} & 8. & Diet behavioral skills & $8-32$ & $(\alpha)=.739^{*}$ \\
\cline { 2 - 5 } & 9. & Exercise behavioral skills & $6-24$ & $(\alpha)=.628$ \\
\cline { 2 - 5 } & 10. & Diet adherence & 4 items & $(\alpha)=.940^{*}$ \\
\cline { 2 - 5 } & 11. & Exercise adherence & 2 items & $(\alpha)=.821^{*}$ \\
\hline
\end{tabular}

The IMB-DSC questionnaire revealed a population with a respectable diet knowledge score, and reasonable motivation to follow their diet. The participants also had a respectable exercise knowledge score, and were motivated to follow an exercise plan, although they experienced difficulty in following it. Their motivation was enhanced by good family and health care provider support systems. During the semistructured interview sessions, participants expressed concerns about the legitimacy of their responses, admitting that they frequently did not read food labels, count 
carbohydrates, control food portions or perform regular exercise. Chapter 5 discusses the possible explanations for these findings.

Table 3. Mean scores of independent and dependent variables $(\mathrm{N}=83)$.

\begin{tabular}{|l|c|c|c|c|}
\hline \multicolumn{1}{|c|}{ IMB Diet Measures } & Range & $\begin{array}{c}\text { Mean } \\
\text { Value }\end{array}$ & $\begin{array}{c}\text { Standard } \\
\text { Deviation }\end{array}$ & $\begin{array}{c}\text { Alpha } \\
\text { Coefficient }\end{array}$ \\
\hline $\begin{array}{l}\text { Diet information } \\
\text { Diet motivation }\end{array}$ & $0-21$ & 13.78 & 2.47 & $(\alpha)=.492$ \\
$\quad$ Attitudes & $0-50$ & 44.93 & 7.42 & $(\alpha)=.800$ \\
$\quad$ Subjective norms & $0-30$ & 23.69 & 9.07 & $(\alpha)=.908$ \\
$\quad$ Food label reading & $0-20$ & 12.98 & 5.22 & $(\alpha)=.940$ \\
$\quad$ Diet adherence & $0-56$ & 29.69 & 14.36 & $(\alpha)=.821$ \\
\hline IMB Exercise Measures & & & & \\
\hline Exercise information & $0-28$ & 25.84 & 2.64 & $(\alpha)=.407$ \\
Exercise motivation & & & & \\
$\quad$ Attitudes & $0-30$ & 29.54 & 1.95 & $(\alpha)=.749$ \\
$\quad$ Subjective norms & $0-18$ & 14.92 & 5.70 & $(\alpha)=.971$ \\
$\quad$ Exercise adherence & $0-14$ & 6.11 & 3.09 & $(\alpha)=.227$ \\
\hline Blood Glucose Control: & $5.2-$ & 8.30 & 2.12 & \\
HbAlc & 14.4 & & & \\
\hline
\end{tabular}

Research Questions

The study answered four key questions:

1. Is the Information-Motivation-Behavioral Skill Measure of Diabetes Self-Care (IMB-DSC) self-report questionnaire a valid and reliable tool for use in Mexican-American adults with type 2 diabetes?

2. What is the relationship between gender and IMB scores?

3. What is the relationship between IMB scores and gender on diabetic health outcomes $(\mathrm{HbAlc})$ values?

4. Did the IMB-DSC instrument accurately assess their knowledge (information,) motivation, and behavioral skill level regarding their diabetes and its management? 
Research Question 1

Is the Information-Motivation-Behavioral Skill Measure of Diabetes Self-Care (IMB-DSC) self-report questionnaire a valid and reliable tool for use in MexicanAmerican adults with type 2 diabetes? Cronbach's alpha, which is a measure of how strong an affiliation scale items have to each other, was used to assess the internal consistency of the data obtained from each of the IMB-DSCs 11 sub-scores; in addition, qualitative findings obtained from participant interviews were used to report on the content validity of the scale. In addition, the inter-correlations between each item within selected subscales are also reported and indicate whether the items are inter-related. The aim of this stage of the analysis was to determine if each subscale measured the characteristics of the underlying construct. The items bearing the highest correlation indicate a stronger relationship to the other items of the subscale. Ideally, all items in a reliable scale, assessing the same construct, should correlate with the total score. Because this instrument had subscales measuring different constructs, there was not a total scale score but total subscale scores which necessitated the assessment of each subscale reliability coefficient.

Before reviewing the results of each of the subscales in turn it is important to introduce the subject of negative skewness that were evident in several of the subscales. Skewness illustrates the degree of asymmetry of a distribution around its mean. The significance of such findings is that is that skewness, whether positive or negative, may reduce the reliability of a norm-referenced test but not necessarily a criterion-referenced test. This instrument was a criterion-referenced questionnaire and as such, the issue of skewness does not influence the reliability of the questionnaire; however, content validity 
assessment raised red flags about the reliability of some of the subscales (Tabachnick \& Fidell, 1996)

Scale \#1 (Diet Information) was the combination of two subscales in the original instrument. For the purpose of this study, the original "general diet knowledge" and "ethnic carbohydrate-containing diet knowledge" were collapsed into one Diet Information scale, hereafter referred to as Scale \#1. The composite scale thus provided 21 items that assessed adult Mexican-Americans' understanding or cognitive perceptions of the importance of choosing appropriate food items to regulate blood glucose levels, the effect of regular eating patterns aimed at controlling portions of carbohydrates throughout the day, and the affect that carbohydrates had on blood glucose levels. Participants were asked to answer the questions related to dietary knowledge in scale \#1 using a "true", "false" and "I don't know" format and used a "yes", "no", and "I don't know" format to answer the dietary carbohydrate content questions. Correct items were summed to produce a combined diet knowledge score with a range from $0-21$. Reliability of the items in this scale demonstrated a low internal consistency $(\alpha=.492)$. Content Validity of the subscale was an issue since the findings from the semi-structured interview questions concluded that all participants considered that the scale adequately assessed their general knowledge about diabetes and their specific knowledge regarding the carbohydrate content of some of the more common ethnic food that could easily be included in a healthy diabetic diet plan; however, participants found the questions difficult to answer because of the wording of the questions. For example negative wording of the following question "Skipping meals does not affect blood glucose levels" confused participants and required further explanation of the meaning and "People with diabetes should eat the 
same amount of food at each meal" caused participants to self-clarify the specific meaning of the question interpreting "same amount" to mean "small amount". Issues such as these with the questionnaire may have contributed to the low internal consistency score.

Scale \#2 (Exercise Information) dealt with participant knowledge regarding exercise and its role in controlling and maintaining a stable blood glucose level. Participants were asked to answer the seven questions using a 4 -point Likert scale that

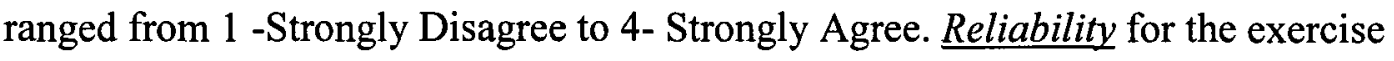
knowledge subscale also displayed a low internal consistency of $(\alpha=.407)$. Content Validity of the subscale was also a concern as all participants reported that the scale was an adequate measure of their general knowledge about the role of exercise in controlling their blood glucose level and reducing their risk of diabetic complications. However, like scale \#1, participants found the questions difficult to answer because of the wording and ambiguous nature of the questions. For example, "People who exercise eat more", and "Blood glucose is controlled for many hours after exercising." To answer these questions rigorously, the participant would need to know more precisely what is meant by "eat more" and "many hours." The vagueness of the questions may have contributed to the low internal consistency score.

Scales \#3 (Diet Attitude) explored the attitudes that participants had toward following a healthful, regular diet, keeping track of their daily consumption of carbohydrates and performing regular exercise as means to control their blood levels of glucose. Using two separate 5-point Likert scales, part (a) posed the question "During the next 30 days how good or bad would it be for your health to eat breakfast, lunch, and 
dinner every day?" Responses ranged from 1 - Very bad to 5- Very Good. Part (b) asked the question "How pleasant or unpleasant it would be to perform the behavior during the next 30 days?" Responses ranged from Very Unpleasant to Very Pleasant. The final scale thus consisted of 10 items. Reliability of the Diet Attitude subscale displayed a high internal consistency $(\alpha=.800)$ indicating that it was indeed measuring the attribute of attitude. Content Validity of the subscale found that participants thought the content/questions were repetitive and reported that answers to earlier questions in the scale had guided their responses to subsequent questions, which also may have contributed to the higher internal consistency score.

Scale \#4 (Exercise Attitude) explored the attitudes that participants had toward exercise and incorporating a regular exercise program into their DSM regime as another means to control their blood levels of glucose. Using two separate 5-point Likert scales, part (a) posed the question "During the next 30 days how good or bad would it be for your health to eat breakfast, lunch, and dinner every day?" Responses ranged from 1 Very Bad to 5- Very Good. Part (b) asked the question "How pleasant or unpleasant it would be to perform the behavior during the next 30 days?" Responses ranged from Very Unpleasant to Very Pleasant. The final scale thus consisted of 6 items. Reliability of the exercise attitude scale displayed a high internal consistency $(\alpha=.749)$. Content Validity was affected as participants indicated that like scale \#3, the content of the overall exercise scale was repetitive and reported that answers to earlier questions in this scale had affected their responses to subsequent questions, which also may have contributed to the higher internal consistency score. 
Scale \#5 (Diet motivation) explored the concept of social motivation or whether friends, relatives and other important support systems thought that performing eating healthily and regularly was a good thing to do. An example of questions asked was "The majority of the important people in your life think that you should eat breakfast, lunch and dinner daily." Responses ranged from 1 - Very False, to 6 - Very True. The Diet Motivation scale consisted of five items.

Scale \#6 (Exercise Motivation) explored the concept of social motivation or whether friends, relatives and other important support systems thought that performing regular exercise was a good thing to do. An example of questions asked was "The majority of the important people in your life think that you should eat breakfast, lunch and dinner daily." Responses ranged from 1 - Very False, to 6 - Very True. The Exercise Motivation scale consisted of three items. Reliability of these two subscales found both showing a high internal consistency ( $\alpha=.908 \& \alpha=.971$ respectively). Content Validity of both subscales was questionable as participants reported receiving very high levels of social support from friends, relatives and other significant persons; however, the Likert scale responses were difficult to differentiate between "very false" and "false" or "very true" and "true." Also, the questions were repetitive and responses to earlier questions in the subscale prompted similar responses to successive questions thus greatly influencing the overall set of responses and the higher internal consistency score.

Scale \#7 (Diet Behavioral Skills) explored the behavioral skills necessary for participants to follow a DSM diet plan. Using two separate 4-point Likert scales, part (a) posed the question of "How easy or hard would it be for you to eat breakfast, lunch, and dinner every day?" Responses ranged from 1 - Very Hard to 5- Very Good. Part (b) 
asked the question "How effective or ineffectively could you count how many carbohydrates you eat at breakfast?" Responses ranged from 1 Very Ineffectively to 5 Very Effectively. The final scale consisted of eight items. Reliability of this subscale had high degree of internal consistency $(\alpha=.739)$. Content Validity of this subscale was a concern as participants thought the questions rather repetitive as similar ideas regarding carbohydrate counting, regular meals, and exercising had been reviewed in previous questions. The Likert scale responses were difficult to differentiate between "very hard or very ineffectively" and "hard or ineffectively" or "very good or very effectively" and "good or effectively." Some questioned the use of the term "hard" in relation to food consumption as they considered eating at least three meals a day to be a very easy and pleasurable activity to perform.

Scale \#8 (Exercise Behavioral Skills) explored the behavioral skills necessary for participants to follow a DSM exercise plan. Using two separate 4-point Likert scales, part (a) posed the question of "How easy or hard would it be for you pick a convenient time of day to exercise?" Responses ranged from 1 - Very Hard to 5- Very Good. Part (b) asked the question "How effectively or ineffectively could you find activities to do when the weather is bad? " Responses ranged from 1 Very Ineffectively to 5 Very Effectively. The final scale consisted of six items. Reliability of the scale showed a high internal consistency $(\alpha=.628)$, but had frequency distribution scores that were negatively skewed which could significantly affect the consistency value. Content Validity of the scale raised similar concerns by the participants on the other subscales: they thought the questions rather repetitive and repetitiveness influenced their subsequent responses. The Likert scale responses were difficult to differentiate between "very hard or very 
ineffectively" and "hard or ineffectively" or "very good or very effectively" and "good or effectively." Participants were confused by the terminology of "ineffective" and "effective" and asked for clarification of the use of nature of the questions and how previous responses to questions were influencing their responses and raises questions about the reliability coefficients on subscales 3-8.

Scale \#9 (Reading Food Label Behavior Skill) explored the behavior pattern of reading food labels. Participants were asked how often during the last 30 days they undertook such activities as looking at serving sizes checking carbohydrate content, counting carbohydrates and selecting foods that were low in carbohydrates. Reliability of the subscale demonstrated a high internal consistency, $\alpha=.940$. Content Validity of this subscale correlated with the reliability coefficient as participants had no difficulty with the wording or meaning of these questions and thought that they adequately and simply probed their behavior patterns regarding the activity of reading of food labels.

Scale \#10 (Diabetic Diet Adherence) explored the behavior pattern of following a healthy diabetic diet plan. Participants were asked how often during the last 30 days, during a typical week how many days would they undertake such activities as eating healthily, following a diabetic eating plan, and consuming three well proportioned, carbohydrate controlled meals a day. Responses were reported by indicating the number of days that each behavior was done. Reliability of the scale showed a high internal consistency, $\alpha=.821$. Content Validity of this scale was similar to Scale \#9 in that participants found the questions easy to understand and thought that they adequately inquired about their behavior patterns regarding following the dietary guidelines that had been recommended to them by their health care provider. 
Scale \#11 (Exercise Adherence) explored participants exercise behavior pattern. Participants responded to two questions regarding the number of days that they participated in physical exercise. Questions such as "On how many of the last seven days did you participate in at least 30 minutes of physical activity?" were responded to by indicating the number of days that each activity was done. Reliability of this scale had a very low level of consistency $\alpha=.227$. Content Validity of the scale was of concern as the definition of exercise varied with each participant despite the fact that participants found the questions easy to understand.

Mean scores for the 11 subscales are found in Table 3 while Table 2 reflects the IMB-DSC internal consistency scores. Alpha scores of 0.7 or higher are generally considered acceptable for scales. In summary to answer research question 1: scales 3,4 , $5,6,7,9,10$ demonstrated an acceptable level of internal consistency; however, content validity concerns raised questions about the reliability of subscales $3,4,5,6$, and 7 . The semi-structured interview questions gave good insight about the participants' issues with these subscales. As a consequence of the content validity component of this study, the overall scale, in its original form, cannot be considered a reliable nor valid tool for assessing adherence problems in this population of Mexican-Americans with diabetes type 2 .

To assess construct validity, participants at or below the recommended HbAlc level $<7$ (regarded as optimal values [American Diabetes Association, 2008]), were compared with those who were above the recommended national HbAlc values $\geq 7$ (regarded as suboptimal). The differences in the two scores obtained by each of the groups were examined. The results of the t-tests to determine the differences are shown 
below in Table 4 . There were significant differences in IMB scores between those participants with suboptimal $\mathrm{HbAlc}$ values and those with optimal HbAlc values on only two of the five selected subscales. The two scales, namely food label reading and diet adherence, showed significance ( $p=.01 \& .02$ respectively) among participants that had optimal HbAlc levels.

Table 4. T-test results for the known groups' comparison.

\begin{tabular}{|c|c|c|c|c|c|c|c|}
\hline $\begin{array}{c}\text { HbAlc categorical: } \\
1=\text { suboptimal HbAlc } \\
2=\text { optimal HbAlc }\end{array}$ & & $\mathrm{N}$ & Mean & $\begin{array}{l}\text { Std. } \\
\text { Dev. }\end{array}$ & $\begin{array}{l}\text { Std. } \\
\text { Error } \\
\text { Mean }\end{array}$ & $\mathrm{t}$ & $\begin{array}{l}\text { Sig. (2- } \\
\text { tailed) }\end{array}$ \\
\hline $\begin{array}{l}\text { Scale \#1: } \\
\text { Diet Information }\end{array}$ & $\begin{array}{l}1 \\
2 \\
\end{array}$ & $\begin{array}{l}56 \\
27\end{array}$ & 13.91 & 2.732 & .582 & .674 & .502 \\
\hline $\begin{array}{l}\text { Scale \#2: } \\
\text { Exercise Information }\end{array}$ & $\begin{array}{l}1 \\
2\end{array}$ & $\begin{array}{l}56 \\
27\end{array}$ & $\begin{array}{l}25.82 \\
25.89\end{array}$ & $\begin{array}{l}2.777 \\
2.391\end{array}$ & $\begin{array}{l}.371 \\
.460\end{array}$ & -108 & .914 \\
\hline $\begin{array}{l}\text { Scale \#3 } \\
\text { Diet Attitudes }\end{array}$ & $\begin{array}{l}1 \\
2\end{array}$ & $\begin{array}{l}56 \\
27\end{array}$ & $\begin{array}{l}43.95 \\
46.96\end{array}$ & $\begin{array}{l}8.394 \\
4.283\end{array}$ & $\begin{array}{c}1.122 \\
.824\end{array}$ & -2.167 & 0.33 \\
\hline $\begin{array}{l}\text { Scale \#4 } \\
\text { Exercise Attitudes }\end{array}$ & $\begin{array}{l}1 \\
2\end{array}$ & $\begin{array}{l}56 \\
27\end{array}$ & $\begin{array}{l}29.64 \\
29.33\end{array}$ & $\begin{array}{l}1.700 \\
2.418\end{array}$ & $\begin{array}{l}.227 \\
.465\end{array}$ & .674 & .502 \\
\hline $\begin{array}{l}\text { Scale \#5 } \\
\text { Diet Motivation }\end{array}$ & $\begin{array}{l}1 \\
2\end{array}$ & $\begin{array}{l}56 \\
27\end{array}$ & $\begin{array}{l}22.79 \\
25.56\end{array}$ & $\begin{array}{l}9.853 \\
6.980\end{array}$ & $\begin{array}{l}1.317 \\
1.343\end{array}$ & -1.473 & .145 \\
\hline $\begin{array}{l}\text { Scale \#6 } \\
\text { Exercise Motivation }\end{array}$ & $\begin{array}{l}1 \\
2\end{array}$ & $\begin{array}{l}56 \\
27\end{array}$ & $\begin{array}{l}14.14 \\
16.52\end{array}$ & $\begin{array}{l}6.306 \\
3.796\end{array}$ & $\begin{array}{l}.843 \\
.731\end{array}$ & 1.117 & .271 \\
\hline $\begin{array}{l}\text { Scale \#7 } \\
\text { Diet Behavioral Skills }\end{array}$ & $\begin{array}{l}1 \\
2\end{array}$ & $\begin{array}{l}56 \\
27\end{array}$ & $\begin{array}{l}17.57 \\
18.22\end{array}$ & $\begin{array}{l}2.716 \\
2.651\end{array}$ & $\begin{array}{l}.363 \\
.510 \\
\end{array}$ &.-1.031 & .306 \\
\hline $\begin{array}{l}\text { Scale \#8 } \\
\text { Exercise Behavioral Skills }\end{array}$ & $\begin{array}{l}1 \\
2\end{array}$ & $\begin{array}{l}56 \\
27\end{array}$ & $\begin{array}{l}20.16 \\
21.78\end{array}$ & $\begin{array}{l}3.789 \\
2.764\end{array}$ & $\begin{array}{l}.506 \\
.532\end{array}$ & -1.976 & .052 \\
\hline $\begin{array}{l}\text { Scale \# } 9 \\
\text { Reading Food label (behav.) }\end{array}$ & $\begin{array}{l}1 \\
2\end{array}$ & $\begin{array}{l}56 \\
27\end{array}$ & $\begin{array}{l}11.98 \\
15.04\end{array}$ & $\begin{array}{l}5.069 \\
5.011\end{array}$ & $\begin{array}{l}.677 \\
.964\end{array}$ & -2.582 & $.012^{*}$ \\
\hline $\begin{array}{l}\text { Scale \# } 10 \\
\text { Diet Adherence }\end{array}$ & $\begin{array}{l}1 \\
2\end{array}$ & $\begin{array}{l}56 \\
27 \\
\end{array}$ & $\begin{array}{l}27.16 \\
34.93 \\
\end{array}$ & $\begin{array}{l}13.948 \\
14.027 \\
\end{array}$ & $\begin{array}{l}1.864 \\
2.700\end{array}$ & -2.372 & $.020^{*}$ \\
\hline $\begin{array}{l}\text { Scale \#11 } \\
\text { Exercise Adherence }\end{array}$ & $\begin{array}{l}1 \\
2\end{array}$ & $\begin{array}{l}56 \\
27\end{array}$ & $\begin{array}{l}5.91 \\
6.52\end{array}$ & $\begin{array}{l}3.181 \\
2.914\end{array}$ & $\begin{array}{l}.425 \\
.561 \\
\end{array}$ & -.837 & .405 \\
\hline
\end{tabular}




\section{Research Question 2}

What is the relationship between gender and IMB scores? An independent samples t-test was used to determine the relationship between gender and the IMB scores the results of which are shown in Table 5 below. Women scored higher on diet knowledge (Scale \#1), diet behavioral skills (Scale \#7), exercise behavioral skills (Scale \#8), food label reading (Scale \#9), diet behavior/dietary adherence (Scale \#10), and exercise behavior/exercise adherence (Scale \#11) than men. Men on the other hand scored higher than women on exercise knowledge (Scale \#2), diet attitudes (Scale \#3), exercise attitudes (Scale \#4), diet motivation (Scale \#5), and exercise motivation (Scale \#6) than women. There was statistical significance between gender and IMB scores on

Table 5: T-test Group Statistics for the relationship between gender and IMB scores

\begin{tabular}{|c|c|c|c|c|c|c|c|c|}
\hline & Subscales & Sex & $\mathbf{N}$ & $\begin{array}{c}\text { Mean } \\
\text { IMB } \\
\text { Scores }\end{array}$ & $\begin{array}{c}\text { Std. } \\
\text { Deviation }\end{array}$ & $\begin{array}{l}\text { Std. } \\
\text { Error } \\
\text { Mean }\end{array}$ & $T$ & $\begin{array}{c}\text { Sig. } \\
\text { 2-tailed }\end{array}$ \\
\hline \multirow[t]{2}{*}{ Iaformation } & $\begin{array}{l}\text { Diet Knowledge } \\
\text { (general) }\end{array}$ & $\begin{array}{l}\text { Male } \\
\text { Female }\end{array}$ & $\begin{array}{l}19 \\
64 \\
\end{array}$ & $\begin{array}{l}13.16 \\
13.97 \\
\end{array}$ & $\begin{array}{l}2.544 \\
2.443 \\
\end{array}$ & $\begin{array}{l}.584 \\
.305\end{array}$ & -1.259 & .212 \\
\hline & $\begin{array}{l}\text { Exercise } \\
\text { Knowledge }\end{array}$ & $\begin{array}{l}\text { Male } \\
\text { Female } \\
\end{array}$ & $\begin{array}{l}19 \\
64 \\
\end{array}$ & $\begin{array}{l}26.63 \\
25.61 \\
\end{array}$ & $\begin{array}{l}2.314 \\
2.706 \\
\end{array}$ & $\begin{array}{l}. \mathbf{5 3 1} \\
. \mathbf{3 3 8} \\
\end{array}$ & 1.491 & .140 \\
\hline \multirow[t]{4}{*}{ Motivation } & $\begin{array}{l}\text { Diet } \\
\text { Attitudes } \\
\end{array}$ & $\begin{array}{l}\text { Male } \\
\text { Female } \\
\end{array}$ & $\begin{array}{l}19 \\
64 \\
\end{array}$ & $\begin{array}{l}46.11 \\
44.58 \\
\end{array}$ & $\begin{array}{l}4.545 \\
8.079 \\
\end{array}$ & $\begin{array}{l}1.043 \\
1.010 \\
\end{array}$ & .786 & .434 \\
\hline & $\begin{array}{l}\text { Exercise } \\
\text { Attitudes }\end{array}$ & $\begin{array}{l}\text { Male } \\
\text { Female } \\
\end{array}$ & $\begin{array}{l}19 \\
64 \\
\end{array}$ & $\begin{array}{l}29.68 \\
29.50 \\
\end{array}$ & $\begin{array}{l}1.003 \\
2.160 \\
\end{array}$ & $\begin{array}{l}.230 \\
.270 \\
\end{array}$ & .359 & .720 \\
\hline & $\begin{array}{l}\text { Diet } \\
\text { Norms }\end{array}$ & $\begin{array}{l}\text { Male } \\
\text { Female } \\
\end{array}$ & $\begin{array}{l}19 \\
64 \\
\end{array}$ & \begin{tabular}{|l|}
25.79 \\
23.06 \\
\end{tabular} & $\begin{array}{ll}7.864 \\
9.364 \\
\end{array}$ & $\begin{array}{l}1.804 \\
1.170 \\
\end{array}$ & 1.268 & .213 \\
\hline & $\begin{array}{l}\text { Exercise } \\
\text { Norms }\end{array}$ & $\begin{array}{l}\text { Male } \\
\text { Female }\end{array}$ & $\begin{array}{l}19 \\
64 \\
\end{array}$ & $\begin{array}{l}16.05 \\
14.58 \\
\end{array}$ & $\begin{array}{l}4.755 \\
5.944 \\
\end{array}$ & $\begin{array}{l}1.091 \\
.743\end{array}$ & 1.117 & .271 \\
\hline \multirow[t]{2}{*}{$\begin{array}{l}\text { Behavior } \\
\text { Skills }\end{array}$} & $\begin{array}{l}\text { Díet Behaviar } \\
\text { Skills } \\
\end{array}$ & $\begin{array}{l}\text { Male } \\
\text { Female } \\
\end{array}$ & $\begin{array}{l}19 \\
64 \\
\end{array}$ & 18.11 & 2.644 & .506 & .591 & .556 \\
\hline & $\begin{array}{l}\text { Exercise } \\
\text { Behavior Skills }\end{array}$ & $\begin{array}{l}\text { Male } \\
\text { Female }\end{array}$ & $\begin{array}{l}19 \\
64 \\
\end{array}$ & 20.74 & 4.357 & 1.000 & 0.070 & .945 \\
\hline \multirow[t]{3}{*}{ Behavior } & $\begin{array}{l}\text { Reading Food } \\
\text { Labels } \\
\end{array}$ & $\begin{array}{l}\text { Male } \\
\text { Female }\end{array}$ & $\begin{array}{l}19 \\
64 \\
\end{array}$ & $\begin{array}{l}11.32 \\
13.47 \\
\end{array}$ & $\begin{array}{l}5.034 \\
5.213 \\
\end{array}$ & $\begin{array}{l}1.155 \\
.625 \\
\end{array}$ & -1.593 & .115 \\
\hline & $\begin{array}{l}\text { General diet } \\
\text { score }\end{array}$ & $\begin{array}{l}\text { Male } \\
\text { Female } \\
\end{array}$ & $\begin{array}{r}19 \\
64 \\
\end{array}$ & $\begin{array}{l}26.11 \\
30.75 \\
\end{array}$ & $\begin{array}{l}14.314 \\
14.315 \\
\end{array}$ & $\begin{array}{l}3.284 \\
1.789 \\
\end{array}$ & -1.242 & .218 \\
\hline & Exercise score & $\begin{array}{l}\text { Male } \\
\text { Female } \\
\end{array}$ & $\begin{array}{l}19 \\
64 \\
\end{array}$ & $\begin{array}{l}4.58 \\
6.56 \\
\end{array}$ & $\begin{array}{l}2.388 \\
3.147 \\
\end{array}$ & $\begin{array}{l}.548 \\
.393 \\
\end{array}$ & -2.535 & .013 \\
\hline Gender & & & 83 & 1.77 & .423 & - & -1.387 & .170 \\
\hline
\end{tabular}


only one scale, the Exercise Adherence subscale: female ( $M=6.56$, SE .393), men ( $M=$ 4.58, $\mathrm{SE}=.548), p \geq .69:$ see Table 5.

These trends and statistical significance indicate that the women in this study demonstrated a slightly greater knowledge about how to control and regulate their eating habits and, as the homemaker and meal maker for the family, it would be expected that the woman would be attentive to these two issues. Of interest was the fact that they also indicated they were more active and exercised more regularly than the men, despite the men's jobs as hard day laborers. This perspective from female participants could have been the participant's inability to separate leisure time physical activity from a man's occupational activities which can be considered another form of exercise. Men alternatively, showed greater knowledge about exercise and had better attitudes and greater external support regarding maintaining their diet and exercise regimes than women. It would appear, therefore, that men felt more motivated to follow their diabetes self-management regimes due to the greater amount of family support that they were receiving but yet as with the women, they were not being adherent and following through in their daily actions.

\section{Research Question 3}

What is the relationship between IMB scores on diabetic health outcomes (HbAlc)? Pearson product moment correlation coefficient and linear regression were used to determine the inter-relationship between selected IMB scores and $\mathrm{HbAlc}$ values, as shown in the Table 6. Preliminary analyses were performed to ensure no violation of the assumptions of normality, linearity, and homoscedasticity. Table 6 reflects the correlational results. Reading food labels and diet behavior showed a 
small trend towards negative correlation between the variables reading food labels, following a dietary plan, and HbAlc values. An inverse relationship can imply that those who read food labels and those that followed a dietary plan were more likely to have lower resultant HbAlc values; however, the difference was not found to be significant. Women were more likely to achieve lower HbAlc scores than men and were also found to have higher scores on label reading and following their diets than men but these values were not statistically significant.

\section{Research Question 4}

Did the IMB-DSC instrument accurately assess their knowledge (information), motivation, and behavioral skill level regarding their diabetes and its management?

Participants were asked to respond to seven semi-structured, free response questions that were designed to answer the above question and to identify gaps in knowledge,

Table 6. Summary of Pearson intercorrelations for 12 subscales.

\begin{tabular}{|c|c|c|c|c|c|c|c|c|c|c|c|c|}
\hline Subscale & 1 & 2 & 3 & 4 & 5 & 6 & 7 & 8 & 9 & 10 & 11 & 12 \\
\hline 1. Diet Knowledge & -- & -.07 & .02 & .10 & .10 & .13 & .48 & .14 & .18 & .10 & .01 & .03 \\
\hline 2. Exercise Knowledge & & - & -.03 & .03 & .03 & -.05 & .18 & .20 & $.09^{\circ}$ & .11 & .06 & .02 \\
\hline 3. Diet Attitudes & & & -- & .20 & .16 & .16 & $.31^{\text {***}}$ & $.24^{*}$ & $.30^{* *}$ & .12 & .11 & -.15 \\
\hline 4. Exercise Attitudes & & & &.- & .13 & .15 & .02 & .21 & .09 & .08 & .07 & .03 \\
\hline 5. Diet Motivation & & & & & -- & $.88^{* *}$ & $.22^{* *}$ & .21 & $.28^{* *}$ & $30^{* *}$ & .20 & .06 \\
\hline 6. Exercise Motivation & & & & & & - & .17 & .15 & $.27^{\star \star *}$ & $.34^{* *}$ & .07 & .07 \\
\hline 7. Diet Behavioral Skills & & & & & & & $\ldots$ & $.51^{* * *}$ & .16 & $.22^{*}$ & $.22^{*}$ & -.05 \\
\hline 8. Exercise Behavioral Skills & & & & & & & & - & .15 & $.27^{*}$ & $.32^{* *}$ & -.16 \\
\hline 9. Food Label Reading & & & & & & & & & - & $.40^{* *}$ & .11 & $-.28^{* *}$ \\
\hline 10. Diet Adherence & & & & & & & & & & - & .22 & $-.28^{* *}$ \\
\hline 11. Exercise Adherence & & & & & & & & & & & -- & .02 \\
\hline 12. $\mathrm{HgbA} 1 \mathrm{c}$ & & & & & & & & & & & & - \\
\hline
\end{tabular}


motivation and behavioral skills that would impede adherence to DSM goals. Free Response Question 1

Did the questions in this questionnaire adequately evaluate your knowledge about your diabetes? Participants believed that the subscales related to knowledge explored their knowledge about their diabetes management in terms of food and exercise; however, it failed to include the medication component of their diabetes management plan which they considered to be equally important. The majority of participants commented that they were aware of the diet knowledge content in the questionnaire due to the teaching that they received from the providers at their routine visits, the diabetic education classes, and from discussions with family members also with diabetes. They stated "Lo que necesitamos es más tiempo para revisar los medicamentos porque es my confundido recordar cuando y cuantos tabletas tenemos que tomar." ("We receive instruction about diet and exercise all the time what we also need though is someone to spend time going over the medication with us as it gets confusing remembering when and how many tablets we have to take.)

Free Response Question 2

Do the questions make you think deeply about your motivation to follow the healthy program planned for you? Participants reported that they had rarely been asked about the thoughts and concerns of their families in assisting them in managing their diabetes and considered that the questions did made them seriously think about how diabetes affected the whole family. One participant in particular mentioned that she would like her family involved in her care and expressed her request in the following manner, "Me gustaria que mi familia vengan conmigo a pero ellos tienen que trabajar y 
no tienen tiempo para acompanarme. Es una lastima porque yo no puedo recorder siempre lo que me dicen..." ("I would like my family to with me but they have to work. It is a shame as I cannot always remember what they say to me...."). Though motivated by family and health care providers, something seemed to be missing in their motivation that adversely affected their management of their diabetes type 2 .

Free Response Question 3

Do the questions make you think about the behavioral skills that you consider are necessary to reach the goals that you have set in managing your diabetes? Participants considered that acquiring healthy dietary and exercise skills were very important to their success in managing their diabetes. They also thought the questions made them examine their current eating and exercise habits. One male participant offered the following comment when asked about his poor adherence to his dietary regime. "Quiero comer lo que me recomiendan pero es dificil porque me encanta mas las comidas que son malas." While a female participant commenting on her lack of exercise responded with the following; "En el caso de ejecicio tengo vergüenza admitirlo pero normalmente después un dia con mis nietos no quiero hace ningún ejercicio, soy cansado. Once again, though such questions made them think about their eating and exercise habits, something appears to be interfering with their ability to operationalize these skills.

Free Response Question 4

Do you think your time in the U.S. has affected your knowledge of diabetes? Participants responded that living or residing in the U.S. had undoubtedly heightened their awareness of diabetes as an illness as well as its treatment and management options. 
However, such knowledge and access is not enough of a factor to encourage adherence to their medical regime.

Free Response Question 5

Do you think that your time in the U.S. has affected your desire to control your diabetes? Participant responses were very favorable towards health care providers who they reported were very skillful at encouraging them to follow the DSM program developed for them. They also reported on the care and compassion they had received from members of the health care team and how the support provided some motivation to comply with the directions of the health care provider. As stated above, health care provider relations was not as significant of a factor as it could be to encourage adherence with their medical regime.

Free Response Question 6

Do you think your time in the U.S. has affected your skills to be able to manage your diabetes? Participants reported that the skills that they had acquired here in the U.S. in terms of appropriate food options, portion control, eating patterns, and exercise regimes was attributed to the superior DSM education that they had experienced whilst living in the U.S. However, even these skill sets do not appear to influence their adherence. "Atención medico aquí en Los Estados Unidos es mejor que en México porque no hay recursos -- sin embargo es muy dificil comer lo que me recomiendan especialmente cuando trabajo. Pienso de que debo comer pero en realidad tengo mucho hambre ..." ("Medical attention here for diabetes is much better that in Mexico where resources are scarce -- nonetheless it is still difficult to follow my diet especially when I am at work. I think about what I should eat but I'm hungry"). These were some of the 
comments obtained from male participants in response to my questions about managing their diabetes whilst residing here in the United States.

Free Response Question 7

Was the format of the questions easy to answer? Participants reported that they found the "yes", "no", "I don't know" and "true", "false" questions easier to answer than the Likert scale questions that asked for such responses as "Very Hard", "Hard", "Easy" and "Very Easy". They reported finding the multiple options presented to them in questions of this type confusing and remarked on the difficulty of deciding between two very similar responses such as "Easy" and "Very Easy." Several commented on the difficulty they had in comprehending the meaning of many of the questions. Some believed that the questions didn't adequately reflect what they do to help control their diabetes: (e.g., the men commented on the physical exertion they expend in their day job that makes it impossible to participate in "formal" exercise regimes at home; therefore, the subscale did not adequately assess "true" exercise involvement). Since this instrument was written at a $6^{\text {th }}$ grade level, as is common when using self-report questionnaires (Brown et al., 2000, Hill-Briggs \& Smith, 2008), and most of the participants only had a $3^{\text {rd }}$ grade education, it was no wonder that comprehension of many of the questions was a problem. Male participants in particular commented on their desire to exercise but lack of time to do so. "I work hard during the day in construction and to me this is my exercise. I have no energy to do anything else when I get home." Estoy en construcción y trabajo muy duro. A mi esta es una forma de ejercicio. Cuando regreso a mi casa yo no tengo ganas ni energía hacer más actividades." 


\section{Summary of Results}

This chapter presented the findings of this descriptive cross-sectional study of the psychometric properties of the Information, Motivation, and Behavioral Skills Diabetes Scale (IMB-DSC). The observations by the participants may indicate important factor that influence the reliability of the subscales and the content validity of the instrument. The results may indicate that the IMB-DSC instrument may be problematic in accurately assessing the adherence issues for Mexican-American adults with diabetes type 2 . The concerns raised by this researcher about the reliability and content validity of this scale are: 1) the tool was not written at a grade-appropriate level for the educational level of the participants. 2) Too many questions were repetitive which appeared to guide the answers the participants gave for each successive item. As a researcher, one wonders if the participants thought repetitiveness was a hint to answer each successive item more positively. 3) The Likert scale format is not a format appropriate for Mexican-Americans who are not able to adequately differentiate between leveling terms (e.g., very hard versus hard or very easy versus easy). 4) The tool did not address other adherence issues such as medication use or the internal/personal motivators that influence the individual's desire to act. Further research is needed to develop an instrument that would be usable for caregivers to provide more culturally appropriate care to Mexican-Americans with diabetes type 2 .

Regardless of the participants' belief about greater access to care and more qualified people who truly wanted to help them, they continued to lack adherence with the diabetic regimes prescribed. Is it the lack of adequate public education for immigrants coming from Mexico; is the educational material presented at too high of a grade level; is 
it the lack of internal motivation to be adherent with their medical regime, despite the plethora of their external motivators; or is there some variable affecting lack of adherence that was not captured in this study? Chapter 5 will further delineate the meaning of the research findings. 


\title{
CHAPTER 5: DISCUSSION
}

\author{
Introduction
}

This chapter discusses the meaning of the research results. The study, evaluating the reliability and validity of the IMB-DSC scale, answered four key questions. Using a triangulated approach, the results have helped this researcher better understand the perspectives of the Mexican-American participants and their management of diabetes type 2 .

\section{Socio-demographic Findings}

Of the Mexican-American adults who participated in this study, the majority were middle-aged women with a $3^{\text {rd }}$-grade or lower education, employed in unskilled jobs with no health insurance, who spoke very little English despite their longevity in the U.S., and preferred living in a predominantly Spanish-speaking area of Orange County with little integration into the main culture. The participants' choices about living in the U.S. indicated their strong desire to maintain their Hispanic heritage with little desire to acculturate.

Acculturation, the process by which immigrants increasingly take on the cultural habits of the majority or dominant culture, can influence an immigrant's understanding and adherence to the medical regimes recommended by providers in their host country (Antshel, 2002). Comprehension and valuing these medical recommendations is not only dependent on acculturation but are highly influenced by the level of education, insurance coverage, financial viability, ease versus difficulty in adhering to a medical regime, and 
cultural views on chronic health problems requiring "forever" interventions (Brown et al., 2000).

Despite the participants' positive feelings about the health care they were provided and the people with whom they interacted at the clinic, it is possible that cultural health beliefs, lack of education, lack of health insurance, and lack of money negatively influenced their adherence. The problem with adherence was exacerbated by three other key factors: 1) inability to fully comprehend the diabetes education provided; 2) lack of internal motivators to adhere to treatment plans; and 3) gender - men being less adherent than women.

Providers need to consider these socio-demographic factors when developing treatment recommendations and education. However, evidence-based practice requires that further research be conducted to assess the following: 1) Would adherence improve if the cultural inhibitors to adherence were explored and solutions identified? 2) Could diabetes educators discuss the phenomenon of "chronic illness", provide financially viable options for nutrition and exercise regimes, and present the material considering grade level achievement of the participants? 3) Would adherence improve if genderappropriate care were provided so as to meet the unique needs of men and women managing their chronic illness? 4) Would adherence improve if the internal motivators of the individual were fostered?

The IMB-DSC Instrument

The answer to effective diabetes control continues to point to greater adherence to diabetic self-management programs. With the most successful of programs focusing on changing previous, well-established behavior patterns through modifying personal 
attitudes and increasing motivation, there is a great need for a more thorough and complete understanding of exactly how to enhance adherence with a complicated selfmanagement program. Identifying and incorporating cultural and ethnic influences that could be used to design a culturally acceptable program of treatment for ethnic minorities is essential (Brown et al., 2000; Osborn, 2006); and culturally appropriate assessment and evaluation tools are a necessary initial step in identifying these factors that hinder adherence to DSM regimes. Tools that can assist providers in pin-pointing the barriers to successful diabetes self management that ethnic minorities experience can stimulate understanding and promote inclusion of these identified deficits into diabetes intervention education programs.

The Information-Motivation-Behavioral Skills Measure of Diabetes Self-Care (IMB-DSC) is an instrument that holds the promise of being an effective assessment tool in identifying discrepancies in behavior patterns that result in observed poor adherence rates (Albarracin, Johnson, Fishbein, \& Muellerleile, 2001; Albarracin, Kumkale, \& Johnson, 2004; Fisher, Fisher, \& Harman, 2003; Osborn, 2006). It has been shown to be reliable and valid in one Spanish-speaking culture; however, it cannot be assumed that it is transferrable to all Spanish-speaking cultures as was the case in this study. Therefore, researchers and providers need to assure that assessment tools are ethnically and culturally individualized before they can be used to determine the success or failure of interventions.

Such individualism is inherent when evaluating an instrument for its validity and reliability. Face, content, and construct validity are affected by the differences in beliefs and health practices of people from all variations of that culture (Brown et al., 2007). Nor 
can it be assumed that a $6^{\text {th }}$ grade reading level is an appropriate reading level for all research participants. In some cases like the participants in this study, these immigrants did not have the privilege of a primary or secondary education. It is possible that instruments developed on the Western research model may not appropriate to use in large research studies with immigrants until the educational level of the participants has been assessed.

\section{Information}

\section{Diet Information}

This subscale demonstrated low reliability in this study. Comments by the participants such as "no puedo leer" (I can't read) o "no puedo leer bien" (I can't read well) were frequent responses and most likely was related to their low grade level achievement and low literacy. All but one completely bilingual participant requested that the questionnaire be read to them as they were concerned that they would not be able to understand the questions. They also admitted they had trouble processing the written material provided in their diabetic education classes. Arcury, Skelly, Gesler and Dougherty (2004), Daniulaityte (2004), Rosal, Olendzki, \& Reed (2005) and von Goeler et al. (2003) support this conclusion with their findings that low educational and literacy levels were associated with lack of dietary knowledge and is a barriers to adherence to medical regimes in some Hispanics.

Participants in this research study were moderately aware of the cultural foods that caused high blood glucose levels and that eating small but frequent meals was the recommended behavior pattern. Despite this knowledge, participants expressed difficulty in following such a rigid regime because they became hungry when they 
reduced food quantities to recommended levels and, in turn, ate non-healthy, readily accessible snacks they knew would raise their blood glucose levels. They reported a lack of appropriate information regarding the specific types of food to be eaten at each meal and reported confusion regarding identifying carbohydrates as a food group. Aware that many of their favorite foods such as tortillas, arroz, (rice) and frijoles (beans) were grouped into this category, participants requested needing a reference list they could use to keep them on track. Lack of financial resources was also reported as a deterrent to purchasing the fresh fruits and vegetables recommended to be eaten as between meal snacks. These findings with respect to diet and knowledge base have been supported by other researchers (Hatcher \& Whittemore, 2007; Rivera, 2003; von Goeler et al., 2003). Providers and diabetes educators need to consider this ethnic food factor in the educational materials presented.

Thus in the area of diet knowledge, health care practitioners must consider grade level and literacy level in the development and teaching diabetic education classes; the provision of more appropriate information regarding the specific types of food to be eaten at each meal; the development of a reference list to help identify what ethnic foods fit into which food group (especially carbohydrates); recommending ways to satisfy hunger when on a reduced calorie diet; providing better methods to enable patients in understanding portion size; and helping to reduce the cost of fruits and vegetables that are used to satisfy hunger (e.g., planting an indoor or small outdoor garden to grow some of these food items). Despite the lack of acceptable reliability of this subscale, the aforementioned information may be valuable in helping to refine this tool for future use with Mexican American patients with diabetes type 2. 


\section{Exercise Information}

This subscale also demonstrated low reliability. Though participants were able to clearly identify the effects that regular exercise and household chores had upon lowering their blood glucose levels, the lack of scale reliability may be related to the issue of low literacy or to the instrument's lack of acknowledgement of the physical energy expended in household and physically laborious jobs. The fundamental role that exercise plays in maintaining blood glucose is well known and clearly endorsed by the American Diabetes Association (2008b). It is also strongly endorsed at the study site. The participants' score of 25 out of a possible 28 points on this subscale indicated a high level of exercise awareness. An example of comments made by 65 of the 83 participants (78\%) was: "Sabemos bien que hacer ejercicio es una actividad buena para controlar el azucar en la sangre y tenemos que hacerlo por lo menos 5 veces por semana pero, as dificil hacerlo regularmente" - ("We know that exercise is good for controlling blood glucose levels but it is hard to do it regularly.") Does exercise in the diabetes education class include the concept of household and work energy expenditure? The instrument only inquired about formal, structured exercise programs. It is proposed that the high reliability coefficient indicates that participants truly did have knowledge about exercise, yet the scale was not able to reflect the value of alternative energy expenditure in which these participants were engaged. Of interest is these results contrast with those of Honda (2004), who reported that health care providers rarely counseled patients about the value of physical activity. Public health messages have actively advocated incorporating moderate intensity activity as part of a daily exercise routine and have included common household and lifestyle activities in this category (Hendelman, Miller, Baggett, Debold, \& Freedson, 
2000; Pate, Pratt, Blair, Haskell, Macera, Bouchard et al., 1995). There is a need for providers to evaluate patient's level of activity from a broader perspective and patients educated as to the benefits of incorporating or increasing physical activity within the household as well as in the work environment.

Participants experienced problems responding to the Likert scale format and were openly hesitant and often struggled to clearly differentiate the extreme response choices ("strongly") from the lesser values options. Such lack of differentiation can be related to lack of education and low-literacy rates and support findings of other studies who have reported issues with Likert scales with low literacy populations unable to understand the difference between closely related responses (Garcia, Villagomez, Brown, Kouzekanani, \& Hanis, 2001; Lujan, 2008). This issue of low-literacy is one which providers need to consider when using questionnaires as assessment tools. Likert scales may not be appropriate for participants of low literacy. "Yes, no, I don't know" formats may have been appropriate.

Clarifying what providers mean by "exercise" may also help the financiallystrapped patient incorporate alternative, but just as important, activity into their health management plan. Possibly incorporating an activity checklist into the patient assessment could be a better way to evaluate a patient's personal progress, quickly identify deviations, and begin interventions that may get patients back on track with their selfmanagement program.

\section{Motivation}

Motivation, which is essential to maintaining behavior change, consists of two primary components: external and internal factors. Personal motivation relies on 
personal, internal attitudes towards changing one's behavior. Social motivation relies on the external support of others in influencing behavior changes (Ajzen \& Fishbein, 1980; Fishbein \& Ajzen, 1975). Both personal and social motivations are essential to effective adherence in long term treatment programs. In this study the four subscales of diet and exercise attitude and diet and exercise subjective norms were used to capture participant motivation.

Attitudes (Diet)

Though this subscale was reliable $(\alpha=.800)$ in this study, there were concerns raised about the reliability of this scale during the content validity component of the study. Participants' reflected their very positive attitudes about the value of dietary behavior modifications such as eating three small meals every day; as well as the beneficial effects to their health of keeping track of their carbohydrates at each meal. They also considered both eating small regular meals and counting their carbohydrates for the most part a very pleasant thing to do. These participants believed in their ability to change their eating behavior patterns; however, it was the follow through in following the guidelines that became problematic. Insufficient finances restricted consuming the number of meals recommended as well as severely impacted the necessary food content. "Cuando hay comida, sí, podemos, pero cuando no hay que podemos hacer? Tenemos que comer lo que hay". ("When there is food, yes we can, but when there is none what can we do? We have to eat what there is.")

Participants' positive comments about following dietary recommendations and the majority of participants scoring high on the test may simply indicate the success of the teaching strategies used by both the diabetic educator and the health care providers. Of 
concern is whether the high scores could be the result of the participants' giving responses that they knew would create a favorable impression of themselves to the interviewer. This phenomenon, known as social-desirability, is commonly exhibited in persons of low socio-economic status and who consider themselves to be dependent upon the approval of others (Ross \& Mirowsky, 1984). Possibly integrating the Social Desirability Scale into assessing the reliability of instruments used with immigrants could be a way to help account for this phenomenon. Attitudes (Exercise)

Like the Diet Attitude scale, this was a reliable subscale but with concerns about its reliability raised during the content validity component of the study. In general the majority had very favorable attitudes toward physical activity, indicating walking as the principal exercise of choice. Other activities mentioned, however, were salsa dancing, using store bought weights in the home to improve muscle strength and tone and making use of the aerobic exercise programs broadcast on local TV stations. Regular exercise was not only considered a good health option but a pleasant one for the majority of participants both male and female who considered walking to be a stress reliever. It is proposed that these attitude results, with negative skewness, could be attributed to the strong emphasis placed by providers on the beneficial effects of physical activity and the continued reinforcement given to clinic patients by health care providers at their routine follow-up visits; as well as to the strong provider-patient relationship that exists.

Females composed the majority of participants in this particular study $(77 \%$ vs $23 \%$ males) and they had much to say about exercise. "Es el unico tiempo que tengo para mi mismo el resto del tiempo preocupo mi por la familia. Adoro caminar pero no es 
siempre posible porque tengo muchas responsibilidades especialmente cuando tengo que cuidar a mis nietos:" ("It is the only time that I find for myself, the rest of the time I worry about my family. I love to walk but it isn't always possible as I have a lot of responsibilities especially when I have to take care of my grandchildren.") Even though many women mentioned how little time they had to exercise, they were nonetheless aware of how beneficial exercise was in controlling their blood glucose levels and in maintaining good physically and mental health.

Traditional Latina women have been reported in the literature as having a tendency to live sedentary lifestyles and show reluctance to engage in physical activity. These characteristics attributed to low acculturation levels have been shown to result in negative cultural beliefs about performing physical activity and traditional gender based women's roles (Pichon, Arredondo, Roesch, Sallis, Ayala, \& Elder, 2007). The findings in this study, however, despite the identified low acculturation level of the participants, reflect a positive attitude towards physical activity and the health recommendations made by the professionals.

Male participants like their female counterparts, although less emphatic about performing exercise, exhibited similar attitudes regarding the health care benefits findings. This supports the continued emphasis that diabetes educator and health care provider need to adopt in continuously reinforcing the positive benefits of eating small meals at regular intervals, keeping count of carbohydrate intake at each meal and exercising on a regular basis. 
Diet (Social Support) and Exercise (Social Support)

Both scales were reliable $(\alpha=.908)$. These scales assessed the value participants placed on the perceptions and influences of their family members and significant others on managing their diabetes. Familism or familismo features prominently in the MexicanAmerican culture and refers to a set of traditional beliefs and values that govern the family relationships. Drawing upon family members for advice and direction when dealing with health care concerns is a fundamental role of the collective family unit and has been shown to enhance comprehension of complicated subject matter as well as to provide motivational resources (Carbone et al., 2006). For the most part, family members were very supportive of the demands called for in controlling blood glucose levels and ultimately halting progression of diabetic complications. Many had immediate family members with uncontrolled diabetes and were poignantly aware of the dangers of living with uncontrolled diabetes. Having a family member die in Mexico from a blood infection as a result of multiple limb amputations were not uncommon occurrences. It reinforced to the participants that problems are possible with unmanaged diabetes.

The findings of this study thus support the results of previous studies that have identified family support as having a direct influence upon self-care practices (Alcozer, 2000; Beroelos, 2007; Hatcher \& Whittemore, 2007). The relationship between family support, adherence and glycemic control in adults, however, continues to be controversial. It is interesting to note that family support in this study did not seem to be sufficient enough motivation to persuade participants to follow their medical regime. Internal or personal motivational reasons, therefore, may appear to be contributing factors and these will be addressed below. 
Conversely, other studies, have found that no such relationship exists (GleesonKrieg \& Woolley, 2002). Family and support systems serve as external motivators for people. In an effort to effect change in an individual's behavior, the individual must want to do for themselves; they must find an internal motivator. Participants in this study, despite strong family support, were more likely to be non-adherent with their diabetic regime and have unacceptable $\mathrm{HgbAlc}$ levels because they had yet to find that internal motivator to adhere to diet and exercise.

\section{Behavioral Skills}

\section{Diet Behavioral Skills}

The Diet Behavior subscale attempted to measure self-efficacy, i.e. how confident participants felt about controlling their dietary intake by performing such skills as following a dietary plan of consuming small, frequent meals, counting carbohydrates and creating appropriately sized food portions. Although participants considered it "Very Easy" to eat regularly and monitor portion sizes, they were often not able to effectively count carbohydrates and use the Nutrition Facts label on food items to determine the carbohydrate content. Participants reported not having sufficient knowledge and skills to be able to count carbohydrates and read food labels even though they were aware of how important this information was in controlling their blood glucose. Insufficient instruction from health care providers and the diabetic educators was the reason given for this deficit. The findings are consistent with those of other studies that have identified the lack of practical skills among some Hispanic populations with diabetes type 2 (Quatromoni et al., 1994; von Goeler et al., 2003) 
The discovery that participants had such low behavioral skills regarding overall dietary management was surprising, especially as the majority of the participants in the study reported having attended diabetes education classes at the clinic within the past year. Lack of access to diabetes education, therefore, cannot explain the limited dietary behavioral skills reported. Von Goeler et al. (2003) reported that the low educational attainment level found in their study resulted in limited retention of the more complicated concepts of diabetes management which may explain the situation arising in this study. Other possibilities to consider are the quality of the diabetes education classes and linguistic barriers between health care providers both of which have been found to affect the acquisition of appropriate behavioral skills necessary to control and monitor blood glucose levels (Lipton et al., 1998). Exercise Knowledge and Exercise Behavioral Skills

These scales ascertained knowledge the participants had about exercise, the ease with which participants would perform exercise, and how effective they considered physical activity in general to be when performed alone or with a companion. Explanations for the high awareness and skill level of participants can be attributed to the emphasis placed by health care providers in the clinic on the benefits of exercise in lowering blood glucose levels and reducing diabetes related complications.

Many participants reported having at least one family member with diabetes and commented on how familiar they were with the benefits of exercise in diabetes management. Following a regular plan of exercise such as walking for over 30 minutes per day, to many, was far more accessible goal than altering their eating habits. Many participants also remarked on how exercise reduced their stress level and that this was an 
activity in which they could involve other members of the family. Those with young family members reported walking them to and from school on weekdays and taking more leisurely walks on the weekend with additional family members that wished to participate. The few participants in this study that reported a low interest in physical activity gave reasons such as arthritis pain, lack of motivation and poor weather for their reluctance to exercise, findings which are consistent with results of other studies with Hispanic communities (Rosal, Goins, Carbone, \& Cortes, 2004).

For the majority of participants, therefore, regular exercise was considered to be an important component of their self-management regime, findings which are similar to those of Jezewski \& Poss (2002). However, gender differences were apparent in how feasible such practices were in reality which could possibly be the result of the instrument's lack of sensitivity in valuing the "exercise" of men and women participating in household chores or physically laborious jobs? Many men reported lack of time as a barrier to engaging in regular exercise due to heavy work schedules and family commitments. Women, on the other hand, were more prone to participate in regular physical activity and reported allocating time to do so by walking children to and from school in order to help lower their weight and to control their glucose levels. Other women reported doing additional exercise by watching and participating in televised exercise programs. They often combined these less active methods with weight training to strengthen muscles or engaged in vigorous housework activities such as mopping floors, making beds, dusting and gardening.

A few participants were not actively involved in some form of physical activity and reported they were unable to perform exercise because of chronic health problems 
i.e. such as arthritis, and lack of safety. These findings correlate with those of Kieffer et al. (2002). The present study supports the results of similar studies in identifying time constraints as a common barrier inhibiting men from getting involved in regular exercise. The women in this study, despite their low acculturation and traditional roles in the home were finding ways to incorporate changes in their family diet and discovering creative ways to take part in exercise as advised by health care providers. As mentioned before, providers and educators need to explore alternative activity/exercise options in which patients can engage. Keeping active and expending calories is the key, not necessarily achieving extreme fitness.

\section{Behavior}

\section{Reading Food Labels Behavior}

A reliable subscale, this one assessed how often participants actually read food labels over the past 30 days. Most of the participants did not engage in reading labels and their explanation was that very little of the food items they consumed bore nutritional food labels. Many of the women reported shopping for fresh produce such as fruit and vegetables, milk, tortillas, and other items which they purchased from local markets in their communities where they found favorable prices. When they did have to buy supplemental processed food items (which were often more expensive) reasons given for not reading nutrition food labels were low-literacy, poor eye sight and difficulty reading the small print on the labels. Non-Spanish labels on food items and insufficient instruction regarding salient points to identify on the labels were also reported as barriers to dietary adherence. Given the importance of this knowledge in controlling blood glucose, health care advocates could solicit for the production of food labels in Spanish, 
in larger print, and in simpler language. Diabetic educators should consider including this skill in the teachings they offer so people with diabetes have the skill sets necessary for them to achieve glucose control.

\section{Dietary Adherence}

This reliable scale determined how often participants adhered to the general diabetic diet plan. The majority of the participants did not closely follow the dietary regime recommended by their health care provider. They saw the dietary plan as restrictive, complicated and often left them feeling hungry. These participants also felt overwhelmed by the number of food items they were told they could not eat and thought it difficult and confusing to have to constantly think about what to eat at each meal. Some participants expressed difficulty in preparing meals that their family would accept. Comments like "My husband works as a gardener and is outside all day. When he comes home he just wants to eat normal food not what I am supposed to eat." exemplified the difficulty many of the women experienced. Requests for more specific information about precisely what could be consumed and recipes that would help them prepare healthier meals were frequent.

Lack of finances was another particular barrier to following a healthy diet. Beans, grains and tortillas for the most part could be purchased cheaply. Fresh fruit and vegetables on sale at local markets could also be obtained cheaply. Purchasing sufficient meat for the family was often very expensive Participants commented on the difficulty of preparing meals that were both healthy and filling. Consuming small portions of recommended foods such as meat, fish, vegetables and a few tortillas often left them feeling hungry and dissatisfied such that food was on their mind until the next meal. "We 
Mexicans like our tortillas and beans" one participant commented "But we are asked not to eat them now, which is impossible!" Other comments made reference to the influence that children in the home can have upon food options. A few participants commented on how their children's' dietary preferences negatively affected their food purchases and their resolve to follow dietary plans. "Tener que cocinar comidas diferentes para mi porque mis hijos y esposo no comen lo que yo como, lo hace bien dificil para mi seguir lo que el doctor me dice a mi que haga." ("Having to cook separate meals for myself because my children and my husband will not eat what I eat makes it very difficult for me to follow what the doctor has told me to do.") Conversely some participants reported having young family members who were very amenable to following a healthy eating plan being motivated by nutrition and health classes that they had been exposed to at school.

These conflicting results are supported by findings from other studies (Arcury, Skelly, Gesler, \& Dougherty, 2004; Hampl \& Sass, 2001; von, Goeler et al., 2003; Wen, Shepherd, \& Parchman, 2004). As a result of the findings from this scale it would he fitting for both health care providers and diabetic educators to be sensitive to the literacy levels of their patients in order to provide them with information appropriate to their level of understanding. To supply specific information regarding dietary options, a one-on-one visits or family group consultations with a registered dietician would be an asset to any patient on a diabetes self management program. A finely tuned and more appropriate diet could, therefore, be devised through collaboration with the family as a unit. 
Exercise Adherence

This scale asked participants how many of the last 7 days they participated in at least 30 minutes of physical activity and participated in a specific exercise session other than household or work activities. Participants' actual scores on this scale indicated they were not participating in regular exercise even though they were aware of the beneficial effects of doing so. These findings support the hypothesis drawn from the other subscales related to exercise - the participants aren't doing "formal/structured" exercise programs and the reasons why have been sufficiently elaborated upon.

These exercise findings are consistent with previous studies that have reported relatively low rates of physical activity in Latinos (Terre, 2007; Wen et al., 2004). It is not too difficult to understand why this dimension of the tool was so different from the other exercise dimensions. Female participants in particular have been identified in previous studies as tending to live sedentary lifestyles and not engaging in physical activity (Marquez \& McAuley, 2006; Pichon et al., 2007). Some of the perceived barriers to physical activity mentioned in this study were time constraints and women's roles as caregiver and homemaker. Many women reported having to care for family members which together with their other multiple role responsibilities added to their constant state of fatigue and tiredness that contributed to their lack of motivation to exercise on a routine basis. An additional cultural factor that needs to be considered particularly in Latina women is that of body weight. Among women in the U. S. culture a primary motivator for engaging in physical activity if to obtain a slimmer figure. As less acculturated Latinas have a slightly heavier body weight than more acculturated Latinas, the motivation to exercise in order to lose weight and be slimmer may not be 
such a driving force to promote physical activity (Ayala, Mickens, Galindo, \& Elder, 2007; Olvera, Suminski, \& Power, 2005).

Both external and internal factors were mentioned as barriers to regular exercise. Both male and female participants had concerns about neighborhood safety, weather, transportation and the cost of a structured exercise sessions. However, internal factors seemed to be mentioned most frequently with participants commenting on a feeling of sluggishness, or laziness which dampened their desire and motivation to exercise, especially after a long day at work. Men in particular related a lack of energy and internal motivation due to their heavy daily occupational activities. Resolving these issues to promote an increase in physical activity for our Hispanic population is a formidable challenge for health care providers with scant resources. Participants' solutions to managing these issues were to offer transport to and from exercise classes that were currently being held on a regular basis at the clinic and the organization of walking groups. The provision of child care at these events was also suggested.

\section{IMB Scores and Gender}

The study findings indicate that the women had greater knowledge about how to control and regulate their eating habits than men. They also read food labels more frequently, and tended to be more active and exercise on a more regular basis. This difference could be attributed to the traditional gender roles within Latino families where women stay at home to attend to childcare responsibilities (Marquez, McAuley, \& Overman, 2004; Juarbe, Turok, \& Perez-Stable, 2002. The traditional Latino male role of machismo means men are providers and protectors of their family, never weak or sickly, with their work role usually one involving heavy physical labor which does not require 
that one also participate in additional exercise programs as leisure time is so limited (Marquez \& McAuley, 2006;).

The traditional female dominance in the kitchen and household can positively affect the family's meal choices. The women in this study discussed their role in food preparation in the household and they were more likely to read food labels, if they could, when choosing appropriate foods. Diabetic women were also more likely to control their own diet and were able to achieve overall lower HbAlc scores, even though these still in the suboptimal range, than the diabetic men who either depended on their wife or themselves to prepare their meals. If the wife was not a diabetic and had not received any of the diabetic education her understanding of what her husband required in a healthy diet was limited. Men reported difficulty in following their diet while at work where they were exposed to mobile "lunch trucks" with high carbohydrate and high fat meals, or "fast food" restaurants that also offer high carbohydrate and high fat meal options at economical prices. These findings support the results from other research studies (Wong, Gucciardi, Li, \& Grace, 2006) and indicate the need for family members to be included in patient visits and diabetes education classes to encourage greater support for identifying food options when confronted with cultural practices, financial constraints, and work settings.

Women in the study who were able to incorporate regular physical activity into their routine reported that they were able to do so because they accompanied small children to and from school each day which enabled them to exercise through walking. Others reported performing vigorous household activities, watching televised exercise programs, and attending occasional dance classes to satisfy their exercise requirement. 
These findings are consistent with those of another study that had identified these types of physical activities in Latina women (Juarbe et al., 2002). The majority of men in this study reported heavy daily workload commitments and long hours as reasons for their lack of motivation to exercise regularly, as well as their belief that their work activity was sufficient to meet the "exercise" requirement. Regardless of gender, heavy and vigorous work activities can be just as effective in burning calories and maintaining weight as formal/structured exercise programs (Crespo, Smit Carter-Pokras, \& Anderson, 2001; King, Castro, Eyler, Sallis, \& Brownson, 2000; Marquez et al., 2004).

The findings from this study suggest that acculturation may play an important role in the physical activity of Latinos. There are a variety of factors that influence these low observed rates of physical activity, including acculturation and occupation. With the low level of acculturation of the study participants and the large proportion of homemakers among the females, there is little surprise that low rates of formal/structured physical activity were reported. Consistent with previous studies, particular barriers to performing regular exercise were gender- based childcare and household responsibilities, personal health, and both external and internal factors (Juaarbe, Turok, \& Perez-Stable, 2002). Additional factors that have been found to influence physical activity include selfefficacy, social support, and lack of education about the importance of physical activity (Marquez et al., 2004). These concepts were all assessed by appropriate subscales of the IMB-DSC questionnaire and participants were found to score moderate to high in all aspects.

With many Hispanic women traditionally actively engaged in vigorous household duties and Hispanic men traditionally employed in physically demanding occupations 
such as gardening and construction work outside the family domain, the concept of performing regular exercise in one's leisure or free time when there are no responsibilities to anyone or anything may not exist (Tortolero et al., 1999). A consideration for health care providers, therefore, is how to reconceptualize the measurement of physical activity. According to current literature, Latinos appear to be more sedentary than their non-Latino counterparts as they do not appear to participate in leisure time physical activity (LTPA), which is defined as being "activity undertaken in the individual's discretionary time that leads to any substantial increase in the daily energy expenditure" (Bouchard \& Shephard, 1994). The non-LTPA forms of physical activity in which they participate, e.g., heavy occupational activity, may satisfy the prescribed physical activity requirements. Given that public health messages have advocated that common household and lifestyle activities qualify as moderate-intensity forms of exercise and that the American Diabetes Association promotes moderate amounts of daily activity in controlling blood glucose levels, health care providers need to be more attuned to the role that heavy occupational activity in Hispanics plays in monitoring blood glucose (Eyler, Baker, Cromer, King, Brownson, \& Donatelle, 1988; Eyler, Wilcox, Matson-Koffman, Evenson, Sanderson, Thompson, et al., 2002)).

A weakness, therefore, in the IMB instrument is the lack of sensitivity to cultural gender role responsibilities and its influence on diet and exercise. Cultural foods, available food choices in a work setting, walking activities when caring for children, and manual labor activities need to be considered in the diabetic education provided to Mexican-Americans and their family. 


\section{Participant Interviews}

The interview portion of the study provided important insight into the problems and concerns of the participants in the self-management of their diabetes type 2 . Participants believed that retaining connections to their cultural heritage was important because of the ease with which medication could be bought in Mexico to control diabetes; however, instructions and education given when dispensing the medication were often inadequate. Also they found adherence difficult because of the cultural conflicts with the restrictive diet and exercise plans recommended.

Many used home remedies in combination with their prescribed medications. They believed that these natural and milder medicinal forms were as beneficial to them as the Westernized medications. They used both medications one in conjunction with the other. Participants also commented that often they stopped taking their prescribed medication entirely in favor of the herbal remedies because of the low blood glucose level that resulted when both were taken together. "I'm too embarrassed to tell the doctors just in case they get angry with me "remarked one participant. "Y por eso yo le digo nada," ("And so I don't say anything"). The most common herbal remedy used by participants was nopal, the leaf of the prickly pear cactus that participants either prepared as a shake taken at least once a day in the morning or eaten as a vegetable with the afternoon or evening meal.

The interview portion of the study also provided insight into the participants' support of the care they received in the U.S. but there were both problems and benefits. They believed that there was greater access to care and qualified health care providers in the U.S. These participants were motivated by health care providers that they felt 
demonstrated simpatia or kindness and with whom they could form a connection. They were put off and intimidated by those providers who threatened them (e.g., threatening the use of insulin should they not follow directions).

This information was important to these participants in their ability to form a relationship with their health care provider. Personalismo, which relates to the character of the relationship that exists between the patient and provider is important to Latinos, who generally prefer being closer spatially to each other than do Caucasians.

Experiencing a friendly gesture in a clinical situation, such as touching one's shoulder or hand during an encounter, is viewed as a way of developing a relationship with someone that the patient views as an authority figure and fosters a trust which promotes adherence to treatment (Antshel, 2002).

The education classes, "platicas, "served to reinforce the dietary and exercise information given to them by the health care providers. Participants felt comfortable when health care providers invited their families to become involved in their care and suggested that families be invited to the platicas so that they could hear directly what was involved in the dietary and exercise modifications recommended to them. These results are well supported by current literature which confirms the strong influence that family support has on improving adherence particularly in Latino populations where the effects of familia or family influence many health care decisions (Antshel, 2002; Oomen et al., 1999; von Goeler et al., 2003).

It follows that more emphasis needs to be placed on instruction aimed at improving the skill level of this population in reading food labels, counting carbohydrates and controlling portion size. Suggestions from participants included small group sessions 
where they could interact more closely with the diabetes educator and where they could work at their own pace and feel less intimidated in asking for clarification of ideas that they may not have grasped initially. Family participation was also reiterated as participants thought that they would receive more support on this topic if family members were also involved in the learning process. These findings relate directly to familismo and the impact and influence that the family has upon decision-making and social support when managing treatment options.

The classes did not cover in enough detail how to count carbohydrates, how to read nutrition labels on food items and how to actually prepare appropriate healthy meals. They recommended that more time be spent in education classes on helping to formulate a reasonable meal plan that they could follow. They also recommended cooking classes with information booklets prepared in a simple and clear manner with an emphasis on graphic presentation. The findings correlate well with other studies involving populations that have low-literacy levels (Rosal et a., 2004).

Overall the greatest issues were around their poor reading level which made it difficult for them to understand written materials that were handed to them. Also the lack of effective communication and their inability to fully express their concerns and problems to their health care providers in their own language. Language barriers hindered a close relationship with the health care provider such that many participants reported being too embarrassed to tell health care providers that they could not read and sometimes left the clinic not fully understanding the information given them or not being able to express their true practices and fears. Participants reported that the skills that they had acquired here in the U.S, such as choosing appropriate food options, portion control, 
regular eating patterns, and exercise regimes were not readily available to them in Mexico.

In general, many participants did not feel confident to carry out these specialized skills, especially as they were unable to discuss these issues in regular visits with their provider due to time constraints and cultural reserve. Even though the majority of participants realized that acquiring the skills of reading food labels, counting carbohydrates and portion control would have an impact on controlling their blood glucose levels, they were not fully aware of the extent to which acquiring these skills could be of benefit to them. The reluctance to carry out the behaviors was in part a result of lack of sufficient knowledge about skills which were considered specialized and feeling uncomfortable asking providers about the details of performing such activities.

Validity and Reliability of the IMB-DSC Scale

The Information- Motivation- Behavioral Skills Diabetes Self-care scale (IMBDSC) was evaluated to determine its use as a tool to identify gaps in diabetes-related diet and exercise knowledge, motivational influences and behavioral skill practices. Results of the study indicate the following: 1) These Mexican-Americans had difficulty identifying the high carbohydrate ethnic foods. 2) They did not know how to read and interpret food labels so as to choose better foods. 3) They had difficulty reducing the calorie intake and satisfying their hunger. 4) They had difficulty preparing the prescribed diet because family members won't eat the more nutritious meal. 5) It was difficult to afford the recommended foods with limited finances. 6) They were knowledgeable about the importance of exercise in managing diabetes but are often hampered by other family responsibilities or their compromised health state. 7) They had a low literacy ability 
which affected their comprehension of information taught in diabetic classes and their ability to read labels and count carbohydrates. 8) They had strong family support systems but little internal motivators to adhere to diet and exercise regimens. 9) Women participated in regular exercise more often than men and were more adherent with their diet.

The IMB-DSC instrument's reliability in this study is questioned. Reliability refers to the consistency with which the tool is able to measure the characteristic being studied and validity refers to the degree to which the instrument measures that attribute. (Polit \& Beck, 2008). In this study Cronbach alpha score was used to evaluate each of the constructs in each of the 11 subscales to determine the internal consistency reliability. The alphas for the subscales ranged from $.227-.908$ as shown in Table 1. Issues around reliability appeared to be related to (1) the discomfort and difficulty felt by participants of low literacy and educational levels in responding to Likert scale-type questions; (2) the effects of social desirability in which participants give socially-desirable responses or the 'right' answers to put on a "good face;" and (3) possible measurement error by having to read the questions to the participants which could have influenced their response. The overall scale, therefore, in its original form with this specific Mexican-American community, has questionable utility with this population in assessing and identifying barriers to diabetes self management.

The lessons learned from this instrument review were: 1) it is important to clarify the question being asked; 2) define the terms being assessed; 3) incorporate a reading level appropriate to the population; 4) consider gender differences and cultural role responsibilities when interpreting results; 5) consider the context of each component of a 
scale and examine how one component correlates to other similar components before making final judgments; 6) limit redundancy of questions in a tool so as not to lead the respondent; and 7) explore alternatives to the typical Likert scale when working with immigrants. The implications of this study suggest that many factors contributed to the reliability problems evident with the IMB-DSC instrument and when there are literacy problems, comprehension problems, and external and internal barriers, there is an increased risk of poor dietary and exercise behavior and $\mathrm{HbAlc}$ values above the recommendations American Diabetes Association (2009).

Conclusions

The primary purpose of this study was to evaluate the reliability and content validity of the IMB-DSC scale and appraise its use as an assessment tool for identifying gaps in diabetes knowledge, motivational influences and other self-management practices among a population of Mexican-American women and men. The present study assessed a questionnaire originally designed for type 2 diabetics of Puerto Rican ancestry living in the southeastern United States (Osborn, 2006). The results of the present study indicate that, in its current form, the questionnaire is not as reliable of an assessment tool as one would like for low-literacy Mexican-Americans with diabetes type 2. An accurate assessment instrument for this population is highly essential, as it is an integral component of any effective diabetes self-management program.

The findings of this research have uncovered some of the gaps in the delivery process of diabetes care that directly hinder Mexican-Americans in their quest to successfully manage their diabetes type 2 and have revealed the important role of cultural traditions in this population. 
The study revealed that this particular sample of Mexican-American diabetics retained strong links to their cultural attitudes and beliefs. It revealed deficiencies in several important aspects of diabetes self-management, particularly problems reading food nutrition labels, counting carbohydrates and controlling portion size. Some of the problems appear to be related to the low literacy level of the group, which negatively impacted the transfer of information between health care provider and patient. There is still a distinct need for a comprehensive and reliable assessment tool able to identify barriers to DSM in a population with low literacy and acculturation rates.

\section{Clinical Implications}

The results of this study support previous work (Carbone et al., 2006, Quatromoni et al., 2003; Rosal et al., 2004, von Goeler et al., 2003) in that many patients are lacking in sufficient knowledge, adequate motivation and behavioral skills to enable them to eat appropriately and be physically active. Low literacy levels contribute to the confusion about what constitutes an appropriate diet, and the effect of foods upon blood glucose levels and portion sizes. The present study yielded some new and interesting insights on the effective delivery of DSM education. Several of these insights could be incorporated into health care practice guidelines in similar populations. Participants appeared to be lacking at all of the basic component levels of the IMB model: knowledge, motivation, and behavioral skills. Their overall HBAlc levels exceeded the national average reported by the American Diabetes Association (2008) of 8.3. Deficiencies with regard to reading food labels, counting carbohydrates and managing portion control were identified barriers to achieving a appropriate diet and effective glucose control. 
The services of a nutritionist or an individual competent in nutritional education should be incorporated into diabetes management programs. Comments made by patients about the importance of the provider-patient relationship support the conclusions of Rosal et al. (2004). Providing health care services and education in a manner that promotes a trusting, warm relationship is an essential goal in all areas of health care. Patients express themselves more openly and with less embarrassment when treated in a friendly and non-intimidating fashion, whether on an individual basis or in a group or family session.

The majority of patients had an average of a third grade education. To overcome this limitation, the diabetes educator may need to use alternative teaching methods and materials that consisting of more graphic presentations. Family support and active involvement in education classes should be encouraged and promoted. The use of peer speakers to motivate self efficacy and the exposure of patients to practical demonstrations of preparing food, reading food labels, and measuring food portions would actively engage them in their daily routine.

As few participants actually exercised on a regular basis regardless of their awareness of the benefits in lowering their blood glucose, strategies need to be implemented that can encourage and motivate patients to perform some form of physical activity. Yoga, and dance classes as well as walking clubs could be instigated by peer volunteers or even student health care providers.

Many providers are already aware of the importance of providing culturally specific and sensitive care, however, individual assessment through reliable and valid 
culturally specific assessment tools will allow them to fine tune and "tailor" programs to the needs of the patient.

\section{Limitation of the Study}

The several limitations of this study should be noted. 1) The sample size was not particularly large $(\mathrm{N}=83)$. 2) The study participants were recruited from a small community clinic and the results may not be generalizable to other populations of Mexican-Americans. 3) The acculturation scale used in the IMB questionnaire consisted of only five questions, which, based on other studies, may not provide an adequate measure of acculturation. 4) The participants in this study had difficulty understanding the questions and differentiating extreme responses on the Likert type subscales. 5) Bias may have resulted from the fact that the survey was conducted at the same clinic where the participants received their medical care and their responses were influenced by their fear that medical care would otherwise be withheld. 6) Bias may have also resulted by the need for the researcher to read the questions to many of the participants and such reading could have influenced the response.

The descriptive study provides a platform for further research into the use of the IMB model in diabetes studies. Use of the instrument however, has highlighted areas that need to be improved:

1. A full acculturation scale needs to be incorporated into the questionnaire so that the acculturation level of the population group under study can be adequately assessed.

2. The reading level of the questionnaire needs to be lowered to that of a level appropriate to the study population. 
3. The questionnaires should be kept as brief as possible, while still covering essential material.

4. When conducting interviewer or self-administered questionnaires with MexicanAmericans of low literacy, the "yes, no, and I don't know" format for responses should be used whenever possible.

5. Formulating the questionnaire so that regardless of whether the questions are actually repetitive or not, they should not appear to be repetitive.

6. When administering the subscales that require attitudinal responses in the form of Likert scale, the technique used by Brown, Garcia, et al. (2002) might be more effective. The researcher asks participants whether they agree or disagree with a statement. Depending upon the response a more refined choice is offered. At that point, the participant may choose either "slightly agree" or "definitely agree" if the initial choice is agree and "slightly disagree" or definitely disagree" if the initial choice was disagree.

Despite its limitations, the questionnaire did identify several important aspects of self-management in this particular population of Mexican-Americans. It revealed shortcomings in patient awareness concerning several areas of dietary control, specifically controlling portion size, reading food labels and counting carbohydrates. The need for better support systems to provide motivational strategies and encourage patients to participate in some form of physical exercise was also recognized. The importance of the family environment and the nature of the patient-provider relationship in promoting open communication needs to be addressed by all health care providers. Strategies must 
be adopted which allow for collaborative practice and the incorporation of discussion about alternative treatment options. 


\section{REFERENCES}

Abraido-Lanza, A. F., White, K., \& Vasques, E. (2004). Immigrant populations and health_Newbury Park, CA: Sage.

Abu-Lebdeh, H. S. (2007). Diabetes mellitus and other metabolic disorders. In P. M Camacho, H. Gharib, \& G. W. Sizemore (Eds.), Evidence-Based Endocrinology, Philadelphia: Lippincott.

Acury, T. A., Skelly, A. H., Gesler, W. M., \& Dougherty, M. C. (2004). Diabetes meanings among those without diabetes: Explanatory models of immigrant Latinos in rural North Carolina. Social Science \& Medicine, 59, 2183-2193.

Adams, C. R. (2003). Lessons learned from urban Latinas with type 2 diabetes mellitus. Journal of Transcultural Nursing_14, 255-265.

Ajzen, I. (1990). Attitudes, personality, and behavior. Chicago: Dorsey Press.

Ajzen, I., \& Fishbein, M. (1980). Understanding attitudes and predicting social behavior. Englewood Cliffs, NJ: Prentice-Hall.

Ajzen, I. \& Madden, J.T. (1986). Prediction of goal directed behavior: Attitudes, intentions and perceived behavioral control. Journal of Experimental Social Psychology. 22, 253-274.

Albarracin, D., Johnson, B. T., Fishbein, M., \& Muellerleile, P. (2001). Theories of reasoned action and planned behavior as models of condom use: A meta-analysis. Psychological Bulletin, 127, 142-161. 
Albarracín, D., Kumkale, G. T., \& Johnson, B. T. (2004). Influences of social power and normative support on condom use decisions: A research synthesis. Aids Care, 16, 700-723.

Alberti, G., Zimniet, P., Shaw, J., Bloomgarden, Z., Kaufman, F., \& Silink, M. (2004).

Type 2 diabetes in the young: The evolving epidemic. The International Diabetes Federation Consensus Workshop. Diabetes Care, 27, 1798-1811.

Alcozer, F. (2000). Secondary analysis of perceptions and meanings of type 2 diabetes among Mexican American women. TheDiabetes Educator, 26, 785-795.

American Association of Clinical Endocrinologists. (2007). Medical guidelines for clinical practice for the management of diabetes mellitus. AACE Diabetes Mellitus Guidelines, Endocrine Practice, 13(Suppl 1).

American Diabetes Association. (2007a). Standards of medical care in diabetes. Diabetes Care 30(Suppl. 1), S4-S41.

American Diabetes Association. (2007b). Clinical Practice recommendations. Diabetes Care 30(Suppl.1), S1-S103.

American Diabetes Association. (2007c). Economic costs of diabetes mellitus in the U.S. in 2007. Diabetes Care, 31, 596-615.

American Diabetes Association. (2007d). Diabetes Statistics. Retrieved August $31^{\text {st }} 2008$ from http://www.diabetes.org/diabetes-stistics.jsp.

American Diabetes Association. (2007e). Diagnosis and classification of diabetes mellitus. Diabetes Care, 30(Suppl. 1), S42-S47.

American Diabetes Association. (2008a). Standards of Medical Care in Diabetes. Diabetes Care 31(Suppl. 1), S12-S54. 
American Diabetes Association. (2008b). Nutrition principles and recommendations.

Diabetes Care 27(Suppl. 1), 536-546.

American Diabetes Association. (2008c). Standards of medical care in diabetes. IV.

Prevention/delay of type 2 diabetes. Diabetes Care, 31(Suppl. 1), S12-S54.

Antshel, K. M. (2002). Integrating culture as a means of improving treatment adherence in the Latino population. Psychology, Health \& Medicine, 7, 435-449.

Arcury, T. A., Skelly, A. H., Gesler, W. M., \& Dougherty, M. C. (2004). Diabetes meanings among those without diabetes: Explanatory models of immigrant Latinos in rural North Carolina. Social Science \& Medicine, 59, 2183-2193. Ayala, G. X., Mickens, L., Galindo, P., \& Elder, J. P. (2007). Acculturation and body image perception among Latino youth. Ethnicity and Health, 12, 21-41.

Bacardi-Gascon, M., Rosales-Garay, P., \& Jiménez, A. (2004). Effect of diabetes intervention programs on physical activity among migrant Mexican women with type 2 diabetes. Diabetes Care, 27, 616.

Bandura, A. (1986). Social foundations of thought and action: A social cognitive theory. Englewood Cliffs, NJ, Prentice-Hall.

Bandura, A. (1989). Perceived self-efficacy in the exercise of control over AIDS infection. In Mays, V. M., Albee, G. W. and Schneider, S. F. (Eds), Primary Prevention of AIDS: Psychological Approach, (pp. 28-141). Newbury Park, CA: Page.

Bandura, A. (1994). Social cognitive theory and exercise control of HIV infection. In "R. J. DiClemenmte \& J. L. Peterson (Eds.), Preventing AIDS: Theories and methods of behavioral interventions (pp.25-59). New York: Plenum. 
Barron, F., Hunter, A., Mayo, R., \& Willoughby, D. (2004). Acculturation and adherence: Issues for health care providers working with clients of Mexican origin. Journal of Transcultural Nursing, 15, 331-337.

Bates, L.M., Acevedo-Garcia, S.M., Alegría, M., \& Krieger, N. (2008). Immigration and Generational Trends in Body Mass Index and Obesity in the United States: Results of the National Latino and Asian American Survey, 2002-2003. American Journal of Public Health, 98, 70-77.

Benavides-Vaello, S., Garcia, A. A., Brownm S. A., \& Winchell, M. (2004). Using focus groups to plan and evaluate diabetes self-management interventions for Mexican Americans. Diabetes Educator, 30, 242-238.

Bereolos, M. N. (2007). The Role of Acculturation in the Health Belief Model for Mexican-Americans with Type II Diabetes. (UMI No. 3288243).

Berry, J. W. (1990). Psychology of acculturation: Understanding individuals moving between cultures. In R. W. Brislin (Ed.), Applied cross-cultural psychology (pp. 232-252). Newbury Park, CA: Sage.

Bouchard, C., \& Shepherd, R. J. (1994). Physical activity, fitness, and health: The model and key concepts. In C. Bouchard, R.J. Shephard, \& T. Stephens (Eds.). Physical activity, fitness, and health. Champaign, IL: Human Kinetics.

Boyle, J. P., Honeycutt, A. A., Narayan, K. M., Hoerger, T. J., Geiss, L. S., Chen, H. \& Thompson, T. J. (2001). Projection of diabetes burden through 2050: Impact of changing demography and disease prevalence in the U.S. Diabetes Care, 24, 1936-1940. 
Brown, S. A. (1999), Interventions to promote diabetes self-management: State of the science. Diabetes Educator, 25(Suppl.), 52-61.

Brown, S. A., Duchin, S. P., \& Villagomez, E. T. (1992). Diabetes education in a Mexican American population: Pilot testing of research-based videotape. Diabetes Educator, 18, 47-51.

Brown, A. F., Gerzoff, R.B., Karter, A.J., Gregg, E., Safford, M., Waitzfelder, B., Beckles, G.L. Brusuelas, R, \& Mangione, C.M. (2003). Health behaviors and quality of care among Latinos with diabetes in managed care. American Journal of Public Health 93, 1694-1698.

Brown, S. A., Becker, H. A., Garcia, A. A., Barton, S. A., \& Hanis, C. L. (2002). Measuring health beliefs in Spanish-speaking Mexican Americans with type 2 diabetes: Adapting an existing instrument. Research in Nursing and Health. 25, 145158.

Brown, S. A., Blozis, S. A., Kouzekanani, K., Garcia, A. A., Winchell, M., \& Hanis, C. L. (2007). Health Beliefs of Mexican Americans with Type 2 diabetes. The Starr County Border Health Initiative. Diabetes Educator, 33, 300-308.

Brown, S. A., Garcia, A. A., Kouzekanani, K., \& Hanis, C. L. (2002). Culturally competent DSM education for Mexican-Americans. Starr County Border Health Initiative. Diabetes Care, 25, 259-268.

Brown, S. A., Harris, R. B., Villagomez, E. T., Segura, M., Barton, S. A., \& Hanis, C. L. (2000). Gender and treatment differences in knowledge, health beliefs, and metabolic control in Mexican-Americans with type 2 diabetes. The Diabetes Educator, 26, 425-438. 
Brunton, S., Carmichael, B., Funnell, M., Lorber, D., Rakel, R., \& Rubin, R. (2005). Type 2 diabetes: The role of insulin. The Journal of Family Practice, 54(Suppl.), $445-452$.

Caballero, A. E. T. \& Tenzer, P. (2007). Building cultural competency for improved diabetes care: Latino Americans and diabetes. The Journal of Family Practice (Suppl.), S21-S30.

Caban, A. \& Walker, E. A. (2006). A Systematic Review of Research on Culturally Relevant Issues for Hispanics With Diabetes. The Diabetes Educator, 32, 584-595.

Candib, L. M. (2007). Obesity and diabetes in vulnerable populations: Reflection on proximal and distal causes. Annals of Family Medicine, 5, 547-556.

Carbone, E. T., Rosal, M. C., Torres, M. I., Goins, K. V. \& Bermudez, O. I. (2007). Diabetes self-management: Perspectives of Latino patients and their health care providers. Patient Education and Counseling, 66, 202-210.

Centers for Disease Control and Prevention. (2005). National diabetes fact sheet: National estimates and general information on diabetes in the United States. Atlanta, GA.

Centers for Disease Control and Prevention (2007a). Clinical practice recommendations. Diabetes Care 30(Suppl. 1), 1-103.

Centers for Disease Control and Prevention (2007b). National diabetes fact sheet: National estimates and general information on diabetes in the United States. U.S. Department of Health and Human Services, Atlanta, GA.

Centers for Disease Control and Prevention (2008). Press Release: Number of People with diabetes increases to 24 million. Retrieved August $29^{\text {th }} 2008$ from 
http://www.cdc.gov/print.do?url=http\%3A

//www.cdc.gov/media/pressrel/2008/r080624htm

Charles, M. A. (Ed). (2002). Type 2 diabetes mellitus. Manual of Endocinology and Metabolism. Philadelphia, Lippincott Williams \& Wijkins.

Chilton, L. Hu, J. \& Wallace, D. C. (2006). Health-Promoting Lifestyle and Diabetes Knowledge in Hispanic American Adults. Home health Care Management Practice, $18,378-385$.

Coronado GD, Thompson B, Tejeda S, Godina R. (2004) Attitudes and Beliefs among Mexican Americans about Type 2 Diabetes. Journal of Health Care for the Poor and Underserved, $15,576-588$.

Crespo, C. J., Smit, E., Carter-Pokras, O. \& Anderson, R. (2001). Aculturation and leisure-time physical inactivity in Mexican-American adults: Results from NHANES III, 1988-1994. American Journal of Public Health, 91, 1254-1257.

Cuellar, I.., Arnold, B., \& Maldonado, R. (1995). Acculturation Rating Scale for Mexican-Americans - II: A revision of the original ARSMA Scale, Hispanic Journal of Behavioral Sciences, 17, 275-304.

Daniulaityte, R. (2004). Making sense of diabetes: Cultural models, gender and individual adjustment to Type 2 diabetes in a Mexican community. Social Science and Medicine. 59, 1899-1912

Davidson, M. B., Ansari, A. \& Karlan, V. J. (2007). Effects of a Nurse-Directed Diabetes Disease Management Program on Urgent Care/Emergency Room Visits and Hospitalizations in a Minority Population. Diabetes Care, 30, 224-227 
Deakin, T., McShane, C. E., Cade, J. E., \& Williams, J. E. (2005) Group based training for self-management strategies in people with type 2 diabetes mellitus. Cochrane Database of Systemic Reviews 2005, Issue 2

Devlin, H., Roberts, M., Okaya, A., \& Xiong, Y.M. (2006). Our lives were healthier before: Focus groups with African-American, American Indian, Hispanic/Latino, and Hmong People with diabetes, Health Promotion and Practice, 7, 47-55.

Diabetes Control and Complications Trial Research Group. (1993). The effect of intensive treatment of diabetes on the development and progression of long-term complications in insulin-dependent diabetes mellitus." New England Journal of Medicine, 329, 977-986.

Diabetes Control and Complications Trial Research Group. (1996). Lifetime benefits and costs of intensive therapy as practiced in the diabetes control and complications trial. Journal American Medical Association, 276, 1409-1415.

Dunstan, D. W., Daly, R. M., Owen, N., Jolley, D., Courten, M., Shaw, J., \& Zimmet, P. (2002). High-intensity resistance training improves glycemic control in older patients with type 2 diabetes. Diabetes Care, 25, 1729-1736.

Edelman, S. \& Kim, D. (Eds.). (2002). Diabetes mellitus: Recent developments and clinical implications. Manual of Endocrinology and Metabolism. Philadelphia: Lippincott.

Eyler, A. A., Baker, E., Cromer, L., King, A. C., Brownson, R. C., \& Donatelle, R. J. (1988). Physical Activity and minority women: A qualitative study. Health Education \& Behavior, 25, 640-652. 
Eyler, A. E., Wilcox, S., Matson-Koffman, D., Evenson, K. R., Sanderson, B., Thompson, J., et al. (2002). Correlates of physical activity among women from diverse racial/ethnic groups. Journal of Women's Health \& Gender Based Medicine, 11, 239-253.

Fain, J. A. (2007). Psychometric properties of the Spanish Version of the Diabetes Selfmanagement Assessment Report tool. The Diabetes Educator, 33, 827-831.

Fishbein, M. \& Azjen, I. (1975). Belief, attitude, intention, and behavior: An introduction to theory and research. Reading, MA: Addison-Wesley.

Fishbein, M. \& Middlestadt, S. E. (1989). Using the Theory of Reasoned Action as a framework for understanding and changing AIDS-related behaviors. In V. M. Hays, G. Albee \& S. Schneider (Eds.), Psychological approaches to primary prevention of acquired immunodeficiency syndrome (pp. 93-110). Newbury Park, CA: Sage.

Fisher, J. D. (1992). Changing AIDS-risk behavior. Psychological Bulletin, 111, 455-474.

Fisher, J. D., \& Fisher, W. A. (1992). Changing AIDS risk behavior. Psychological Bulletin, 111, 455-474.

Fisher, J. D, \& Fisher, W. A. (2000). Theoretical approaches to individual-level change. In J. Peterson \& R. Diclemente ( Eds.), HIV prevention handbook (pp. 3-55). New York: Kluwer Academic/Plenum Press.

Fisher, J. D., Fisher, W. A., Amico, K. R., \& Harman, J. J. (2006). An informationmotivation-behavioral skills model of adherence to antiretroviral therapy. Health Psychology, 25, 462-473. 
Fisher, J. D., Fisher, W. A. \& Harman, J. (Eds). (2003). The information-motivationbehavioral skills model: A general social psychological approach to understanding and promoting health behavior. Social Psychological Foundations of Health and Illness. Maiden, MA, Blackwell.

Fisher, J. D., Fisher, W. A., Misovich S. J., Kimble D. L., \& Malloy, T. E. (1996). Changing AIDS risk behavior: Effects of an intervention emphasizing AIDS risk reduction information, motivation, and behavioral skills in a college student population. Health Psychology, 15, 114-123.

Fisher, J. D., Fisher, W. A., Williams, S. S., \& Malloy, T. E. (1994). Empirical tests of an information-motivation-behavioral skills model of AIDS-preventive behavior with gay men and heterosexual university students. Health Psychology, 13, 238-250.

Flaskerud, J.J. (1988). Is the Likert scale format culturally biased? Nursing Research, 37, 185-186.

Ford, E. S. (2004). The metabolic syndrome and mortality from cardiovascular disease and all-causes: Findings from the National Health and Nutrition Examination Survey II Mortality Study. Atherosclerosis, 173, 307-401.

Funnell, M. M., Brown, T. L., Childs, B. P., Haas, L. B., Hosey, G. M., Jensen, B., et al. (2008). National Standards for Diabetes Self-Management Education. Diabetes Care, 31(Suppl.1.), S97-S104.

Garcia, A. A., Villagomez, E. T., Brown, S. A., Kouzekanani, K. \& Hanis, C. L. (2001). The Starr County diabetes Education Study: Development of the Spanish-language diabetes knowledge questionnaire. Diabetes Care, 24, 16-21. 
Giorgino, F., Laviola, L., \& Leonardini, A. (2005). Pathophysiology of type 2 diabetes: Rationale for different oral antidiabetic treatment strategies. Diabetes Research \& Clinical Practice, 68, S22-9.

Gleeson-Krieg, J. A., Bernal, H., \& Woolley, S. (2002). The role of social support in the self-management of diabetes mellitus among a Hispanic population. Public Health Nursing, 19, 215-222.

Gordon, L. (2004). Facing racial and ethnic health disparities. Journal of the American Dietetic Association, 104, 1779-1780.

Groman, R. \& Ginsburg, J. (2004). Racial and ethnic disparities in health care: A position paper of the American College of Physicians. Annals of Internal Medicine, 141, 226-232.

Guthrie, D. V. \& Guthrie, R. A. (Eds.) (1983). The disease process of diabetes mellitus. Nursing Clinics of North America. MD: Aspen Publishers.

Guthrie, R. A. \& Guthrie, D. W. (2004). Pathophysiology of diabetes mellitus. Critical Care Nursing Quarterly, 27, 113-125.

Hall, R. F., Joseph, D. H., \& Schwartz-Barcott. (2003). Overcoming obstacles to behavior change in diabetes self-management. Diabetes Educator, 29, 303-311.

Hampl, J. S., Sass, S. (2001) Focus groups indicate that vegetable and fruit consumption by food stamp-eligible Hispanics is affected by children and unfamiliarity with non-traditional foods. Journal of the American Dietetic Association. 101, 685687. 
Hargraves, J. L., Cunningham, P. L., \& Hughes, R.G. (2001). Racial and ethnic differences in access to medical care in managed care plans. Health Services Research, 36, 853-868.

Harris, M. I. (2001). Racial and ethnic differences in health care access and health outcomes for adults with type 2 diabetes. Diabetes Care, 24, 454-459.

Hatcher, E., \& Whittemore, R. (2007). Hispanic adults' beliefs about type 2 diabetes: Clinical implications. Journal of the American Academy of Nurse Practitioners, $19,536-545$.

Hendelman, D., Miller, K., Baggett, C., Debold, E., \& Freedson, P. (2000). Validity of accelerometry for the assessment of moderate intensitiy physical activity in the field. Medicine and Science in Sports and Exercise, 32(Suppl.1), S442-S449.

Hill-Briggs, F., Smith, A. S. (2008). Evaluation of Diabetes and Cardiovascular Disease Print Patient Education Materials for Use with Low Health Literate Populations Diabetes Care, 31, 667-671

Honda, K. (2004). Factors underlying variation in receipt of physician advice on diet and exercise: Applications of the behavioral model of health care utilization. American Journal of Health Promotion, 18, 370-377.

Jezewski, M., \& Poss, J. (2002). Mexican-Americans' explanatory model of type 2 diabetes. Western Journal of Nursing Research, 24, 840-858.

Johnson RL, Saha S, Arbelaez JJ, Beach MC, Cooper LA. (2004). Racial and ethnic differences in patient perceptions of bias and cultural competence in health care. Journal of General Internal Medicine, 19, 101-110. 
Juarbe, T., Turok, X. P. \& Perez-Stable, E. J. (2002). Perceived Benefits and barriers to Physical Activity among older Latina women. Western Journal of Nursing Research. 24, 868-886.

Krichbaum, K. Aarestad, V., Buethe, M. (2003. Exploring the connection between selfefficacy and effective diabetes self-management. The Diabetes Educator, 29, 653.

Koch, J. (2002). The role of exercise in the African-American woman with type 2 diabetes mellitus: Application of the health belief model. Journal of the American Academy of Nurse Practitioners, 14, 126-129.

Koenigsberg, M. R., Bartlett, R., \& Cramern, J. S. (2004). Facilitating treatment adherence with lifestyle changes in diabetes. American Family Physician, 69, 269$270,273$.

Koro, C.E., Bowlin, S. J., Bourgeois, N. \& Fedder, D. O. (2004). Glycemic control from 1988 to 2000 among US adults diagnosed with type 2 diabetes, Diabetes Care, 27 $17-20$.

Kreuter, M. W., Lukwago, S. N., Bucholtz, D. C., Clark, E. M., \& Sanders-Thompson, V. (2003). Achieving cultural appropriateness in health promotion programs: Targeted and tailored approaches. Health Education and Behavior 30, 133-146.

Kreuter, M. W. \& Skinner, C. S. (2000). Tailoring: What's in a name? Health Education Research, 15, 1-4.

Kreuter, M. W., Strecher, V. J. \& Glassman, B. (1999). One size does not fit all: The case for tailoring print materials. Annals of Behavioral Medicine, 21, 1-9. 
Lanting, L. C. Joung, I. M. A., Mackenbach, J. P. Lamberts, S. W. J. \& Bootsma, A. H. (2005). Ethnic differences in mortality, end-stage complications, quality of care among diabetic patients: A review. Diabetes Care, 28, 2280-2288.

Lara, M., Gamboa, C., Kahramanian, M. I., Morales, L. S. \& Hayes Bautista, D. E. (2005). Acculturation and Latino health in the United States: A review of the literature and its sociopolitical context. Annual Review of Public Health, 26, 367397.

Lipton, R. B., Losey, L. M., Giachello, A., Mendez, J., \& Girotti, M. H. (1998). Factors affecting diabetes treatment and patient education among Latinos: Results of a preliminary study in Chicago. Journal of Medical Systems, 20, 267-276.

Lorenzo, C., Serrano-Rios, M. Martinez-Larrad, M. T., Gabriel, R., Williams, K.\& Gonzalez-Vallalpando, C., et al. (2001). Was the historic contribution of Spain to the Mexican gene pool partially responsible for higher prevalence of type 2 diabetes in Mexican-origin populations? Diabetes Care, 24, 2059-2064.

Lujan, J. (2008). Testing the Diabetes Knowledge and health Beliefs of MexicanAmericans on the Texas-Mexico Border. Hispanic Health Care International, 6, 9-20.

Lujan, J., Ostwald, S. K., \& Ortiz, M. (2007). Promotora diabetes intervention for Mexican Americans. The Diabetes Educator, 33, 660-670.

Mainous, A. G., Diaz, V.A. \& Geesey, M. E. (2008). Acculturation and healthy lifestyle among Latinos with diabetes. Annals of Family Medicine, 6, 131-137.

Mainous, A. G., Diaz, V. A., Koopman, R. J. \& Everett, C. J. (2007). Quality of care for Hispanic adults with diabetes 1, Family Medicine, 39, 351-356. 
Marquez, D. X. \& McAuley, E. (2006). Gender and acculturation influences on physical activity in Latino adults. Annals of Behavioral Medicine, 31, 138-144.

Marquez, D.X., McAuley, E. and Overman, N. (2004) Psychosocial correlates and outcomes of physical activity among Latinos: A Review, Hispanic Journal of Behavioral Science, 26, 195-229.

Mauldon, M., Melkus, G. D., \& Cagganello, M. (2006). Tomando Control: A Culturally Appropriate Diabetes Program for Spanish-Speaking Individuals with Type 2 Diabetes Mellitus - Evaluation of a Pilot Project. The Diabetes Educator, 32, 751-759.

McBean, A. M., Li, S., Gilbertson, D. T., \& Collins, A. J. (2004). Differences in diabetes prevalence, incidence, and mortality among the elderly of four racial/ethnic groups: Whites, Blacks, Hispanics, and Asians. Diabetes Care, 27, 2317-2324.

McGoldrick, M., Pearce, J. K., \& Giordano, J. (1982). Ethnicity and family therapy. New York. Gulford Press.

McNabb, W. L. (1997), Adherence in diabetes: Can we define it and can we measure it? Diabetes Care, 20, 215-218.

Melnik, T.A., Hosler, A. S., Sekhobo, J. P., Duffy, T. P., Tierney, E. F., Engelgau, M. M., \& Geiss, L. S. (2004). Diabetes prevalence among Puerto Rican adults in New York City, NY. American Journal of Public Health, 94, 434-437

Misovich, S. J., Martinez, T., Fisher, J.D., Bryan, A. D., \& Catapano, N. (2003). Breast self-examination: A test of the information, motivation, and behavioral skills model. Journal of Applied Social Psychology, 33, 775-790. 
Murray, 2001 (2001). Exploring motorcycle safety gear use: A theoretical approach. Unpublished master's thesis, University of Connecticut, Storrs Connecticut. Nagelkerk, J.,Reick, K.\& Meengs, L. (2006). Perceived barriers and effective strategies to diabetes self-management. Journal of Advanced Nursing 54, 151-158.

Narayan, K. M. V., Boyle, J. P., Geiss, L. S., Saaddine, J. B. \& Thonpson, T. J. (2006), Impact of recent increase in incidence on future diabetes burden. Diabetes Care, 29, 2114-1268.

Nathan, D. M., Buse, J. B., Davidson, M. B., Heine, R.J., Holman, R. R., Sherwin, R., Zinman, B.; Professional Practice Committee, American Diabetes Association; European Association for the Study of Diabetes. (2006). Management of hyperglycaemia in type 2 diabetes: A consensus algorithm for the initiation and adjustment of therapy. A consensus statement from the American Diabetes Association and the European Association for the Study of Diabetes.

Diabetologia, 49, 1711-1721.

National Diabetes Information Clearinghouse. (2007). National Diabetes Statistics, 2007. Retrieved August $29^{\text {th }}, 2008$ from http://diabetes.niddk.nih.gov/dm/pubs.

Norris S.L., Engelgau, M. M., \& Naranyan, K, M. V. (2001). Effectiveness of selfmanagement training in type 2 diabetes: A systematic review of randomized controlled trails. Diabetes Care, 24, $561-587$.

Norris, S. L., Lau, J, Smith, S. J., Schmid, C. H., Engelgau, M. M. (2002). Selfmanagement education for adults with type 2 diabetes: A meta-analysis on the effect on glycemic control. Diabetes Care, 25, 1159-1171. 
Olvera, N., Suminski, R., \& Power, T. G. (2005). Intergenerational perceptions of body image in Hispanics: Role of BMI, gender, and acculturation. Obesity Research, 12, 1970-1979.

Oomen, J. S., Owen, L. J., Suggs, L. S. (1999). Culture counts: Why current treatment models fail Hispanic women with type 2 diabetes. The Diabetes Educator, 25, $220-225$.

Osborn, C. Y. (2006). Using the IMB model of health behavior change to promote selfmanagement behaviors in Puerto Ricans with diabetes with diabetes. Unpublished doctoral dissertation, University of Connecticut, Storrs.

Oster, N. V., Welch, V., Schild, L., Gazmararian, G., Rask, K., \& Spettell, C. (2006). Differences in self-management behaviors and use of preventive services among diabetes management enrollees by race and ethnicity. Disease Management, 9 , $167-175$.

Pate, R. R., Pratt, M., Blair, S. N., Haskell, W. L., Macera, C. A., Bouchard, C., et al. (1995). Physical activity and public health: Recommendation from the Centers for Disease Control and Prevention and the American College of Sports Medicine. Journal of the American Medical Association, 273, 402-407.

Paterson, A. D., Rutledge, B. N., Cleary, P. A., Lachin, J. M., \& Crow, R. S. (2007). The Effect of intensive diabetes treatment on resting heart rate in type 1 diabetes Diabetes Care, 30, 2107-2112.

Peyrot, M., Rubin, R.R., Lauritzen, T., Snoek, F.J., Matthews, D. R., \& Skovlund, S.E. (2005). Psychosocial problems and barriers to improved diabetes management: 
Results of the Cross-National Diabetes Attitudes, Wishes and Needs (DAWN) Study. Diabetic Medicine, 22, 1379-1385.

Pichon, L. C., Arredondo, E. M., Roesch, S., Sallis, J. F., Ayala, G. X., \& Elder, J. P. (2007). The relation of acculturation to Latinas' perceived neighborhood safety and physical activity: A structural equation analysis. Annals of Behavioral Medicine, 34, 295-303.

Polit, D. F. \& Beck, C. T. (2008). Nursing Research: Generating and assessing evidence for nursing practice $\left(8^{\text {th }} \mathrm{ed}\right.$.). New York: Lippincott.

Ponzo, M. G., Gucciardi, G., Weiland, M., Masi, R..Lee, R., \& Grace, S. L. (2006). Gender, ethnocultural, and psychosocial barriers to diabetes self-management in Italian women and men with type 2 diabetes. Behavioral Medicine, 31, 153-160.

Quatromoni, P., Milbauer, M., Posner, B. M. Carballeira, N. P., Brunt, M., \& Chipkin, S. R. (1994). Use of focus groups to explore nutrition practices and health beliefs of urban Caribbean Latinos with diabetes. Diabetes Care, 17, 869-873.

Rivera, C. (2003). Lessons learned from urban Latinas with type 2 diabetes mellitus. Journal of Transcultural Nursing, 14, 255-265.

Rosal, M. C., Goins, K. V., Carbone, E. T., \& Cortes, D. E. (2004). Views and Preferences of low-literate Hispanics regarding diabetes education: Results of formative research. Health Education and Behavior, 31, 388-405.

Rosal, M. C., Olendzki, B., Reed, G. W., Gumieniak, O., Scavron, J, \& Ockene, I. (2005). Diabetes self-management among low-income Spanish-speaking patients: A pilot study. Annals of Behavioral Medicine. 29, 225-235. 
Rutter, D., \& Quine, L. (Eds.). (2002). Changing health behavior: Intervention and research with social cognition models, Philadelphia: Open University Press.

Samaan, R.A. (2000). The influences of race, ethnicity, and poverty on the mental health of children. Journal of Health Care for the Poor and Underserved, 11, 100-110.

Sarkisian, C. A., Brown, A. F., Norris, K. C., Wintz, R. L., \& Mangione, C. M. (2003). A systematic review of diabetes self-care interventions for older African-American, or Latino adults. The Diabetes Educator, 29, 467-479.

Seid, M., Castañeda, D., Mize, R., Zivkovic, M., Varni, J. W. (2003). Crossing the border for health care: Access and primary care characteristics for young children of Latino farm workers along the US-Mexico border. Ambulatory Pediatrics, 3, 121130.

Starace, F., Massa, A., Amico, K. R., \& Fisher, J. D. (2006). Adherence to antiretroviral therapy: An empirical test of the information-motivation-behavioral skills model. Health Psychology, 25, 153-162.

Tabachnick, B. G., \& Fidell, L. S. (1996). Using multivariate statistics (3rd ed.). New York: Harper Collins.

Terre, L. (2007). Behavioral medicine review: Strategic management of diabetes risk. American Journal of Lifestyle Medicine, 1, 351-355.

Toolbert, D. J., Hampson, S. E., \& Glasgow, R. E. (2000). The summary of diabetes selfcare activities measure: Results from 7 studies and a revised scale. Diabetes Care, $23,943-950$. 
Tortolero, S. F., Masse, L. C., Fulton, J. E., Torres, I., \& Kohl, H.W. (1999). Assessing physical activity among minority women: Focus group results. Women's Health Issues, 9, 135-142.

United Kingdom Department of Health. (2001). National service framework for diabetes: Standards. UKDOH, Product No. 26192, 45 p., UK: Crown Copyright. United Kingdom Prospective Diabetes Study Group. (1998a). Intensive blood-glucose control with sulphonylureas or insulin compared with conventional treatment and risk of complications in patients with type 2 diabetes. (UKPDS 33) Lancet, 352 , 837-853.

United Kingdom Prospective Diabetes Study Group. (1998b). The blood pressure control and risk of macrovascular and microvascular complications in type 2 diabetes. (UKPDS 38). British Medical Journal, 317, 703-713.

U. S. Census Bureau. Retrieved February 14, 2009 from http://www.census.gov/PressRelease/www/releases/archives/population/012496.html

Van, J T., Pan, J., Wasty, T., Chan, E., Wu, X. \& Arthur, C. (2002). Comparison of extended-release niacin and atorvastatin monotherapies and combination treatment of the atherogenic lipid profile in diabetes mellitus. American Journal of Cardiology, 89, 1306-1308.

Van Der Ven, N. C., Weinger, K, Yi, J., Pouwer, F., Ader, H., Van Der Ploeg, H. M. \& Snoek, F.J. (2003). The confidence in diabetes self-care scale: Sychometric properties of a new measure of diabetes-specific self-efficacy in Dutch and US patients with type 1 diabetes. Diabetes Care, 26, 713-718. 
Van Ryn, M. (2002) Research on the provider contribution to race/ethnicity disparities in medical care. Medical Care,40, I-140-I-151.

von Goeler, D. S., Rosal, M. C., Ockene, J. K., Scavron, J., \& De Torrijos, F. (2003) Self-management of type 2 diabetes: A survey of low-income urban Puerto Ricans. The Diabetes Educator, 29, 663-672.

Walsh, M. E., Katz, M. A., \& Sechrest, L. (2002). Unpacking cultural factors in adaptation to type 2 diabetes mellitus. Medical Care, 40(Suppl.1), 1129-1139.

Wang, C. Y. \& Chan, S. M. (2005). Culturally tailored diabetes education program for Chinese-Americans: A pilot study._Nursing Research, 54, 347-353.

Weiler, D. (2007 unpubl.). Socio-cultural influences and process of living with diabetes for the migrant Latino adult. College of Nursing, Univ. of Arizona. Ph.D. Dissertation. Unpubl. 135p.

Welch, V. L. Oster, N. V. Gazmararian, J. A. Rask, K. Schild, L. Cutler, C. Spettell, C. Reardon, M. (2006). Impact of diabetes disease management program by race and ethnicity. Disease Management and Health Outcomes, 14, 245-252.

Wen, L. K., Shepherd, M. D. \& Parchman, M. L. (2004). Family support, diet, and exercise among older Mexican-Americans with type 2 diabetes. The Diabetes Educator, 30, 980-993.

Wing, R. R. (2001). Weight loss in the management of type 2 diabetes. In H. H. R. Gerstein (Ed.), Evidence based diabetes care (pp. 252-276). Ontario, Canada: Decker, Inc. 
Wong, M., Gucciardi, E., Li, L. \& Grace, S.L. (2005). Meal preparation in patients with type 2 diabetes and their spouses: A quantitative and qualitative study. Canadian Journal of Dietetic Practice and Research, 66, 215-220 


\section{APPENDIX A: QUESTIONNAIRE (ENGLISH)}

IMB DLABETES QUESTIONNAIRE

Interviewer name:

Date of interview:

Time of the interview

AM PM

\section{DEMOGRAPHICS}

What is your gender? $\square_{1}$ Male $\square_{2}$ Female

What is your age?

What is your birthdate?

month day year

In which language do you prefer to be interviewed?

1. English

$\square_{2}$ Spanish

What is the last grade of school you completed?

$\square$. No formal schooling

$\square$ Eighth grade or less

$\square_{3}$ Some high school

$\square_{4}$ High school graduate or GED

$\square$ Some College

$\square 6$ Finished 4 years of college

Which of the following best describes your current employment status? (check one box)

$\square$. Working

$\square 2$ Unemployed

$\square$ Homemaker

$\square_{4}$ In school

$\square$ 5 Retired

$\square 6$ Disabled, not able to work

Do you have health insurance?

$\square$ yes
$\square_{2}$ no
$\square_{3}$ I don't know

What is your current marital status?

$\square$. Single/no partner

$\square_{2}$ Married

$\square_{3}$ Divorced

$\square_{4}$ Widowed 


\section{Self-Identification}

How do you identify yourself?

$\square$, Puerto Rican
$\square{ }_{2}$ Hispanic or Latino
$\square{ }_{3}^{3}$ American
$\square{ }_{4}$ Other

\section{$\underline{\text { Language }}$}

How well do you speak English?

Not at all Very Well
0
1
2
3
4
5
6

What language do you primarily speak in your home?

$\square$. English

$\square{ }_{2}$ English and Spanish equally

$\square_{3}$ Spanish

How many years have you lived in the United States? years

Where did you live the most as a child (before age 18)?

$\square_{1}$ United States
$\square_{2}$ Puerto Rico
$\square_{3}$ Other

Where have you lived the most as an adult (after age 18)?

$\square_{1}$ United States

$\square_{2}$ Puerto Rico

$\square_{3}$ Other

\section{DIETKNOWLEDGE}

Please tell us if the statement is TRUE or FALSE. Please answer as honestly and accurately as possible. True $=1$, False $=2$, I don't know $=3$.

1. High blood glucose causes diabetes complications.

2. Only food with sugar causes blood glucose to go up.

3. Protein makes blood glucose go up more than carbohydrates.

4. Fat makes blood glucose go up more than carbohydrates.

5. Skipping meals does not affect blood glucose levels.

6. People with diabetes should eat the same amount of food at each meal.

7. People with diabetes should eat more carbohydrates for lunch than for dinner.

8. People with diabetes should eat breakfast, lunch, and dinner to control blood glucose. 


\section{\begin{tabular}{|l|l|l|}
\hline TRUE & FALSE & I DON'T KNOW \\
\hline
\end{tabular}}

Please answer the question with a "Yes", "No", or "I don't know". Please answer as honestly and accurately as possible. Yes $=0, \mathrm{No}=1$, I don't know $=2$.

\begin{tabular}{|l|l|l|l|}
\hline Which foods have carbohydrates? & Yes & No & I Don't Know \\
\hline 1. Does CORN have carbohydrates? & & & \\
\hline 2. Does CHICKEN have carbohydrates? & & & \\
\hline 3. Do TORTILLAS have carbohydrates? & & & \\
\hline 4. Do REFRIED BEANS have carbohydrates? & & & \\
\hline 5. Do AVOCADOS have carbohydrates? & & & \\
\hline 6. Does ORANGE JUICE have carbohydrates? & & & \\
\hline 7. Does MILK have carbohydrates? & & & \\
\hline 8. Do BANANAS have carbohydrates? & & & \\
\hline 9. Does CHEESE have carbohydrates? & & & \\
\hline 10. Do TOMATOES have carbohydrates? & & & \\
\hline 11. Do POTATOES have carbohydrates? & & & \\
\hline 12. Does OATMEAL have carbohydrates? & & & \\
\hline 13. Do PEPPERS have carbohydrates? & & & \\
\hline
\end{tabular}

\section{EXERCISE KNOWLEDGE}

Please tell us how much you AGREE or DISAGREE with each statement. Please answer as honestly and accurately as possible. Strongly disagree $=1$, Disagree $=2$, Agree $=3$, Strongly Agree $=4$.

1. Exercise prevents diabetes complications.

2. Exercise lowers blood glucose right away.

3. Blood glucose is controlled for many hours after exercising.

4. People who exercise eat more.

5. People who exercise have less stress.

6. People who exercise sleep better.

7. Daily activity (housework) can help control blood glucose.

\begin{tabular}{|c|c|c|c|}
\hline Strongly Disagree & Disagree & Agree & Strongly Agree \\
\hline 1 & 2 & 3 & 4 \\
\hline
\end{tabular}

\section{ATTITUDES (DIET \& EXERCISE)}

(a) Please tell us how GOOD or BAD the following are for your health.

(b) For each question, please tell us how PLEASANT or UNPLEASANT it would be for you to do the behavior. Please provide the answer that best applies to you.

During the next 30 days, how good or bad would it be for your health: 
1. ...to eat breakfast, lunch, and dinner everyday?

2. ...to eat the same amount of food for breakfast, lunch, and dinner everyday?

3. ...to keep track of how many carbohydrates you eat for breakfast everyday?

4. ...to keep track of how many carbohydrates you eat for lunch everyday?

5. ...to keep track of how many carbohydrates you eat for dinner everyday?

6. ...to exercise everyday?

7. ...to go for a walk everyday?

8. ...to add activity to the things you already do everyday (for example, use the stairs instead of the elevator)?

$\square_{1}$ Very bad
$\square_{2}^{2}$ Somewhat bad
$\square_{3}^{3}$ Neither bad or good
$\square_{4}^{4}$ Somewhat good
$\square_{1}$ Very good
$\square_{2}$ Sery unpleasant
$\square_{3}$ Neither unpleasant or pleasant
$\square_{4}$ Somewhat pleasant
$\square_{5}$ Very pleasant

SOCIAL NORMS (DIET \& EXERCISE)

For each question, please tell us how TRUE or UNTRUE it is for you. Please answer as honestly and accurately as possible.

Most people who are important to me think I should...

1. ...eat breakfast, lunch, and dinner.

2. ...eat the same amount of food for breakfast, lunch, and dinner.

3. ...keep track of how many carbohydrates I eat for breakfast.

4. ...keep track of how many carbohydrates I eat for lunch.

5. ...keep track of how many carbohydrates I eat for dinner.

6. ...exercise.

7. ...go for a walk for exercise.

8. ...add activity to the things I already do (for example, use the stairs instead of the elevator).

$1=$ Very Untrue

$2=$ Mostly Untrue

$3=$ Untrue

$4=$ True

$5=$ Mostly True

$6=$ Very True 


\section{BEHAVIORAL SKILLS (DIET \& EXERCISE)}

For the next set of questions, please provide the answer you feel best applies to you.

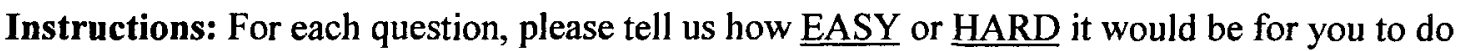
right now.

1. How easy or hard would it be for you to eat breakfast every day?

2. How easy or hard would it be for you to eat breakfast, lunch, and dinner everyday?

3. How easy or hard would it be for you to eat the same amount of food for breakfast, lunch, and dinner everyday?

4. How easy or hard would it be for you to create different exercise activities to do in your home?

5. How easy or hard would it be for you to pick a convenient time of day to exercise?

6. How easy or hard would it be for you to start exercising again when you have not exercised in a long time?

\begin{tabular}{|c|c|c|c|}
\hline Very Hard & Hard & Easy & Very Easy \\
\hline 1 & 2 & 3 & 4 \\
\hline
\end{tabular}

Instructions: For each question, please tell us how EFFECTIVELY or INEFFECTIVELY it would be for you to do right now.

1. How effectively or ineffectively could you count how many carbohydrates you eat at breakfast?

2. How effectively or ineffectively could you count how many carbohydrates you eat at lunch?

3. How effectively or ineffectively could count how many carbohydrates you eat at dinner?

4. How effectively or ineffectively could use the Nutrition Facts label to count carbohydrates?

5. How effectively or ineffectively could create the right size portion of carbohydrates to eat ( $1 / 2$ cup, 1 cup, etc)?

6. How effectively or ineffectively could you add more activity to the things you already do (for example, use the stairs instead of the elevator)?

7. How effectively or ineffectively could you persuade a friend or family member to exercise with you?

8. How effectively or ineffectively could you find activities to do when the weather is bad?

\begin{tabular}{|c|c|c|c|}
\hline Very Ineffectively & Ineffectively & Effectively & Very Effectively \\
\hline 1 & 2 & 3 & 4 \\
\hline
\end{tabular}

\section{BEHAVIOR}

For each question, please tell us how OFTEN you did the specific behavior in the last 30 days. Please answer as honestly and accurately as possible. 
Food Label

1. In the last $\underline{\mathbf{3 0} \text { days, }}$, how OFTEN did you look at the serving size information on a food label?

2. In the last 30 davs, how OFTEN did you look at food labels to look at the total carbohydrate content?

3. In the last $\mathbf{3 0}$ davs, how OFTEN did you look at food labels to count carbohydrates?

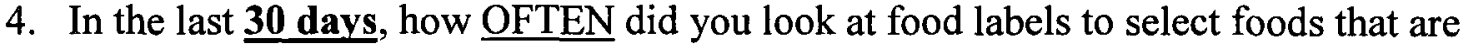
low in carbohydrates?

$\square_{1}$ Never
$\square_{2}$ Rarely
$\square_{3}$ Sometimes
$\square_{4}$ Often
$\square$ 5 Always

(Scoring: Mean number of days for all four items.)

For each question, please tell us on how many DAYS in the last 7 days you did the behavior. Please answer as honestly and accurately as possible.

\section{General Diet}

1. In the last 30 days, during a typical week, how many DAYS would you follow your eating plan? (SDSCA 2)

2. On how many of the last 7 DAYS did you follow a healthful eating plan? (SDSCA 1)

3. On how many of the last 7 DAYS did you eat breakfast, lunch, and dinner?

4. On how many of the last 7 DAYS did you eat the same amount of food at each meal?

5. On how many of the last 7 DAYS did you space carbohydrates evenly throughout the day? (SDSCA 5A)

6. On how many of the last 7DAYS did you control how many carbohydrates you ate at breakfast?

7. On how many of the last 7 DAYS did you control how many carbohydrates you ate at lunch?

8. On how many of the last 7 DAYS did you control how many carbohydrates you ate at dinner?

$\begin{array}{llllllll}0 & 1 & 2 & 3 & 4 & 5 & 6 & 7\end{array}$

(Scoring: Mean number of days for all eight items.)

\section{General Exercise}

1. On how many of the last 7 DAYS did you participate in at least 30 minutes of physical activity? (Total minutes of continuous activity, including walking) (SDSCA 5)

2. On how many of the last 7 DAYS did you participate in a specific exercise session (such as swimming, walking, biking) other than what you do around the house or as part of your work? (SDSCA 6)

$\begin{array}{llllllll}0 & 1 & 2 & 3 & 4 & 5 & 6 & 7\end{array}$




\section{References}

Garcia, A.A., Villagomez, E. T., Brown, S.A. Kouzekanani, K., \& hanis, C.L. (2001). The Starr County Diabetes Education Study: development of the Spanishlanguage diabetes knowledge questionnaire. Diabetes Care, 24(1), 16-21.

Osborn, C. (2006). Using the IMB Model of Health Behavior Change to Promote SelfManagement Behavior in Puerto Ricans with diabetes. Unpublished doctoral dissertation, University of Connecticut, Massachusetts.

Toobert, D. J., Hampson, S. E., \& Glasgow, R. E. (2000). The summary of diabetes selfcare activities measure: Results from seven studies and a revised scale. Diabetes Care, 23, $943-949$. 


\section{APPENDIX B: QUESTIONNAIRE (SPANISH)}

\section{IMB CUESTIONARIO DE DLABETES}

Nombre del Entrevistador:

Fecha de la Entrevista:

Hora de la Entrevista AM PM

\section{CONDICIÓN DEMOGRÁFICA}

¿Cuál es su sexo?: $\square$ 1 Masculino $\square_{2}$ Femenino ¿Cuál es su edad?:

¿Cuándo es su fecha de nacimiento?:

$\overbrace{\text { mes }} \frac{}{\text { día }} \frac{}{\text { año }}$

¿En qué lenguaje prefiere ser entrevistado?

$\square$ Inglés

]$_{2}$ Español

¿Cuál fue el último grado escolar que completó?

$\square_{1}$ Ninguna educación escolar

$\square_{2}$ Octavo grado o menos

$\square_{3}$ Algo de escuela superior

$\square 4$ Graduada de escuela superior o GED equivalente

$\square_{5}$ Algo de colegio

$\square$ Terminó 4 años de colegio

¿Cuál de las siguientes opciones describe mejor su situación de empleo? (marque un encasillado)

$\square_{1}$ Trabaja tiempo completo, 35 horas o más a la semana

$\square_{2}$ Desempleado o despedido y buscando trabajo

$\square 3$ Ama de casa

$\square$ En la escuela

$\square_{5}$ Retirado

$\square$ Incapacitado, no puede trabajar

¿Tiene Ud. seguro médico?

$\square_{1}$ Sí
$\square_{2}$ No
$\square$
${ }_{3}$ No sé

¿Cuál es su estado civil actual?

$\square$ Soltero(a)/sin pareja 
$\square$ Casado(a)

$\square 3$ Divorciado(a)

$\square_{4}$ Viudo(a)

ACULTURACIÓN

Identificación propia

¿Cómo se identifica usted?

$\square_{1}$ Puertorriqueña(o)
$\square$ Hispana(o) o Latina(o)
$\square_{3}$ Americana(o)
$\square$
$\square$ Otro

Idioma o lenguaje:

¿Qué tanto inglés sabe usted?

Nada 0

12

23

4

5

Muy bien

6

¿Qué idioma/lenguaje usa usted con más frecuencia en su hogar?

$\square_{1}$ Inglés
$\square_{2}$ Inglés y español igualmente
$\square \square_{3}$ Español

¿Cuántos años ha vivido en los Estados Unidos? años

¿Dónde vivió la mayoría de su infancia (antes de los 18 años)?

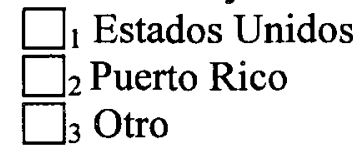

¿Dónde ha vivido la mayoría de su vida como adulto (después de los 18 años)?

$\square_{1}$ Estados Unidos
$\square_{2}$ Puerto Rico
$\square_{3}$ Otro

HÁBITOS DIETÉTICOS ¿Usted cocina normalmente las comidas de la casa? ¿Usted compra normalmente la comida de la casa? CONOCIMIENTO DIETETICO

Por favor díganos si la declaración es CIERTA o FALSA. Por favor conteste honestamente y con precisión. 
La alta glucosa causa complicaciones diabéticas.

1. Solamente la comida con azúcar causa que suba la glucosa.

2. La proteína sube la glucosa más que los carbohidratos.

3. La grasa causa que suba la glucosa más que los carbohidratos.

4. La ausencia de comida no afecta los niveles de la glucosa.

5. La gente con diabetes debe comer la misma cantidad en cada comida.

6. La gente con diabetes debe comer más carbohidratos en el almuerzo que en la cena.

7. La gente con diabetes debe comer el desayuno, el almuerzo, y la cena para controlar la glucosa.

\begin{tabular}{|c|c|c|}
\hline Falsa & Cierta & No sé \\
\hline
\end{tabular}

\begin{tabular}{|l|l|l|l|}
\hline ¿Contiene carbohidratos? & Sí & No & No sé \\
\hline 1. ¿El MAÍZ contiene carbohidratos? & & & \\
\hline 2. ¿El POLLO contiene carbohidratos? & & & \\
\hline 3. ¿Las BANANAS contienen carbohidratos? & & & \\
\hline 4. ¿Los FRIJOLES REFRITOS contienen carbohidratos? & & & \\
\hline 5. ¿Los AGUACATES contienen carbohidratos? & & & \\
\hline 6. ¿El JUGO DE NARANJA contiene carbohidratos? & & & \\
\hline 7. ¿La LECHE contiene carbohidratos? & & & \\
\hline 8. ¿Las PAPAYAS contienen carbohidratos? & & & \\
\hline 9. ¿El QUESO contiene carbohidratos? & & & \\
\hline 10. ¿Los TOMATES contienen carbohidratos? & & & \\
\hline 11. ¿Las PAPAS contienen carbohidratos? & & & \\
\hline 12. ¿La AVENA contiene carbohidratos? & & & \\
\hline 13. ¿Los PIMIENTOS contienen carbohidratos? & & & \\
\hline
\end{tabular}

\section{CONOCIMIENTO DE EJERCICIO..}

Por favor díganos qué tanto está de ACUERDO o en DESCUARDO con cada declaración. Por favor conteste honestamente y con precisión.

1. El ejercicio previene las complicaciones diabéticas.

2. El ejercicio baja la glucosa inmediatamente.

3. La glucosa es controlada por muchas horas después del ejercicio.

4. La gente que hace ejercicio come más.

5. La gente que hace ejercicio tiene menos estrés.

6. La gente que hace ejercicio duerme mejor.

7. Las tareas domésticas diarias pueden ayudar a controlar la glucosa.

\begin{tabular}{|c|c|c|c|}
\hline $\begin{array}{c}\text { Sumamente en } \\
\text { desacuerdo }\end{array}$ & En desacuerdo & De acuerdo & $\begin{array}{c}\text { Sumamente de } \\
\text { acuerdo }\end{array}$ \\
\hline 1 & 2 & 3 & 4 \\
\hline
\end{tabular}


ACTITUDES (DIETA \& EJERCICIO)

(a) Por favor díganos qué tan BUENO o MALO sería para su salud lo que se indica.

(b) Por cada pregunta, por favor díganos qué tan AGRADABLE o DESAGRADABLE sería hacer lo que se indica. Por favor facilite la respuesta mejor aplicada a usted.

Durante los próximos 30 días, ¿qué tan bueno o malo seria para su salud:

Durante los próximos 30 días, ¿qué tan agradable o desagradable sería para usted:

1. comer el desayuno, el almuerzo, y la cena a diario?

2. comer la misma cantidad de comida para el desayuno, almuerzo, y la cena diariamente?

3. tomar en cuenta cuántos carbohidratos come para el desayuno diariamente?

4. tomar en cuenta cuántos carbohidratos come para el almuerzo diariamente?

5. tomar en cuenta cuántos carbohidratos come para la cena diariamente?

6. hacer ejercicio a diario?

7. ir a caminar diariamente?

8. añadir una actividad a las cosas que ya hace a diario (por ejemplo, usar las escaleras en vez del elevador)?

$\square$ Muy malo
$\square$ 2 Más o menos malo
$\square_{3}$ Ni malo ni bueno
$\square{ }_{4}$ Más o menos bien
$\square$
5 Muy bien

$\square_{1}$ Muy desagradable

$\square$ Más o menos desagradable

$\square_{3} \mathrm{Ni}$ desagradable ni agradable

$\square$ Más o menos agradable

$\square_{5}$ Muy agradable

\section{NORMAS SOCIALES (DIETA \& EJERCICIO)}

Por cada pregunta díganos si la declaración es CIERTA o FALSA para usted. Por favor conteste honestamente y con precisión.

La mayoría de la gente importante en mi vida piensa que yo debería...

1. comer el desayuno, el almuerzo, y la cena a diario.

2. comer la misma cantidad de comida para el desayuno, el almuerzo, y la cena.

3. tomar en cuenta cuántos carbohidratos como para el desayuno.

4. tomar en cuenta cuántos carbohidratos como para el almuerzo.

5. tomar en cuenta cuántos carbohidratos como para la cena.

6. hacer ejercicio.

7. caminar para hacer ejercicio. 
8. añadir una actividad a las cosas que ya hago a diario (por ejemplo, usar las escaleras en vez del elevador).

$1=$ Muy falsa

$2=$ La mayor parte falsa

$3=$ Falsa

$4=$ Cierta

$5=$ La mayor parte cierta

$6=$ Muy cierta

INTENCIONES (DIETA \& EJERCICIO)

Por cada pregunta, díganos cuántos DÍAS durante la semana planea hacer lo que se indica en los próximos 30 días. Por favor conteste honestamente y con precisión.

En los siguientes 30 días, ¿cuántos DÍAS a la semana va a:

1. comer el desayuno, el almuerzo, y la cena a diario?

2. comer la misma cantidad de comida para el desayuno, el almuerzo, y la cena?

3. tomar en cuenta cuántos carbohidratos come para el desayuno?

4. tomar en cuenta cuántos carbohidratos come para el almuerzo?

5. tomar en cuenta cuántos carbohidratos come para la cena?

6. hacer ejercicio?

7. caminar para hacer ejercicio?

8. añadir una actividad a las cosas que ya hago a diario (por ejemplo, usar las escaleras en vez del elevador)?

$\begin{array}{llllllll}0 & 1 & 2 & 3 & 4 & 5 & 6 & 7\end{array}$

\section{CONOCIMIENTO DE COMPORTAMIENTO (DIETA \& EJERCICIO)}

En las siguientes preguntas, por favor facilite la respuesta que mejor se aplica a usted.

Instrucciones: Por cada pregunta, por favor díganos qué tan FÁCIL o DIFÍCIL sería para hacer en este momento:

1. ¿Qué tan fácil o dificil sería para usted desayunar a diario?

2. ¿Qué tan fácil o difícil sería para usted comer el desayuno, el almuerzo, y la cena a diario?

3. ¿Qué tan fácil o difícil sería para usted comer la misma cantidad de comida para el desayuno, el almuerzo, y la cena?

4. ¿Qué tan fácil o difícil sería para usted crear diferentes actividades de ejercicio para hacer en la casa?

5. ¿Qué tan fácil o difícil sería para usted un tiempo conveniente para hacer ejercicio?

6. ¿Qué tan fácil o difícil sería para usted empezar hacer ejercicio después de no haber hecho ejercicio en mucho tiempo? 


\begin{tabular}{|c|c|c|c|}
\hline Muy difícil & Difícil & Fácil & Muy fácil \\
\hline 1 & 2 & 3 & 4 \\
\hline
\end{tabular}

Instrucciones: Para cada pregunta, por favor díganos qué tan EFECTIVO 0 INEFECTIVO sería para usted hacer en este momento.

1. ¿Qué tan efectivamente o inefectivamente contaría la cantidad de carbohidratos que come en el desayuno?

2. ¿Qué tan efectivamente o inefectivamente contaría la cantidad de carbohidratos que come en el almuerzo?

3. ¿Qué tan efectivamente o inefectivamente contaría la cantidad de carbohidratos que come en la cena?

4. ¿Qué tan efectivamente o inefectivamente usaria la etiqueta de los datos de nutrición para contar los carbohidratos?

5. ¿Qué tan efectivamente o inefectivamente crearía la porción correcta de carbohidratos para comer $(1 / 2$ taza, 1 taza, etc.)?

6. ¿Qué tan efectivamente o inefectivamente añadiría una actividad más a las cosas que ya hace a diario (por ejemplo, usar las escaleras en vez del elevador)?

7. ¿Qué tan efectivo o inefectivo sería Ud. para convencer a un(a) amigo(a) o familiar para hacer ejercicio contigo?

8. ¿Qué tan efectivo o inefectivo sería encontrar actividades físicas para hacer cuando el tiempo este mal?

\begin{tabular}{|c|c|c|c|}
\hline Muy inefectivo & Inefectivo & Efectivo & Muy Efectivo \\
\hline 1 & 2 & 3 & 4 \\
\hline
\end{tabular}

COMPORTAMIENTO

Por cada pregunta, por favor díganos qué tan FRECUENTEMENTE realizo lo que se pregunta en los últimos 30 días. Por favor conteste honestamente y con precisión.

Etiqueta de alimentos

1. En los últimos 30 días, ¿Con qué FRECUENCIA chequeó usted el tamaño de la porción en la etiqueta de alimentos?

2. En los últimos 30 días, ¿Con qué FRECUENCIA chequeó usted el contenido de carbohidratos en la etiqueta de alimentos?

3. En los últimos 30 días, ¿Con qué FRECUENCIA chequeó usted las etiquetas de comida para contar los carbohidratos?

4. En los últimos 30 días, ¿Con qué FRECUENCIA chequeó usted la etiqueta de alimentos para seleccionar alimentos que son bajos en carbohidratos? 
$\square_{2}$ Raramente
$\square_{3}^{3}$ A veces
$\square_{4}$ Frecuentemente
$\square_{5}$ Siempre

Por cada pregunta, díganos cuántos DÍAS hizo lo siguiente en los últimos 7 días. Por favor contesta honestamente y con precisión.

\section{Dieta General}

En los últimos 30 días, durante una semana típica, cuántos DÍAS seguiría su plan de comer? (SDSCA 2)

1. ¿En cuántos de los últimos 7 DÍAS siguió un plan de comer saludable? (SDSCA 1)

2. ¿En cuántos de los últimos 7 DíAS desayunó, almorzó, y cenó?

3. ¿En cuántos de los últimos 7 DÍAS comió la misma cantidad en cada comida?

4. ¿En cuántos de los últimos 7 DíAS separó los carbohidratos igualmente durante el día? (SDSCA 5A)

5. ¿En cuántos de los últimos 7 DÍAS controló cuantos carbohidratos comió en el desayuno?

6. ¿En cuántos de los últimos 7 DÍAS controló cuantos carbohidratos comió en el almuerzo?

7. ¿En cuántos de los últimos 7 DÍAS controló cuantos carbohidratos comió en la cena?

$\begin{array}{llllllll}0 & 1 & 2 & 3 & 4 & 5 & 6 & 7\end{array}$

\section{Ejercicio General}

1. ¿En los últimos 7 DÍAS hizo usted por lo menos 30 minutos de actividad física continua? (total de minutos de actividad física continua, incluyendo caminar) (SDSCA 5)

2. ¿En los últimos 7 DÍAS participó Ud. en una sesión de ejercicio específico (como nadar, caminar montar la bicicleta) aparte de lo que hace alrededor de la casa o como parte de su trabajo?

3. (SDSCA 6)

$$
\begin{array}{llllllll}
0 & 1 & 2 & 3 & 4 & 5 & 6 & 7
\end{array}
$$

\section{References}

Garcia, A.A., Villagomez, E. T., Brown, S.A. Kouzekanani, K., \& hanis, C.L. (2001). The Starr County Diabetes Education Study: development of the Spanish-language diabetes knowledge questionnaire. Diabetes Care, 24(1), 16-21.

Osborn, C. (2006). Using the IMB Model of Health Behavior Change to Promote SelfManagement Behavior in Puerto Ricans with diabetes. Unpublished doctoral dissertation, University of Connecticut, Massachusetts. 
Toobert, D. J., Hampson, S. E., \& Glasgow, R. E. (2000). The summary of diabetes selfcare activities measure: Results from seven studies and a revised scale. Diabetes Care, $23,943-949$. 


\section{APPENDIX C: FREE RANGE QUESTIONS}

\section{Semi Structured Interview Guide}

The following questions cover some of the information I would also like to know.

1. Did the questions in this instrument adequately evaluate your knowledge about your diabetes? Yes No Please explain your answer.

2. Did the questions reflect your desire (motivation) to follow the health care program planned for you? Yes No Please explain your answer

3. Did the questions reflect the behavior skills you feel are necessary for you to achieve the goals of diabetes management? Yes No Please explain your answer

4. Do you think your time in the U.S. has affected your knowledge of diabetes, ?Yes No Please explain your answer

5. Do you think your time in the U.S. has affected your desire to control your diabetes? Yes No Please explain your answer

6. Do you think your time in the U.S. has affected your skills to be able to manage your diabetes, ?Yes No Please explain your answer

7. Was the format of the questions easy to answer? ?Yes your answer

No Please explain

\section{Preguntas Semi-estructuradas}

Las preguntas siguientes son algo de la información que también quisiera saber.

1. ¿Las preguntas en este cuestionario evaluaron adecuadamente su conocimiento sobre su diabetes? Sí No ___ Por favor explique su respuesta.

2. ¿Las preguntas hacen una reflexión sobre su deseo (motivación) ha seguir el programa saludable que fue planeado para usted? Sí No . Por favor explique su respuesta.

3. ¿Las preguntas reflejan las habilidades de comportamiento que usted siente son necesarias para lograr sus metas para en el manejo de su diabetes?

a. Si No . Por favor explique su respuesta.

4 ¿Cree que el tiempo que pasó aquí en los Estados Unidos afecto su conocimiento de la diabetes? Sí No . Por favor explique su respuesta. 
4. ¿Cree que el tiempo que pasó aquí en los Estados Unidos afecto su deseo de controlar su diabetes? Sí No . Por favor explique su respuesta.

5. ¿Cree que el tiempo que pasó en los Estados Unidos afecto sus habilidades para poder manejar su diabetes? Sí No ___. Por favor explique su respuesta.

6. ¿El formato de las preguntas fue fácil para contestar? Sí No
a. Por favor explique su respuesta 


\title{
APPENDIX D: CONSENT FORM (ENGLISH)
}

\author{
Research Participant Consent Form \\ Psychometric Testing of the Information-Motivation-Behavioral Skills Measure of \\ Diabetes Self-Care in Mexican Americans with Type II diabetes.
}

Beverley Brownell is a doctoral student in the Hahn School of Nursing and Health Science at the University of San Diego. You are invited to participate in a research project she is conducting for the purpose of testing the information-MotivationBehavioral Skills Model of Behavior change in Mexican Americans with Type II diabetes.

The project will involve filling out a survey, which asks patients general information about themselves such as their level of education, about their dietary and exercise information, there motivational sources and their intentions to follow a dietary and exercise regime. Filling out the complete survey and the short interview afterward will last about 60 to 90 minutes and also will include some questions about you, such as your age, employment and marital status as well as whether you have medical insurance. The interview will take place at Lestonnac Free Clinic at a time convenient for you. Participation is entirely voluntary and you can refuse to answer any question and/or quit at any time. Should you choose to quit, no one will be upset with you and your information will be destroyed right away. If you decide to quit, nothing will change about your access to health care, or the way doctors and nurses care for you.

The information you give will be analyzed and studied in a manner that protects your identity. That means that a code number will be used and that your real name will not appear on any of the study materials All information you provide will remain confidential and locked in a file cabinet in the researcher's office for a minimum of five years before being destroyed.

There may be a risk that (filling out the form and participating in the interview may make you feel tired. Sometimes people feel anxious or sad when talking or reflecting on the things you will be asked about. If you would like to talk to someone about your 
feelings, you can call the Association of Mental Health, Orange County at 1-714- 6388277 at any time, 24 hours a day. Remember, you can stop the interview at any time you feel tired or for any other reason.

The benefit to participating will be in knowing that you helped the doctors, nurses and other health care providers at the clinic learn how to better help you and other people take care of their diabetes. If you complete the study, you will receive a Target gift certificate worth $\$ 10$.

If you have any questions about this research, please contact Beverley Brownell at (949) $6906608 /$ / 949) 215 6396) or Dr A Hunter at the University of San Diego on (619) 260 7608.

I have read and understand this form, and consent to the research it describes to me. I have received a copy of this consent form for my records.

Signature of Participant

Name of Participant (Printed)
Date

Date 


\section{APPENDIX E: CONSENT FORM (SPANISH)}

Documento de consentimiento del participante de la investigación.

Prueba psicométrica de la información del comportamiento de las habilidades de la autosuficiencia de la diabetes en el grupo de mexicoamericanos con diabetes de tipo II.

Beverley Brownell es una estudiante de doctorado en el colegio Hahn de las Ciencias de Enfermería y Salud de la Universidad de San Diego, USD. Les invita a que participe en un proyecto de investigación con el fin de probar el modelo informaciónMotivación-Del comportamiento de las habilidades del cambio del comportamiento en la comunidad mexicoamericana con diabetes de tipo II.

El proyecto implicará completar un cuestionario, en donde se les pide a los pacientes una información de carácter general acerca de sí mismos tales como su nivel de educación, sobre su dieta alimenticia, si hace ejercicios, y si están motivados a seguir un régimen dietético y a hacer ejercicios fisicos. Luego Beverley les hará unas preguntas acerca del cuestionario para ver si fueron fáciles de entender. Ella tomará apuntes mientras Ud. hace comentarios. Completar el sondeo, y una corta entrevista no durará más de 60 minutos e incluirá algunas preguntas personales, tales como su edad, su lugar de empleo, su estado civil y si tiene seguro médico. La entrevista se llevar ción a cabo en un cuarto privado de la clínica de Lestonnac a una hora que sea conveniente para usted. La participación es enteramente voluntaria y si no se siente cómodo, no tiene que contestar todas las preguntas y puede parar la entrevista cuando lo desee. Si decide que no quiere contestar más, su información será destruida enseguida. Si decide parar, nada cambiará en su acceso al cuidado médico de la clínica de Lestonnac y su acceso a todo el cuidado medico, seguirá igual que antes de la entrevista.

La información queUd. da será analizada y estudiada de una forma confidencial y en todo momento se protegerá su identidad. Esto significa que se utilizará un número como código y que su nombre real no aparecerá en los materiales del estudio. Los resultados de la investigación de este proyecto puede que sean utilizados publicamente y la información puede ser publicada en revistas profesionales o discutida en reuniones, pero debe estar seguro de que la información se reportará como un grupo y no individualmente. Toda la información que Ud. proporcione seguirá siendo confidencial y guardada en un gabinete de archivo en la oficina del investigador, por un mínimo de cinco años antes de ser destruida.

Puede ser que se canse al rellenar el documento y al participar en la entrevista. La gente se siente a veces ansiosa o triste al hablar de las cosas que se preguntan en él. Si quisiera hablar con alguien sobre sus sensaciones, puede llamar a la Asociación de Salud Mental del Condado de Orange al teléfono 1-714-638-8277 a cualquier hora, 24 horas al día. Recuerde que Ud. puede parar la entrevista en cualquier momento que se sienta cansado o por cualquier otra razón. 
La ventaja de participar consistirá en saber que ayudó a los doctores/doctoras a enfermeras y enfermeros y a otros proveedores de asistencia sanitaria en la clínica para aprender cómo mejorar y ayudar a otra gente con su diabetes. Si termina este estudio, recibirá un certificado de $\$ 10$ de la tienda "Target". Si tiene cualquier pregunta sobre esta investigación, haga el favor de comunicarse con Beverley Brownell, a los teléfonos (949) $6906608 /(949) 215$ 6396) o con la Dra. Anita Hunter, profesora de Bev, en la Universidad de San Diego, al teléfono (619) 2607608.

He leído y entiendo este documento, y doy mi consentimiento a la investigación que me describe a mí. He recibido una copia de este documento para archivar en mis expedientes.

Firma del participante

Nombre del participante (Impreso)

Firma del investigador principal
Fecha 
APPENDIX F：FLYER (ENGLISH)

Beverley Brownell, MS, RN, FNP is completing a research project for the University of San Diego. She is interested in asking adults of Mexican descent who have type II diabetes about their diet and exercise habits.

If you are:

$>20-70$ years old

$>$ Mexican

$>$ Have had type II diabetes for 1 year or more

$>$ Taking hypoglycemic agents alone or with insulin for the past year (any combination)

$>$ Had an $\mathrm{HbA1C}$ performed within the past year with no hospitalizations

Please ask about being in the study.

The interviews can be done in Spanish or English.

If you would like to take part in this study please contact Beverley Brownell at (949) 6906608 or (714) 6334600

Thank you 
Beverley Brownell, MS, RN, FNP esta terminando un proyecto de investigacion para la Universidad de San Diego. Ella esta interesada in preguntar a los adultos de la ascendencia mexicana que padezcan la diabetes tipo II sobre sus habitos de la dieta y del ejercicio.

Si usted:

$>$ Tiene de 20 a 70 anos de edad

$>$ Es mexicano(a)

$>$ Tiene un ano o mas con la diabetes tipo II

$>$ Tome agentes hipoglicemicos solamente $o$ con la insulina por al menos un ano (cualquier cómbinación)

$>$ Ha tenido un HbAlc realizado dentro el ano sin hospitalizaciones.

Entonces pregunte por favor sobre la posibilidad de participar en este estudio

Los cuestionarios se pueden completar en español o en ingles.

Si quiere participaar en este estudio llame por favor a Beverley Brownell al (949) 6906608 o (714) 6334600

Gracias 


\section{APPENDIX H: RECRUITMENT PRESENTATIONS}

\section{Verbal Script of In-Class (Diabetes Education Class) Recruitment Presentation}

Hello, my name is Beverley Brownell and I am a PhD student in the Department of Nursing at the University of San Diego. I am currently working on my dissertation and am testing a questionnaire which asks people about how they manage their diabetes type II. This research will hopefully lead to a better understanding of the information, motivation, and behavioral skills that are necessary to effectively cope with diabetes type II.

If you volunteer as a participant in this study, you will be asked to fill out a questionnaire which lasts about 40 minutes. After which you will then be asked 7 short questions which will help me to better understand how you deal with your diabetes in general.

This study has been reviewed and received approval from the Office of Research Ethics but the final decision to participate is yours.

If you are interested in participating, please come to see me and I will explain the study to you in more detail.

Thank you.

Escritura Verbal de la Presentación del Reclutamiento de la en-Clase (Clase de la Educación de la Diabetes)

Hola, mi nombre es Beverley Brownell y soy un estudiante del PhD en el departamento de Enfermería en la universidad de San Diego. Estoy trabajando actual en mi disertación que prueba un cuestionario que pregunte a gente acerca de cómo ella maneja su diabetes tipo II. Esta investigación esperanzadamente llevará a una mejor comprensión de la información, de la motivación, y de las habilidades del comportamiento que son necesarias hacer frente con eficacia a la diabetes.

Si se ofrece voluntariamente como participante en este estudio, se pedirán completar un cuestionario cuál dura cerca de 40 minutos. Después de lo cual se entonces harán 7 preguntas cortas cuál me ayudará a entender mejor cómo se ocupa de su diabetes en general.

Se ha repasado este estudio y aprobación recibida de la oficina de las éticas de investigación pero la decisión final a participar es la suya.

Si está interesado en participar, venir por favor ver me y me explicará el estudio a ti más detalladamente.

Gracias. 


\section{APPENDIX I: APPROVAL FROM CLINIC DIRECTOR}

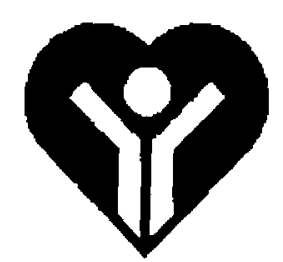

\section{Lestonnac} Free Medical Clinic

L215 E. Chaprsan Auenus Oranga, Cilifornla $92866-2137$ \{711\} 633-4600 (714) 633-315R FAX (714) 633-1412

December $1^{\text {st }}, 2008$

Anita Funter, PhD, RN, CPNP, FAAN

Professor, Haim School of Nursing

University of San Diego

San Diego, CA

Dear Professor Hunter,

I arn delighted to submit my letter of support for the proposed Mexican American Adults with Diabetes Type II study. This proposal was presented to the QA Board of Directors meeting on October 27, 2008 and was approved for study at The Lestonnac Free Clinic.

We at Lestonnac are significanlly impacted by the numbers of Mexican-American Adults whose cascs are complicated because of inadequate knowledge to self-manage their diabetes. In looking at our geographic location as well as our demographic make-up, we are in the heart of an area that would be greatly benefited by research whose findings would improve strategies for diabetes self-management.

As a community heal th center, we would welcome the opportunity to collaborate with Beverly Brownell, RN, FNP, PhDe on this proposal project. The benefit to our healith center as well as to the Mexican-American community that we serve would be welcomed.

Again, we look forward to a mutualiy beneficial program. One that will not only benefit out communily, but that could become a model for other community health centers nation wide.

Sincerely,

Edward Gerber

Executive Director 